\title{
TRADE MEASURES IN MULTILATERAL ENVIRONMENTAL AGREEMENTS
}

\begin{abstract}
A Report by
IUCN - The World Conservation Union on the Effectiveness of Trade Measures Contained in

The Convention on International Trade in Endangered Species of Wild Fauna and Flora (CITES)
\end{abstract}

\author{
Prepared for \\ The Economics, Trade and Environment Unit \\ United Nations Environment Programme
}


TRADE MEASURES IN MULTILATERAL ENVIRONMENTAL AGREEMENTS

A Report by

IUCN - The World Conservation Union on

the Effectiveness of Trade Measures Contained in

The Convention on International Trade in Endangered Species of Wild Fauna and Flora (CITES)

\section{CONTENTS}

\section{EXECUTIVE SUMMARY}

1.

INTRODUCTION

2.

BACKGROUND AND OBJECTIVES OF THE CONVENTION

2.1.

Events Leading To The Adoption Of CITES

2.2. The Objectives of CITES

2.3. Overview of the Basic Provisions of CITES

$2.4 \quad$ Evolution Of CITES

2.4.1 Amendments of the Convention

2.4.2 Recommendations of the Conference of the Parties

2.4.3 Establishment Of Committees

3.

TRADE MEASURES UNDER THE CONVENTION

3.1.

3.1 .1

The Specific Trade Measures

3.1.2

Appendix I Listings.

Appendix II Listings

3.1 .3

Appendix III Listings.

3.2. General Provisions Relating To The Trade Measures

3.2.1 Trade Monitoring and Reporting

3.2.2 Listing Decisions

3.2.3 Exemptions And Special Provisions

3.2.4 Stricter Domestic Measures And Collective Enforcement Measures

3.2.5 Reservations

3.2.6 Trade With Non-Parties

4. POSITIVE OR INNOVATIVE MEASURES" IN CITES

4.1 Historical Overview of Innovative Measures

4.2 An Outline of the Innovative Measures Adopted

4.2.1. Captive Breeding and Artificial Propagation For Species Listed In Appendix I

4.2.1.1 Captive Breeding For Animal Species 
4.2.1.2

Artificial Propagation For Plant Species

\section{Ranching For Species Listed In Appendix I}

Conduct Of A Ranching Operation

Marine Turtle Ranching

\section{Quotas For Species Listed In Appendix I}

Trade in Hunting Trophies of Species Listed in Appendix I

Trade in Leopard Trophies and Skins for Personal Use

Trade in Live Specimens and Hunting Trophies of Cheetah

Trade in Ivory from African Elephants

Special Criteria for Transfer from Appendix I to Appendix II Through a Quota System

Annotations Allowing the Transfer of Species from Appendix I to Appendix II

Trade in Cloth and Wool Sheared from Live Vicuna

Trade in Live Specimens and Hunted Trophies of Southern White Rhinos in South Africa

\section{Significant Trade Process}

Significant Trade in Animal Species

Significant Trade in Plant Species

Capacity Building and Training

\section{ASSESSING THE EFFECTIVENESS OF THETRADE AND INNOVATIVE MEASURES IN CITES}

Do the Trade and Positive Measures form Part of a Sound Legal Regime?

Facilitation of International Cooperation to Regulate Trade

Does the Convention Provide Clear Rules?

Prevention of Abuse and Non-Compliance

Illegal Trade with Non-Parties

Illegal Trade between Parties

\section{Are the Trade Measures Effective in Preventing Species from Being Over-Exploited through International Trade?}

\section{General Considerations}

Factors Affecting the Effectiveness of CITES

Defining and Measuring Suucess or Failure

How to Avoid Confounding Variables in Defining Success

The Effectiveness of the Convention with Spotted Cats

Wild Cats and the Fur Trade

Wild Cats and the Convention

The Apparent Inneffectivness of the Convention with 3 out of 5 Species of Rhinoceros

Rhinos and the Horn Trade

Rhinos and the Convention

Effectiveness With Other Species

Non-Human Primates

Bears

The Trade in Wild Birds with Reference to Macaws

Marine Turtles

Reptile Skins 
5.2.7.6

5.2 .8

5.3
Plants

Changes in Listings in the Appendicies aas a Measure of CITES Effectiveness

\section{An Evaluation of the Positive Measures in the Convention From the Species Conservation Perspective}

An Evaluation of Captive Breeding and Artificial Propagation

Captive Breeding of the Asian Boney Tongue (or Arowana) Scleropages formosus

An Evaluation of Ranching

Ranching of the Nile Crocodile, Crocodylus niloticus

An Evaluation Appendix I Quotas

An Evaluation of the Trade in Leopard Trophies and Skins

An Evaluation of Trade in Live Specimens and Hunting Trophies of Cheetah

Annotations

An Evaluation of Trade in Live Specimens and Hunted Trophies of Southern White Rhinos in South Africa

An Evaluation of Trade in Cloth And Wool Sheared from Live Vicuna

An Evaluation of the Significant Trade Process

Significant Trade in Animal Species

Significant Trade in Plant Species

An Analytical Framework for Assessing the Effectiveness of CITES Measures in Economic Terms

Demand Side

Supply Side

Demand and Supply

Price Elasticity of Demand

Analysis of the Effectiveness of CITES Appendix I Measures in Economic Terms

Trade Ban

Export and Import Permit for Appendix I Listing

Export Permit for Appendix II

Export Permit for Appendix III Listing

\section{Effectiveness of Positive Measures in this Economic Framework}

Captive Breeding and Artificial Propagation

Ranching

Quotas for Species listed on Appendix I

Split-listing

Transfer from Appendix I to Appendix II

Transfer from Appendix II to Appendix I

Annotations

Trade in Live Specimens and Hunted Trophies of Southern White Rhinos in South Africa

Financial Contributions and Technical Co-operation

\section{Sanctions}


5.9

6.

6.1

6.2

6.2.1

6.2 .2

6.2.2.1

6.2.2.2

6.2.2.3

6.2.2.4

6.2.2.5

6.2.2.6

6.2 .2 .7

6.2.2.8

6.2.2.9

Bibliography

ANNEX 1

\section{Reservations}

ECONOMIC IMPACT ANALYSIS OF CITES

The Benefits of Being a Party

The Cost of Being a Party

Costs of Implementing and Enforcing the Convention

The Cost of Foregoing Income from Trade

Bans

Export-Import Permits

Export Permits

Quotas

Captive Breeding

Ranching

Split-Listing

Appendix III Listing

Annotations

IUCN Report $(09 / 11 / 00)-5$

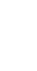




\section{A Report by \\ IUCN - The World Conservation Union on \\ The Effectiveness of Trade Measures Contained in \\ The Convention on International Trade in Endangered Species of Wild Fauna and Flora (CITES)}

\section{Executive Summary}

\section{Overview}

- The Preamble to the Convention states that the objective of CITES is to prevent the overexploitation of species through international trade and to ensure their long term survival. The ultimate aim of the Convention is undoubtedly to promote species conservation, however, legally the convention only has jurisdiction over the regulation of international trade and cannot be held accountable for the effects of other factors which affect species conservation such as habitat conversion.

CITES regulates international trade by means of a number of trade measures, which include the listing of species on Appendix I, II and III, and the use of export/import permit requirements.

- The Convention provides for a series of trade regulations according to the level of extinction threat which each species suffers: species threatened with extinction are listed in Appendix I and are protected from commercial trade; species which may be threatened with extinction if their trade is not strictly regulated are included in Appendix II and species which require regulation within the jurisdiction of a Party can be included in Appendix III. International trade in CITES -listed species must be regulated and monitored to ensure that offtake is not detrimental to the long-term survival of the species in question.

- Unlike more recent international Conventions, CITES does not provide explicitly for incentive measures aimed at ameliorating the costs of implementing the Treaty. However, during the course of its existence, CITES has also adopted a number of so-called "innovative or positive" trade measures. In the context of this study, "incentive" measures refer to those measures adopted, mainly as the Convention has evolved, to recognise the importance of facilitating in certain cases, carefully controlled trade to provide an incentive for the continued conservation of that resource. It has become increasingly clear that where the possible benefits of controlled trade are not recognised, that wildlife habitat maybe replaced by other resource use inimical to wildlife conservation. Consequently the term "incentive" measure in this study does not imply an uncontrolled promotion of trade and is not at odds with the overall aims of the Convention, it simply recognises that in certain circumstances, economic reality dictates that wildlife conservation may be better served by facilitating a controlled limited trade rather than preventing all trade. 
- The innovative measures include: commercial captive breeding for Appendix I species; noncommercial trade in Appendix I trophies, ranching, quotas for trophies of certain Appendix I listed species, special conditions for the transfer of species from Appendix I to Appendix II; annotations allowing the transfer of species listed in Appendix I under specified circumstances and the Significant Trade Process for species listed in Appendix II.

\section{Effectiveness of Trade Measures}

- The effectiveness of the trade and innovative measures are examined from legal, species conservation and economic perspectives, and suggestions are made for further research into the effectiveness of these measures.

- This analysis shows that CITES, through its monitoring requirements, has been very successful in providing the most comprehensive database on international trade in wildlife species available to date. Although there is room for improvement in the compilation of data, current levels of reporting have improved dramatically since the Convention was signed, and this database now provides a useful tool in combating over-exploitation of species.

- From this preliminary assessment, the effectiveness of CITES trade measures are examined for a selection of taxa. CITES, working with other mechanisms, has been very effective in reducing trade in certain species. On the other hand for some species, other factors have precluded CITES from being fully implemented and from improving the situation. Suggestions are made as to how a more systematic analysis of the effectiveness of CITES trade measures may be undertaken in the future.

- The majority of trade studies of CITES listed species (see for example Species In Danger Reports by TRAFFIC) undertaken to date have been stimulated because international trade has been perceived as a problem for that particular species. In contrast, for the majority of species included in the appendices, no assessments have been undertaken, as no problem with CITES implementation for those species has been perceived. Consequently, the reports on CITES implementation on which this analysis relies tend to biased towards those problem species, and may not contribute to a true picture of the effectiveness of the Convention.

\section{Innovative Measures}

- The innovative measures have been adopted through the adoption of Resolutions at successive Meetings of the Conferences of the Parties, and show that the Convention is evolving to meet new challenges associated with the regulation of international wildlife trade and is adopting pragmatic new mechanisms to achieve its objectives. The emerging flexibility of CITES to deal with different pressures appears to be a great strength of the Convention, which will come into play increasingly to ensure creative long-term solutions to some of the international trade and species conservation problems faced by the Convention. 


\section{Economic Analysis}

- The economic framework developed by this project has provided some useful indications of how a demand and supply analysis may be used to assess the approaches taken by governments to international wildlife trade, and the incentives associated with various trade measures. This theoretical framework, now requires testing with data for specific species, on supply and demand levels, on the costs of enforcement and on other conservation expenditure.

- The economic analysis has also used the concept of green goods, noting that consumers may prefer to buy a product which they know has been produced in an environmentally-friendly manner. The concept of eco-labelling is growing, and although it has not yet made much impact in CITES circles, it could be more widely adopted.

- The economic analysis suggests that the demand and supply of the wildlife product can be affected by a number of factors which in turn affect the costs and success of enforcement measures. The effectiveness of CITES regulations is likely to be most responsive to trade in species which are associated with high demand elasticities. For example the more elastic demand is, the more likely the good is to be substituted with another product, or demand can be influenced in some other way. So in a demand and supply culture, CITES regulation will be most effective for species for which the demand is fairly elastic and can be easily manipulated.

- The economic analysis suggests that for an Appendix I listed species a trade ban and enforcement efforts are likely to be most effective in lowering the quantity traded when both the demand and supply curves are elastic. However, for a species for which the demand is inelastic, a ban will have little effect on the incentives for illegal trade, and may even perversely encourage illegal trade in some cases.

- According to economic analysis, both the non-commercial trade in Appendix I species, and an Appendix II listing are similar to the situation for an Appendix I quota, and the conclusion is that the most efficient way to address illegal trade may well be a combination of enforcement to reduce supply of the goods and public education to reduce the demand for the goods.

- Whilst captive breeding, may provide an alternative to domestic livestock production, in the majority of cases examined it appears that the economic benefits arising from captive breeding are not returned to the stakeholders in the wildlife areas, as the captive-breeding is normally carried out in 
closed-cycle operations independent of the wild populations. Furthermore, it is not yet clear whether trade in captive-bred specimens reduces the harvest pressure on wild populations or stimulates further pressure.

- Ranching, like captive breeding provides a substitute product to obviate the need to harvest wild Appendix I listed species; but it can also provide an incentive to conserve the wild populations as a source of further stock for the ranching programme.

- Unlike a number of Conventions, CITES has a means of following up on non-compliance by applying various temporary sanctions, and it is this facility which allows Parties to take co-operative action to overcome non-compliance.

- Unlike more recently concluded Conventions, CITES does not have a series of positive financial incentive measures to assist Parties in implementing the Convention. However, CITES has attracted some multilateral funding and a larger amount of bi-lateral funding. From late 1994 to late 1996, the Trust fund attracted donations of US\$ 4 million for species survey, capacity building, enforcement and support to technical committees. 


\section{INTRODUCTION}

International trade in wildlife and wildlife products is a major commercial activity. International revenues from this trade can be measured in the billions of dollars. The Convention of Trade in Endangered Species of Wild Fauna and Flora (Washington, 1973), known as CITES from its English language acronym, was adopted in the recognition that international action is essential to control and regulate international trade in threatened species of wild animals and plants to ensure their long-term survival. The Convention provides a framework to ensure intergovernmental co-operation in this field. Its adoption was based on the fact that international trade in wildlife is an issue wherein precautionary global action was both feasible and necessary. Further, a multilateral agreement would avoid a situation in which ad hoc unilateral trade restrictions penalised individual importing or exporting countries vis-avis other countries not applying such restrictions.

CITES is one of the most widely accepted and applied international agreements in the field of the environment. The Convention entered into force in 1975 and currently has 143 State Parties throughout the world (see Annex 1 for a table of signatories and Parties to CITES).

This study is a component of a larger UNEP-initiated study on the effectiveness of trade measures in multilateral environmental agreements. In addition to CITES, studies were commissioned on the Basel Convention and the Montreal Protocol. Together these studies have investigated the use of trade measures to achieve environmental objectives in the context of sustainable development as envisioned by the 1992 UN Conference on Environment and Development and Agenda 21 and also in cognizance of the debates around the international trade rules administered by the World Trade Organisation.

Thus this paper seeks to provide a preliminary assessment of:

a) the effectiveness of the trade measures in CITES;

b) the effectiveness of the "innovative" measures in CITES;

c) the economic impact on a country joining CITES; and

d) recommendations for further study of the effectiveness of the trade measures.

Given the nature of the measures in CITES, this paper is structured as follows:

-Part 2 background on the Convention

-Part 3 the objectives of CITES

-Part 4 the trade measures in CITES

-Part 5 the innovative measures in CITES 
-Part 6 an examination of the effectiveness of the trade and innovative measures from the perspective of law, species conservation and economics.

-Part 7 an examination of the economic impact of CITES

This structure differs slightly from that proposed by UNEP in that the identification of trade measures and innovative measures are consecutive, followed by an effectiveness analysis of both. This is because, as discussed later in the paper, most of the innovative measures in CITES are in fact trade measures.

It must be emphasised that the scope of this paper is limited due to resource constraints and the nature of this particular undertaking. The evaluation of the effectiveness of the CITES trade measures is a highly complex task which requires the collection of long term data from a number of highly disparate sources that affect the success of species conservation for many different species. These data range from time-series population data, through information on changes in land uses to information on national conservation budgets, revenues from CITES products and statistics on illegal trade. As such, a thorough analysis of the actual impact of the Convention, from conservation and economic standpoints, will require considerably more information that is currently available. With over 29,000 species covered by the Convention, this could be a huge task. Hence, the evaluations in this paper will necessarily be mostly limited to providing analytic frameworks as a basis for future empirical studies.

In accordance with the instructions of UNEP, this paper pays particular attention to the extent of the economic impact (both positive and negative) on States joining CITES. In undertaking this examination, IUCN does not intend to imply any diminishing of the Treaty's importance from the conservation standpoint, nor to suggest that economic considerations should be the overriding ones in this context.

Finally in seeking to provide a framework for analysing the effectiveness and impact of CITES, the authors believe that a conceptual distinction must be made between the measures contained in the Treaty and those which individual Parties enact to implement the Treaty. As the latter are at the discretion of the Parties, since CITES is not a self-executing Treaty, this paper will limit its focus to the treaty per se. 


\section{BACKGROUND AND OBJECTIVES OF THE CONVENTION}

\subsection{Events Leading to the Adoption of CITES}

Modern concerns about the consequences of unrestricted international commerce in wildlife were first raised by conservationists at the beginning of this century. The first international initiative was the 1900 London Convention Designed to Ensure the Conservation of Various Species of Wild Animals in Africa which are Useful to Man or Inoffensive. While primarily concerned with hunting and wildlife management, this treaty also included some trade provisions. Unfortunately, the 1900 Convention never entered into force. This was due to a lack of ratification by all signatory States -- a requirement for such unanimity was stipulated in its text.

The next initiative, also of the colonial European powers, was the 1933 London Convention Relative to the Preservation of Fauna and Flora in Their Natural State. This treaty did not require ratification by all signatories and entered into force in 1936, with applicability to most of the African region. As with the 1900 treaty, this Convention was designed primarily to deal with wildlife exploitation, but also included provisions for export licenses and import restrictions for certain wildlife products. Britain and the Netherlands extended the import restrictions of this Convention to Aden and India and to Indonesia respectively.

The 1933 Convention was never very successful since it failed to provide decision-making institutions or secretariat services. It attracted few Parties and ultimately with the end of colonialism, was superseded by the 1968 African Convention on the Conservation of Nature and Natural Resources.

The changing political climate of the early 1960's led to calls for new initiatives for international cooperation for wildlife management and the control of wildlife trade. Meeting in Nairobi in 1963, the 8th General Assembly of IUCN adopted a resolution calling for an international convention regulating export, transit and import of rare or threatened wildlife and wildlife products. Over the following years, IUCN's Environmental Law Programme prepared a succession of drafts for such a Convention.

Concurrently, concern about international trade in wildlife was reflected in some national legislation. One of the earliest and most significant examples was the 1900 Lacey Act in the United States which prohibited interstate commerce in wildlife taken illegally. Originally directed towards national commerce, the provisions of the Lacey Act were extended in 1935 to cover wildlife illegally taken in other countries. In 1966 the US Congress adopted the Endangered Species Conservation Act, which, by virtue of its 1969 amendment, provided, inter alia, for the development of a list of wildlife threatened with global extinction. Imports of such species were to be prohibited except for scientific or breeding purposes. In addition, in order to seek a level playing field for international trade, the Act provided that the US Government was to encourage the adoption of similar laws by other countries and to seek the 
convening of an international meeting to conclude a binding international convention on the conservation of endangered species.

Pursuant to this legislative history, in February 1973, the United States of America hosted a plenipotentiary Conference in Washington D.C. to adopt a wildlife trade convention. It provided a draft text for consideration, based on the latest IUCN draft and alternative proposals submitted by Kenya and other African countries.

The Washington Conference, with participation from 88 countries, resulted in the adoption of CITES on 3 March 1973. Following the deposit of its tenth instrument of ratification or accession, the Convention entered into force on 1 July 1975.

\subsection{The Objectives of CITES}

Unlike more modern international environmental agreements, CITES does not contain an explicit provision which states its objective. The Preamble to the Convention states: "The contracting states, Recognising that wild fauna and flora in their many beautiful and varied forms are an irreplaceable part of the natural systems of the earth which must be protected for this and the generations to come;

Conscious of the ever-growing value of wild fauna and flora from aesthetic, scientific, cultural, recreational and economic points of view;

Recognising that peoples and states are and should be the best protectors of their own wild fauna and flora;

Recognising in addition, that international co-operation is essential for the protection of certain species of wild fauna and flora against over exploitation through international trade;

Convinced of the urgency of taking appropriate measures to this end; Have agreed as follows.:"

From this preambular text it is clear that the ultimate objective of CITES is to promote species conservation, but that the Parties limited themselves to achieving this through the proximal means of regulating international trade in wildlife species so as to ensure that it does not threaten the survival of species of wild fauna and flora for this and generations to come.

Although the ultimate aim of regulating international trade in wildlife is to promote species conservation, CITES itself, only has jurisdiction over international trade. Consequently, it must be emphasised that the Convention does not purport to provide a holistic approach to species conservation, but addresses only threats from international trade. Two twin approaches are taken to achieve the primary objective. One, is to strictly regulate international trade in species which are threatened with extinction and which are or 
may be affected by trade. The second, is to control trade to ensuring that species which are not currently threatened with extinction do not become so as a result of un-controlled trade.

The philosophy underlying the latter approach has allowed the trade measures in the Convention to evolve considerably, such that trade, in circumstances where it can provide positive incentives to conserve the species, is considered a useful tool. Resolution Conf. 8.3 notes that, "commercial trade may be beneficial to the conservation of species and ecosystems and/or the development of local people when carried out at levels that are not detrimental to the survival of the species in question."

\subsection{Overview of the Basic Provisions of CITES}

At the heart of CITES is a system of trade measures which provide different levels of regulation for species listed in three appendices to the Convention (see Article II) which are described fully below in Part 3 of this paper. Essentially, commercial trade in Appendix I species is prohibited (see Article III), while such trade is permitted at controlled levels for species in Appendices II (see Article IV) and III (see Article V). These different levels of trade are regulated by the issue of import and export permits by the national authorities. The Convention requires the creation of one or more national Scientific and Management Authorities (Article IX) which are responsible for various aspects of the permitting process. Representatives of the Parties to CITES meet every two years at ordinary meetings of the Conference of the Parties to (a) review implementation of the Convention, (b) revise procedures, and (c) review and amend the CITES Appendices in the light of current information on international trade and the conservation status of species (Article XI). The Convention is serviced by a Secretariat, which arranges the meetings of the Conference of the Parties, circulates information relevant to implementing the Convention, and can receive information on the adverse effects of trade in any species listed in Appendix I or II and notify the Party concerned (Article XIII).

The Government of Switzerland serves as depositary for the Convention (Article XXV), and the United Nations Environment Programme is responsible for the provision of the Convention Secretariat (Article XII).

\subsection{Evolution of CITES}

Since its adoption in 1973, CITES has undergone considerable substantive as well as institutional evolution, as efforts are made to continuously improve the operation and effectiveness of the Convention.

\subsubsection{Amendments of the Convention}

Two Extraordinary Meetings of the Conference of the Parties have been held to adopt amendments to the Convention. The first was convened in 1979 to adjust Article XI to provide the COP with authority to adopt financial provisions. This amendment entered into force in 1987. The second, held in 1983, 
was convened to adjust Article XXI to allow for accession to the Convention by regional economic integration organisations. It has yet to receive the necessary number of acceptances to enter into force.

\subsubsection{Recommendations of the Conference of the Parties}

Although the Convention has not been modified since 1979, the Conference of the Parties has adopted numerous recommendations aimed at improving the effectiveness of the Convention, usually in the form of resolutions, but also sometimes decisions. Although perhaps not legally binding on Parties in the strict sense, resolutions tend to be very influential in practice. Not only do many resolutions clarify how the Convention is to be interpreted or implemented, but many have resulted in the development of "innovative [innovative] measures" which are described more fully in Part 5 of this paper. Resolutions, in some cases, have also set the basis for the adoption of collective enforcement decisions by the Standing Committee. To date, more than 200 resolutions have been passed, and since 1994, a process has been underway to consolidate them so as to facilitate their use; currently, 82 resolutions are still in force.

\subsubsection{Establishment of Committees}

As noted above, the original Convention provided for the creation of two international bodies: the Secretariat and the Conference of the Parties. Since 1975, the Conference of the Parties has established several subsidiary bodies to assist in the effective operation of the Convention. These include the Standing Committee, created in 1979; the Animals, Plants, Identification Manuals and Nomenclature Committees, all given permanent status in 1987 (see Resolution Conf. 9.1 (Rev.)).

The Standing Committee was established to fulfil several administrative functions and is the senior Committee of the Convention. It provides general policy and operational direction to the Secretariat concerning the implementation of the Convention, financial oversight, co-ordination and advice for the various Convention Committees, and co-ordination, preparatory and follow-up work for meetings of the Conference of the Parties. Its membership is comprised of Party representatives on a geographical basis; regions which contain more Parties have correspondingly more representation.

The Plants and Animals Committees were formalised pursuant to Resolution Conf. 6.1 in 1987 (see now Resolution Conf. 9.1 (Rev.)). In many respects they were created as successors to an earlier Technical Committee and were given several functions to ascertain the appropriateness of species listings on the Convention appendices.

In addition, the Committees are charged with undertaking periodic reviews of species listed in the Appendices, providing advice on management techniques to Parties requesting such assistance and drafting resolutions for the consideration of the Conference of the Parties. 
Both the Plants and Animals Committees are comprised of 9 experts chosen from the different geographic regions of the world. The Parties are entitled to be represented at meetings of the Committees by an observer, and other experts may also be invited to participate as observers.

The need for expert assistance in order to identify specimens was recognised early in the life of the Convention. In 1977 a Committee of experts was established for this purpose and was made permanent in 1987 (as the Identification Manual Committee by means of Resolution Conf. 6.1. Under the policy set by the Conference of the Parties, the Committee provides guidance and coordination in the preparation of identification manuals for animal and plant species. It also may provide assistance on the identification of specimens, and may review proposals to amend the Appendices with regard to identification problems. Membership in the Identification Manual Committee is from amongst the Parties on a voluntary basis; geographic representation is not required.

The Nomenclature Committee was formalised by Resolution Conf. 6.1 (now Resolution Conf. 9.1 (Rev.)) to deal with the problem that the biological nomenclature of species varied from country to country and that nomenclature, in any event, was not static. A standardised reference system was seen to be essential for the operation of the Convention. Hence, the Nomenclature Committee was tasked with preparing or proposing for adoption, standardised nomenclature references for animal and plant taxa, for all species listed in the Appendices to the Convention. Membership in this Committee is on a voluntary basis; geographic representation is not required. 


\section{TRADE MEASURES UNDER THE CONVENTION}

This section will identify and describe the trade measures which are detailed in the text of the Convention. For purposes of this paper, "trade measures" are those which affect the quantity or quality of goods and services traded internationally. The next section, on "innovative measures" will consider several other measures which are also trade related, and which have resulted from the evolution of CITES. The CITES trade measures aim to ensure the long term survival of species and to maintain trade at sustainable levels, where appropriate.

\subsection{The Specific Trade Measures}

The trade measures in CITES govern the export, re-export, import, and introduction from the sea of specimens of species listed in three Appendices. The specific trade consequences vary, depending in which Appendix a species is listed.

\subsubsection{Appendix I Listings.}

Appendix I includes species which are "threatened with extinction and are, or may be affected by international trade [Art. II (1)]. Trade in Appendix I species for commercial purposes is prohibited, except in exceptional circumstances (see Art. III and the reference below to exemptions and other special provisions). In these exceptional cases, Appendix I species may only be traded if both export and import permits are issued, by the exporting and importing State, respectively. Before issuing the export permit, the country of export must determine that an import permit has been granted for the species (see below), the export will not be detrimental to the survival of the species ("non-detriment finding"), the specimen was not obtained in contravention of national laws and any living specimen will be prepared and shipped so as to minimise the risk of injury, damage to health or cruel treatment. Before the import permit can be issued, the Management Authority in the importing country must make the determination that the import will be for purposes not detrimental to the survival of the species, that the specimen is not to be used for primarily commercial purposes, and in the case of a living specimen, that the recipient is suitably equipped to house and care for the specimen.

The trade measures associated with trade in Appendix I listed species, include a ban on commercial trade and a system of import and export permits to allow non- commercial trade. Approximately 600 species of animal and 300 plant species are included in Appendix I.

\subsubsection{Appendix II Listings}

Appendix II includes species, "which although not necessarily now threatened with extinction, may become so unless trade in specimens of such species is subject to strict regulation in order to avoid utilisation incompatible with their survival"[Art. II (2)]. 
Appendix II also includes species which may be confused with Appendix I or Appendix II listed species. These species, although not necessarily threatened by international trade may need to be regulated to make effective the measures enacted for the species listed in the appendices in their own right. This means that a number of so-called "Look-alike" species, are also included in Appendix II [Art. II (2)].

Commercial trade in Appendix II species can take place only if an export permit is issued on the basis of the exporting country making similar findings as for Appendix I species [Art. IV]. No import permit is required. The measures regulating trade in Appendix II species are restricted to the need for an export permit, and occasional trade moratoria on certain species, or specimens from certain countries. Some 4000 animal species and more than 250,00 plant species are included in Appendix II.

Although Appendix II listing does not require the issuance of an import permit, the prior presentation of an export permit is required [Art. IV]. Consequently, the importing Party still plays an important implementing role in accepting export permits that are authentic, valid, and which correspond to the specimens being traded .

\subsubsection{Appendix III Listings.}

An Appendix III listing allows individual Parties to choose to enlist the co-operation of other Parties in controlling trade in particular species under their jurisdiction [Art. II \& V] Trade in Appendix III species can only occur if an export permit is issued, based on similar criteria as required for Appendix I export permits. If the specimen originates in a country that has not listed the species, a certificate of origin is required. In all cases, the conditions for re-export are the same as those for export, except that the "non-detriment" finding need not be made once again. Appendix III includes some 200 animal species and 6 plant species.

\subsection{General Provisions Relating to the Trade Measures}

\subsubsection{Trade Monitoring and Reporting}

Monitoring of trade is an essential tool for achieving the aims of the Convention. Scientific Authorities are obliged to monitor export permits granted for Appendix II species and the actual export thereof and must advise their Management Authorities of suitable measures to limit the issue of export permits whenever they determine that the export should be limited in order to maintain a species throughout its range at a level consistent with its role in the ecosystems in which it occurs and well above the level at which it might become eligible for inclusion in Appendix I [Art. IV].

The trade records to be kept by all Parties and reported to the Secretariat on an annual basis provide an important monitoring system. The Annual Reports of all Parties together should provide statistical information on the total volume of world trade in CITES species, which is an invaluable element for the 
assessment of their conservation status. These reports can also be used to reflect the performance of Parties in implementing the Convention, as all reported exports and imports can in theory be compared.

Article VIII paragraphs 6-8 concern the records to be kept and reports to be made by the Parties and Article XII paragraph 2d) requires the Secretariat to study the reports to ensure implementation of the Convention. The World Conservation Monitoring Centre (WCMC) is contracted to provide data management services to the Parties and is responsible for maintaining the CITES Trade Database which logs data in all Annual Reports submitted to the Secretariat. Resolution Conf. 9.4 consolidates all previous resolutions on the preparation of Annual Reports and the Secretariat produces Guidelines for Annual Report preparation. WCMC assists the Secretariat in producing an analysis of annual reports for consideration by the COP at its biennial meetings. It is generally found that only a small percentage of transactions show perfect correlation between the Annual Reports of exporting and importing Parties. Of the transactions which do not correlate, many are caused by systematic errors.

\subsubsection{Listing Decisions}

The Convention provides only basic guidance on criteria for the inclusion of species onto the three Appendices. This has been augmented by the development of biological, trade and other criteria for listing adopted by resolutions of the Conference of the Parties, most recently via Resolution Conf. 9.24. Resolution Conf. 9.24 contains new criteria for categorising and listing species according to their risk of extinction. For the system to be objective, transparent and of general applicability, the criteria have quantitative guidelines. However, this does not mean that rigorous survey data has to be collected: estimation, inference and projection can all be used. This Resolution also provides for a standardised format for the presentation of proposals for amending the Appendices, stresses the importance of prior consultations with range States and concerned intergovernmental bodies, and offers several precautionary measures to be observed in the proposal process which are considered in the best interests of the conservation of the species. To assist the Parties in their deliberations on amendment proposals before the Meetings of the Conference of the Parties to CITES, IUCN has, since 1987, in collaboration with TRAFFIC, produced the "Analyses of the Proposals to amend the CITES Appendices".

\subsubsection{Exemptions and Special Provisions}

Exemptions and special provisions exist for the above-noted trade measures relating to the trade of specimens that are: in transit or transhipment, have been acquired prior to the application of the Convention to that species, are personal or household effects under very specific conditions, have been bred in captivity or artificially propagated, are in non-commercial exchange between registered scientific institutions, or (under strict conditions) are part of a travelling exhibition.

\subsubsection{Stricter Domestic Measures and Collective Enforcement Measures}

Article XIV.1 of the Convention recognises that Parties may take stricter domestic measures concerning trade, taking, possession or transport of species whether included in the Appendices or not, and that 
this may include complete prohibition of trade. Some Parties have enacted legislation to prohibit all international trade in species (e.g. Costa Rica and Paraguay). Several others, as noted above, have adopted stricter measures for, for example, the application of a dual permit system for Appendix II and III species as well as for Appendix I species. Article XIV(1) also provides the legal basis for Parties taking collective sanctions aimed at ensuring that the Convention is given proper effect. The Standing Committee has recommended on a few different occasions that Parties take stricter domestic measures against countries found to be in persistent non-compliance.

\subsubsection{Reservations}

Article XXIII allows Parties to take specific reservations relating to listings on the Appendices: when a country becomes a Party to CITES and for a limited period of time once a decision has been taken to amend the Appendices. Parties entering reservations are then treated as non-Parties (see below) for purposes of trade in that particular species. Article $\mathrm{X}$ addresses the issue of trading with non-Parties and requires non-Parties to provide 'comparable documentation' which 'substantially conforms with the requirements of the present Convention for permits and certificates'. Additionally, non-Parties must have a Scientific and Management Authority and trade can only be conducted when it benefits the conservation of the species. Resolution Conf. 4.25 provides that in the case of reservations pertaining to Appendix I species, the reserving Party should treat the species as if it were included in Appendix II.

\subsubsection{Trade with Non-Parties}

CITES permits trade in listed species with non-Parties in certain specified circumstances. Article X of the Convention provides that where export or re-export is to, or import is from, a non-Party State, comparable documentation (i.e. import and export permits) to that of CITES members must be issued. This documentation must conform substantially with the requirements of the Convention for permits and certificates. Resolution Conf. 9.5, which consolidates earlier resolutions, recommends that documentation not be accepted from non-Party States unless it appears in appropriate form and contains appropriate certification that the trade will not be detrimental to the survival of the species. In certain specific instances, the requirements are such as to de facto prohibit trade with non-Parties, such as with captive-breeding. 


\section{4. "POSITIVE OR INNOVATIVE MEASURES" IN CITES}

This section considers "positive or innovative measures" in CITES. Unlike more recently adopted global environmental treaties, CITES does not contain provisions which are considered by some as "positive" (e.g. a financial mechanism, obligations to transfer technology, differentiated obligations for developing countries). Although there is no formal definition of the term, in this context, positive or innovative measures are taken to refer to those measures which have evolved in response to the realisation that carefully controlled economic incentives derived from trade can help to facilitate implementation of the Convention. These innovative measures can also be considered as trade measures, in that they act to facilitate carefully regulated trade under certain conditions, thereby providing economic benefits as an incentive to promote species conservation. It is important to note that the goal of these measures is not increased trade per se, or even increased financial benefit per se. Rather the innovative measures have been designed to enhance conservation through recognition that incentives for conservation are required under some circumstances.

\subsection{Historical Overview of Innovative Measures}

The Convention was adopted before the theory of incentive measures to promote species conservation was widely recognised and the Articles of the Convention only provide for a regime of international controls for commercial trade in wildlife, with one exception. This exception allows for the commercial trade of captive bred and artificially propagated specimens of species included in Appendix I. Furthermore, no article in the Convention makes reference to the possible benefits of wildlife trade or makes any links between these and successful conservation programmes. Hence, the scene was set for some of the difficulties that CITES has had to deal with since it was ratified over twenty years ago. There has been an obvious dilemma between the provisions of a system of trade controls to conserve endangered species, and the needs of developing countries to use those resources in order to maintain them and thus ensure their conservation (see Swanson 1994, 1997).

Following the signing of CITES, successive Conferences of the Parties have made the link between regulating wildlife trade and its value. In addition, it has been recognised that several species may have been inappropriately listed in Appendix I in 1975, yet the adoption of the Bern Criteria in Resolution Conf. 1.2 prevented their subsequent transfer to Appendix II as evidence was required that the status of the species had actually improved. Consequently, a quota system was specifically designed to allow the transfer of these species to Appendix II (see Resolution Conf. 5.21, Resolution Conf. 7.14 and finally, Resolution Conf. 9.24). Similarly, ranching was established through Resolution Conf. 3.15 when it became clear that many intensive management options under closed systems would not meet the captive breeding criteria (Resolution Conf. 2.12). Resolution Conf. 3.15 on ranching is quite specific that the ranching operation must be beneficial to the conservation of the wild population and must provide evidence that any off-take from the wild shall have no significant detrimental impact on wild populations. Despite the somewhat chequered history of the concept of beneficial trade, the evolution of innovative 
measures has gained considerable momentum. Section 5.2 details the innovative measures that have been taken under CITES, while section 5.3 evaluates their successes and failures.

\subsection{An Outline of the Innovative Measures Adopted}

This section summarises the innovative measures taken under the Convention. Innovative measures for Appendix I species are described under separate headings in their order of historical precedence, followed by the one measure so far adopted for Appendix II species. The sources for the following material comprise mainly Wijnstekers (1995) and Rosser and Haywood (1997). These measures comprise:

- Captive breeding and artificial propagation for Appendix I species

- Ranching for Appendix I species

- Quotas for Appendix I species

- Annotations for Appendix I species

- $\quad$ Significant trade process for Appendix II species

\subsubsection{Captive Breeding and Artificial Propagation for Species Listed in Appendix I}

Article III of the Convention prohibits international trade in specimens of species listed in Appendix I where the import is primarily for commercial purposes. However, Article VII.4 removes that restriction for trade in specimens of animal species bred in captivity, or of plant species artificially propagated, for commercial purposes and deems such specimens to be included in Appendix II. Hence, no import permit is required for such specimens, their housing in the country of import is not subject to any special conditions, and they can be imported for primarily commercial purposes. However, the Articles of the Convention do not define what constitutes captive breeding or artificial propagation.

\subsubsection{Captive Breeding for Animal Species}

To prevent the misuse of Article VII.4, Resolution Conf. 2.12, aimed to define 'bred in captivity'. but was replaced by Resolution Conf. 10.16 which recommended that the term 'bred in captivity' should only refer to specimens, born or otherwise produced in a controlled environment,. It shall apply only if the parents mated or gametes were otherwise transferred in a controlled environment, if reproduction is sexual, or if parents were in a controlled environment when development of the offspring began, if reproduction is asexual. Furthermore, the breeding stock must be established in a manner not detrimental to the survival of the species in the wild, and maintained without the introduction of specimens from the wild, except for the occasional addition of animals, eggs or gametes from wild populations to prevent deleterious inbreeding, to dispose of confiscated specimens and exceptionally, for use as breeding stock. In addition, the breeding stock should have produced offspring of a second generation $(\mathrm{F} 2)$ or subsequent generation $(\mathrm{F} 3, \mathrm{~F} 4)$ in a controlled environment, or should be of a species included in a list of species commonly bred in captivity to second or subsequent generation and managed in a manner that has been demonstrated to be capable of reliably producing second-generation offspring in a controlled environment. The resolution also defined the characteristics of a controlled 
environment, as being one that is intensively manipulated by man for the purposes of producing the species in question, and that has boundaries designed to prevent animals, eggs or gametes of the selected species from entering or leaving the controlled environment. General characteristics of a controlled environment may include, but are not limited to, artificial housing, waste removal, health care, protection from predators and artificial supplied food.

Resolution Conf. 5.10 later restricted the import of Appendix I specimens for captive breeding programmes, to those destined for non-commercial operations. Therefore, it was intended that captive breeding for commercial purposes should largely remain in the purview of the States of origin of the Appendix I species. Indeed, Resolution Conf. 1.6 (Rev.) provides positive encouragement to exporting nations to limit takes from the wild of popular animals in the pet trade from rare island fauna that are becoming endangered. Exporting nations are instead encouraged to breed animals for this purpose, with the objective of eventually limiting the keeping of pets to those species that can be bred in captivity.

An important consideration that emerged in 1985 was the need for adequate registration of captive breeding operations, achieved through Resolution Conf. 4.15. In 1987, it became a condition for authorisation of trade that commercial captive breeding operations involving Appendix I species were included in the Register of Captive Breeding Operations held by the CITES Secretariat (see Resolution Conf. 6.21). Attempts were made in 1989 to frame criteria for approval of commercial captive breeding operations, through Resolution Conf. 7.10. However, this resolution did not clarify the situation and so all previous Resolutions on the subject were repealed with Resolution Conf. 8.15 in 1992 (see Wijnstekers 1995). Meanwhile, the demand for registration of commercial captive breeding operations grows, and involves more species.

\subsubsection{Artificial Propagation for Plant Species}

Resolution Conf. 2.12 also defined artificial propagation in the context of Appendix I species of plants bred for commercial trade. However, with advances in methods of plant propagation, Resolution Conf. 8.17, later replaced by Resolution Conf. 9.18 (Rev.), updated the definition of 'artificially propagated'. Such plants may only be grown from seeds, cuttings, divisions, callus tissues or other plant tissues, spores or other propagules under controlled conditions. Furthermore, the cultivated parental stock used for the artificial propagation must be established and maintained in a manner not detrimental to the survival of the species in the wild, and managed in such a way that long-term maintenance of this cultivated stock is guaranteed. In addition, any grafted plants shall be recognised as artificially propagated only when both the root stock and the graft have been artificially propagated. Resolution Conf. 9.18 (Rev.) also lays out what is meant by 'controlled conditions'. As with captive breeding, the process of registering nurseries exporting artificially propagated specimens of Appendix I species for commercial purposes was first addressed in 1985, through Resolution Conf. 4.15. However, this has been revised subsequently, and Resolution Conf. 9.19 lays out the most up to date conditions for registering a nursery that exports artificially propagated specimens of Appendix I species. An important difference compared with captive breeding operations is that nursery registration is not a condition of being allowed to trade. 


\subsubsection{Ranching for Species Listed in Appendix I}

In contrast to its recognition of captive breeding, the Convention does not provide explicitly for the establishment of ranching operations. However, this has been overcome through various measures adopted in successive conference resolutions. Ranching operations bring young animals or eggs into a controlled environment and rear them until they are of a commercially exploitable size. Initially, Parties allowed the rearing of animals in a controlled environment to pass as captive breeding under the provisions of Article VII.4. However, when the definition of 'captive bred' was established through Resolution Conf. 2.12 and later Resolution Conf 10.16, this specifically excluded any commercial trade in specimens of Appendix I species taken from the wild. Therefore, this presented a problem for ranching operations involving populations of species listed in Appendix I that could withstand a certain level of exploitation. This resulted in several generic resolutions governing the conduct of ranching operations, and some resolutions relating to particular species, that can be divided into two main categories:

$\circ \quad$ Conduct of a ranching operation
$\quad \quad$ Marine turtle ranching

\subsubsection{Conduct of a Ranching Operation}

Resolution Conf. 3.15 on ranching, recognises that populations of species included in Appendix I may vary in their degree of endangerment between countries. Furthermore, it recognises that some countries may wish to restore those species to international trade as soon as this would not be detrimental to the survival of wild populations. Therefore, Resolution Conf. 3.15 recommends that populations of species included in Appendix I, which are not endangered and which are likely to benefit by ranching for commercial trade, be included in Appendix II. In contrast to approaches for captive breeding, it is only possible for the population of a country, or a smaller geographically separate population, of the species to be transferred to Appendix II to conduct a ranching operation, rather than for individual operations to be registered. In order for a population to be considered for transfer to Appendix II to conduct a ranching operation, it must satisfy certain criteria. At the tenth COP, Resolution Conf. 3.15 was repealed by Resolution Conf. 10.18 which emphasises that the overriding objective of the Convention is to conserve wild populations of the species and that positive incentives must be offered to programmes designed to achieve this aim. Resolution Conf. 10.18 details the criteria and requirements to be considered in transferring a population of a species from Appendix I to Appendix 11 for ranching.

Resolution Conf. 10.18 also includes the recognition that whilst ranching has become a potentially valuable positive conservation tool, taking of wild adults needs more careful control. Similarly, it was also recognised that ranching may benefit wild populations of crocodilians more than captive breeding, and that positive incentives were necessary to promote ranching. 


\subsubsection{Marine Turtle Ranching}

Once Resolution Conf. 3.15 on ranching had been adopted, some controversial ranching proposals on green turtles, Chelonia mydas, were put before Conferences to the Parties, but were not accepted. Subsequently, Resolution Conf. 6.23 recognised that some Parties had expressed their desire to provide a means for establishing ranching operations for marine turtles and other species, while also controlling international trade resulting from such operations. However, a scientific basis still needed to be established for the evaluation of proposals. Nevertheless, guidelines for evaluating marine turtle ranching proposals were not accepted until the adoption of Resolution Conf. 9.20 in 1994, later revised as 9.20 (Rev.). This resolution notes that the unique biology of marine turtles makes their sustainable use difficult and imposes special restraints on their exploitation, which requires the use of rigorous controls. Equally, because marine turtles return to specific beaches to nest, protection of habitat and of nesting turtles is a specific responsibility of range States. Therefore, the resolution recognised that sustainable use may have potential benefits for the conservation of marine turtles and their habitats, but stressed the need for regional co-operation in order to achieve such benefits.

One proposal to transfer hawksbill turtles, Eretmochelys imbricata, from Appendix I to Appendix II has been submitted since the adoption of Resolution Conf. 9.20, and elements of this proposal from Cuba related to the establishment of a ranching operation. However, this proposal was not submitted in the form of a ranching proposal, nor was it accepted by the Conference of the Parties in 1997. Consequently this innovative measure cannot be evaluated.

\subsubsection{Quotas for Species Listed in Appendix I}

The application of quota systems, approved by the Conference of the Parties, can be regarded as an innovative measure in CITES, as they are designed to facilitate non-detrimental trade in a carefully regulated number of specimens. However, as the Convention does not provide explicitly for the establishment of quota systems, these have been provided for through various measures adopted in successive conference resolutions, and through annotation of the Appendices. Resolutions have been both generic and related to particular species, and can be divided into five main categories:

- Trade in hunting trophies of species listed in Appendix I

- Trade in leopard trophies and skins for personal use

$\circ \quad$ Trade in live specimens and hunting trophies of cheetah

- Trade in ivory from African elephants

- Special criteria for the transfer of taxa from Appendix I to Appendix II when the countries of origin agree to introduce a quota system

\subsubsection{Trade in Hunting Trophies of Species Listed in Appendix I}

Article III of the Convention requires complimentary controls of trade in species listed in Appendix I by importing and exporting countries. Thus, non-commercial trade in hunted trophies of Appendix I species is only permitted when accompanied by import and export permits. Effectively this meant that 
both the exporting and importing governments must agree that the trade is not detrimental to the survival of the species and this was reinforced through Resolution Conf. 2.11. In certain cases, the importing government has questioned the non-detriment finding of the exporting government and has failed to grant the required import permits. In consequence, a series of Resolutions culminating in Resolution Conf. 9.21 have been adopted which provide that, whenever an export quota has been set by the Conference of the Parties, this action satisfies the requirements of Article III, provided that the quota is not exceeded, and that no new scientific or management data have emerged to indicate that the species population in the range State concerned can no longer sustain the agreed quota. If these conditions are fulfilled, the importing government is expected to accept the non-detriment finding of the exporting country.

Resolution Conf. 2.11 also recommended that the Scientific Authority of the importing country should examine whether the hunting of that species would enhance its survival. However, as Article III does not provide for questions regarding such beneficial effects of trade, this element of Resolution Conf. 2.11 was subsequently revised, but not before this sentiment was established as the basis for the quota in leopard skins (see 5.2.3.2). Resolution Conf. 2.11 (Rev.) continues to apply to species other than the leopard and cheetah, and to trophies from countries of origin without an approved trophy export quota. The role of the Scientific Authority of the importing country has now been substituted by a decision of the Conference of the Parties, bringing Resolution Conf. 2.11 (Rev.) in line with Resolution Conf. 9.21.

No proposals were submitted under Resolution Conf 9.21 to the tenth Conference of the Parties. However, Pakistan was granted a quota of six trophy hunted specimens of the markhor, Capra falconeri, with the adoption of Resolution Conf. 10.15. It is too early to evaluate the effectiveness of this measure.

\subsubsection{Trade in Leopard Trophies and Skins for Personal Use}

The leopard, Panthera pardus, was listed in Appendix I in 1975, as part an overall move to protect spotted cats from commercial trade in their skins (Table 1). Therefore, international trade in it or its products for primarily commercial purposes was prohibited. However, Resolution Conf. 4.13, adopted in 1983, recognised that killing of specimens may be sanctioned by countries of export in defence of life and property and to enhance the survival of the species. Furthermore, this resolution also recognised that the leopard was not endangered in several African countries (see Baillie and Groombridge 1996; Nowell and Jackson 1996). Equally, this resolution recognised the overwhelming desire of Parties not to re-open a commercial market in leopard skins. Thus, Resolution Conf. 4.13 struck a balance by establishing a quota system that was subject to a review every two years at successive Conferences to the Parties. Quotas were initially established from 7 African countries, totalling 460 specimens. Importers were allowed only one skin per person per calendar year, and these were allowed only as personal imports that could not be sold in the country of import.

The leopard quota system was reviewed through Resolution Conf. 5.13 and 6.9, when quotas were raised or added, but the recommendations remained practically the same. Resolution Conf. 7.7 allowed the system to continue without the usual biannual review, but any increase in quota or any state not 
previously having a quota required the consent of the Conference of the Parties. Importers were allowed two skins per person per calendar year. Resolution Conf. 8.10 (Rev.) was repealed by Resolution Conf. 10.14 which contains the currently applicable recommendations. Eleven African range States are now allowed export quotas per calendar year (Table 7), totalling 2085 specimens. Each skin must be tagged by the exporting country to show the country of origin, the number of the specimen in relation to the annual quota and the calendar year to which the quota applies, and the same information must be recorded on the export document. Each exporting state must also submit an annual report to the Secretariat detailing the number of trophies and skins exported in the previous quota year.

\subsubsection{Trade in Live Specimens and Hunting Trophies of Cheetah}

The cheetah, Acinonyx jubatus, was also listed in Appendix I in 1975 (see Table 1). Therefore, international trade in it or its products for primarily commercial purposes was prohibited. The cheetah is known to be considerably more endangered than the leopard (see Nowell and Jackson 1996). Indeed, a proposal to transfer several southern African populations of cheetah from Appendix I to Appendix II submitted in 1992, was rejected. However, an annotation was included in the Interpretation to Appendices I and II, allowing annual export quotas for live specimens and hunting trophies to three African countries (Table 7). The trade in such specimens is subject to the provisions of Article III of the Convention.

\subsubsection{Trade in Ivory from African Elephants}

The problems facing the African elephant, Loxodonta africana, have like those of rhinos, crocodiles and spotted cats, been a dominant force in driving the effective functioning of the Convention, and have demanded a high degree of flexibility and willingness to change direction. African elephants were listed in Appendix II of the Convention in 1977, while their more endangered Asian cousins, Elephas maximus, were listed in Appendix I in 1975. However, it was recognised in the 1980s that, due to the increasing monetary value of ivory, illegal trade activities were reaching significant levels. Ivory was frequently traded with inadequate documentation, and States that were not a Party to the Convention were playing a special role in this trade. At the fourth Conference of the Parties, it was recognised that an Appendix II listing was insufficient to protect the elephant, while an Appendix I listing might be counterproductive. Between the fourth and fifth Meetings of the Conference of the Parties, a solution to the ivory trade problem was sought, the main features of which were export quotas for raw ivory based on scientifically established management programmes, no trade from countries without such quotas and no trade in unmarked ivory. A project was designed that aimed at providing the necessary basis for establishing the quotas. The quota system was approved in 1985, through Resolution Conf. 5.12, and the proposal by the Secretariat to establish an Ivory Control Unit provided the basis for agreeing not to prohibit international trade in African elephant ivory.

Six resolutions to refine the quota system were adopted at the sixth Conference of the Parties in 1987. Meanwhile, the quota system was seen to have failed by the seventh Conference of the Parties in 1989, when the African elephant was included in Appendix I. Much has been written about the failure of this quota system, from both the conservationists' and the economists' perspectives (Douglas-Hamilton 1987; ITRG 1989; Barbier et al. 1990; Swanson 1994). In summary, this failure arose because the 
management quota system provided no external checks on the discretion of producer states in the issuance of permits. In other words, there was no mechanism for ensuring that permits were issued in accordance with a sustainable management system, and there was no requirements for effective investment in elephant management. In addition, there were also no disincentives to cross-border exploitation, since consumer States were allowed to import ivory without question from any exporter issuing permits. Thus Burundi, with a population of one elephant, became the largest exporter under this regime!

Despite the Appendix I listing, all earlier recommendations on trade in ivory of African elephants were consolidated in Resolution Conf. 9.16, with a view to reducing the applicable resolutions. At the recent tenth Conference of the Parties, proposals to downlist the African elephant populations of three countries were agreed under very strict terms (see Resolution Conf 10.9 and 10.10). However, it is currently impossible to undertake any form of evaluation of this innovative measure.

\subsubsection{Special Criteria for Transfer from Appendix I to Appendix II through a Quota System}

Resolution Conf. 1.2, known as the Bern Criteria, originally laid down criteria for the transfer of a species from Appendix I to Appendix II. These criteria required positive scientific evidence that species could withstand exploitation resulting this transfer, including a well-documented population survey, an indication of the population trends showing recovery sufficient to justify the transfer, and an analysis of the potential commercial harvest of the species or population. In many instances, these requirements could not be met. A particular concern surrounded how best to deal with those species that might have been inappropriately listed in Appendix I when the treaty came into force for examples the Nile crocodile Crocodilyus niloticus, and the leopard.

It was recognised that reducing protection by transfer between Appendices was a serious matter and the principle of the Bern Criteria that loss of protection should not lead to loss of the resource was paramount. Consequently the Parties adopted a system whereby internationally agreed quotas could be used to limit the exploitation of a species to an extent that did not threaten its survival. Over the years Resolutions Conf. 2.23, 5.21 and 7.14 were adopted in an effort to allow transfers from Appendix I to Appendix II, but to restrict exploitation by means of internationally agreed quotas. These resolutions have now all been repealed following adoption of the new listing criteria laid down in Resolution Conf. 9.24 .

Under the new listing criteria, any proposals to amend the Appendices shall take into account precautionary measures, as outlined in Annex 4 of Resolution Conf. 9.24. When transferring species from Appendix I to Appendix II, an integral part of the amendment proposal should comprise an export quota that is approved by the Conference of the Parties, based on management measures described in the supporting statement of the amendment proposal, provided that effective enforcement controls are in place.

Given that very few attempts were made to approve quotas under Resolution Confs. 5.21 and 7.14, and that the new listing criteria have only applied to amendment proposals presented to the very recent 
tenth Conference of the Parties, no evaluation of the innovative measure of Quotas applying to the transfer of species from Appendix I to Appendix II is possible.

\subsubsection{Annotations Allowing the Transfer of Species from Appendix I to Appendix II}

The Convention does not allow explicitly for the use of annotations to listings of species in any Appendix. Thus the original text of the Convention foresaw only that the status of a species would either allow, or not allow, commercial trade in all parts or derivatives of that species. However, in recent years there has been increasing recognition or belief that commercial trade can only be carried out in certain circumstances. Thus annotations are now being used to allow downlisting under carefully specified circumstances. There is as yet no generic ruling on the use of annotations, but there are several cases where these have been used for particular species, for example:

- Trade in cloth and wool sheared from live vicuna

$\circ \quad$ Trade in live specimens and hunted trophies of southern white rhinos in South Africa

\subsubsection{Trade in Cloth and Wool Sheared from Live Vicuna}

The vicuna, Vicugna vicugna, was listed in Appendix I in 1975, at a time when it was highly endangered. However, certain populations, designated at provincial level, in Chile (one population) and Peru (five populations) were transferred to Appendix II in 1987 for the exclusive purpose of trading in cloth made from wool sheared from live animals. In 1994, this system was extended and the annotation for the species now allows trade both in wool sheared from live vicunas of the populations included in Appendix II (one population in Chile and the whole population in Peru), in an existing and specified stock of wool in Peru, and in cloth and items made thereof. In 1997, a population in Argentina and a population in Bolivia were also transferred to Appendix II. The Argentinean population can now be the subject of trade in wool sheared from live animals and in cloth and manufactured items made thereof, while the Bolivian population currently has a zero quota for wool sheared from live animals.

Resolution Conf. 8.11 (Rev.) notes that other countries than the main range States also hold stocks of cloth made from vicuna wool, as well as stocks of wool. Therefore, this resolution aims to support the exports of vicuna cloth from the main range States, by encouraging other countries to report their trade in vicuna cloth, only to authorise further imports if they are from the main range States, and for all Parties to employ stricter domestic controls on trade in vicuna cloth.

\subsubsection{Trade in Live Specimens and Hunted Trophies of Southern White Rhinos in South Africa}

The southern white rhino, Ceratotherium simum simum, was listed in Appendix I in 1977, thereby making inclusive the listing of all species of rhinos in Appendix I to prevent trade in their horn (Table 2). Meanwhile, the southern white rhino continued its recovery, particularly in South Africa. An important part of the recovery plan for this sub-species adopted by South Africa was the translocation of white rhinos to former range and to captive breeding facilities, often involving international movement (Cumming et al. 1990). Furthermore, South Africa began trophy hunting of the white rhino on private 
land in 1968, and certain state protected areas in 1982 (Adcock and Emslie 1994). Both the export of live animals and of hunting trophies could proceed under an Appendix I listing through the provisions of Article III of the Convention, and there was no suggestion of any hindrance to this trade under these conditions.

Meanwhile, South Africa put forward proposals to transfer its population of southern white rhino from Appendix I to Appendix II to allow limited trade in their horn, as well as existing uses such as live sales and hunting trophies, in 1992 and in 1994. The proposal in 1992 was totally rejected, but a compromise was reached in 1994 through an annotation to the downlisting of the South African population to Appendix II that allowed trade in live specimens and in hunting trophies only. This compromise served to acknowledge South Africa's role in the recovery of the southern white rhino and to remove the need for an importing state to make a non-detriment finding or issue an import permit for imports specified under the annotation. However, it prevented the re-opening of any trade in white rhino horn from South Africa (Table 2). A proposal in 1997 to change the annotation to allow consideration of a limited trade in white rhino horn, but with a zero quota initially, was rejected. Therefore, the 1994 annotation allowing export of live specimens and of hunting trophies only under an Appendix II listing stands.

\subsubsection{Significant Trade Process}

There has been considerable movement of species towards higher appendices since the Convention was ratified, and many taxa have been included in Appendix I without first being listed in Appendix II (Table 6; Figure 6). However, ideally, taxa should normally be included in Appendix II before their status becomes so bad that they have to be included in Appendix I, as the successful implementation of the provisions relating to Appendix II is critical to the overall and long-term success of CITES (Wijnstekers 1995). The most important of the provisions for achieving sustainability in the use of Appendix II-listed species is the non-detriment finding embodied in Article IV.2a, which stipulates that trade in Appendix II species must not be detrimental to the survival of that species. This is a difficult provision to implement because many countries of origin lack the necessary scientific data on the status of their animal and plant populations, which makes it difficult to calculate how the population is affected by different levels of exploitation. A related provision is embodied in Article IV.3 which requires that the species is maintained throughout its range at a level consistent with its role in the ecosystems in which it occurs. However, the latter is even harder to determine and therefore this requirement is even more difficult to implement than the non-detriment finding.

In order to improve implementation of these provisions, a procedure was established for identifying species listed in Appendix II that might be subject to detrimental levels of trade, and for formulating appropriate remedial measures, through Resolution Conf. 4.7. Once the Animals Committee was established through Resolution Conf. 6.1, it was given responsibility for overseeing the so-called Significant Trade Process, for animals. The procedure was fully revised with the adoption of Resolution Conf. 8.9, on trade in wild-caught specimens, which provides the basis for the ongoing review of significant trade in animals listed in Appendix II. In addition, the ninth meeting of the Conference of the 
Parties adopted a Decision laying down a programme of work for both the Animals and the Plants Committees with regard to significant trade in plant species listed in Appendix II. At the tenth COP this programme of work was refined for plants.

\subsubsection{Significant Trade in Animal Species}

The procedure adopted by the Conference of the Parties for animals empowers the Animals Committee with two main courses of action, ongoing reviews and recommendations (Wijnstekers 1995). During the course of its work, the Animals Committee considers biological and trade data and identifies Appendix II species that might be subject to significant levels of trade, with a view to identifying problems and making recommendations with respect to the implementation of Article IV. The Animals Committee report back to each meeting of the Conference of the Parties on the progress of this review, and on the measures adopted and those recommended to implement Article IV for Appendix II species subject to significant levels of trade.

The Animals Committee, after consultation with the range States, can formulate specific recommendations for significantly traded specimens that take one of two forms. Both the primary and secondary recommendations of the Animals Committee are communicated to the Party concerned by the Secretariat.

- Primary recommendations can include administrative procedures, specific quotas, zero quotas, or temporary restrictions on export. These must be implemented by the Party concerned within 90 days of receipt.

- Secondary recommendations can also include administrative procedures, but may also encompass field surveys or evaluations of other threats to populations, including illegal trade, habitat destruction, internal and other uses, designed to provide the information necessary for the Scientific Authority to make a non-detriment finding. These must be implemented by the Party concerned within 12 months of receipt.

The Secretariat is responsible for deciding if the recommendations have been implemented. If they have not been implemented by the deadline, the Secretariat can make a recommendation to the Standing Committee about strict measures to be taken by all Parties, including suspension of trade in the affected species with that Party. The Secretariat's proposals to the Standing Committee have usually resulted in recommendations to a number of range States to establish cautious export quotas and, where this has not been done, trade has been suspended in specimens of the species concerned from that Party. Such trade has only been reinstated when the Party concerned has demonstrated satisfactorily to the Standing Committee that the recommendations have been implemented.

The Secretariat is required to monitor the implementation of Resolution Conf. 8.9 and to report back to each meeting of the Conference of the Parties. Furthermore, the Conference implored the Parties and all organisations interested in the utilisation and conservation of wildlife to provide the necessary financial 
support and technical assistance to those Parties in need of such assistance to ensure the maintenance of wild populations of species subject to significant levels of trade.

A Decision was taken at the ninth Conference of the Parties to establish a system for the implementation of Resolution Conf. 8.9. This is a complex process, and encompasses a number of steps involving the collaboration of partners working with the Animals Committee and Secretariat, including, WCMC, IUCN and TRAFFIC.

- The Animals Committee should choose a normally safe level of trade for Appendix II species;

- WCMC should produce a print-out from the CITES database showing the recorded net levels of trade in all Appendix II species over the last five years for which reasonable data are available.

Species for which the average net trade over the period over the period has exceed the normally safe level should be selected and a print-out produced showing the levels of export and re-export of these species by country. This will constitute the list of taxa that might be subject to significant levels of trade for consideration in the current period.

- On the basis of common knowledge of the Animals Committee and of other relevant experts, species should be eliminated from the list if it is clear that the level of trade does not adversely affect their populations, and species should be added if a low volume of trade could adversely affect their populations or if there has been a recent increase in trade.

- Consultants should be engaged to compile information about the biology and management of the species remaining in the list, in consultation with the range state, and should divide the species into one of three categories:

a) those for which the information indicates that the global population or the population in a particular range state is being adversely affected by international trade;

b) those for which there is insufficient information to base a judgement; and,

c) those for which trade is evidently not a problem.

- The Animals Committee should review the available information and, if appropriate, revise the categorisation.

- If a species remains in categories (a) or (b), the Secretariat, on behalf of the Animals Committee, should request the range state that have authorised exports to advise on the scientific basis for permitting the recorded levels of trade, within a period of 6 weeks. 
- If a response satisfactory to the Animals Committee is received, the species may be eliminated from the list for the current period with respect to the state concerned.

- Otherwise, the Animals Committee, in consultation with the Secretariat, should formulate recommendations in accordance with Resolution Conf. 8.9.

Species that have been subject to primary recommendations will normally be subject to further review after two consecutive periods between meeting of the Conference of the Parties. Hence, the procedure is envisaged as being cyclical in nature.

The Secretariat was directed to contract IUCN to co-ordinate, in consultation with WCMC, the conduct of the field studies required for the Appendix II species identified by the Animals Committee as being subject to significant levels of trade, and to raise the funds necessary for such studies.

\subsubsection{Significant Trade in Plant Species}

The decision of the Conference of the Parties to lay down a work programme for the Plants Committee to implement a Significant Trade Process for Plants had the following components (see Wijnstekers 1995):

Data on levels of trade, based on annual reports, should be prepared and circulated on a regular basis, at intervals corresponding with the Conferences of the Parties. These data should comprise annual levels of trade for each taxon for the current and previous five years with information on levels of propagated specimens also reported.

The information already compiled on levels of trade in particular plant groups should be made available for review by the IUCN/SSC plant specialist groups. Future reviews should be considered on a routine basis, and as far as possible trade data should be correlated with conservation status information for expert review.

A programme of work was laid down, based on the funding available in the CITES budget for studies of significant trade in plants. These measures included, completing a study of tree ferns by 1994, and starting to review national reporting procedures for trade in plants. By 1995, it was envisaged that the review of reporting procedures would be complete, and the Plants Committee would provide the Parties with recommendations regarding improvement of the reporting of plants in annual reports. Furthermore, a review would begin on the international trade in orchids of Dendrobium species, which would be completed by 1996. At this time, a review of the Significant Trade in Species of Plants listed in Appendix II would begin based on data from 1990-1994, and this review would be completed by 1997, in order for recommendations to be considered by the tenth Conference of the Parties.

\subsubsection{Capacity Building and Training}


The CITES Secretariat staff organise regional training seminars to assist staff in National CITES Management Authorities to meet their obligations under the Convention. As a result of decisions taken at the tenth meeting of the Conference of the Parties, the Secretariat has been mandated to set up a Capacity Building Unit, to assist the Parties.

\title{
5. ASSESSING THE EFFECTIVENESS OF THE TRADE AND INNOVATIVE MEASURES IN CITES
}

This section will examine how effective the trade and innovative measures are in achieving the objectives of CITES. Reflecting the different perspectives from which this issue can be considered, this section will be divided into three sub-sections. The first will consider whether the trade measures form part of a sound legal regime. The second will consider the effectiveness of the trade and innovative measures in affecting the conservation status of listed species. The third will examine the measures from an economic perspective.

\subsection{Do the Trade and Innovative Measures form Part of a Sound Legal Regime?}

To meet its objectives, the trade measures in CITES must:

\author{
${ }^{\circ}$ facilitate international co-operation to regulate trade \\ ${ }^{\circ}$ establish clear rules to regulate trade \\ ${ }^{\circ}$ prevent Abuse and Non-compliance
}

Each of these ingredients of a sound legal regime must be examined.

\subsubsection{Facilitation of International Co-operation to Regulate Trade}

The first question to be answered is whether the trade measures in CITES provide sufficient incentives to encourage States to become Parties. A clear indicator of success is the number of Parties to the agreement.

The trade measures should encourage countries to join by reason that:

○ they provide a collective control mechanism for a Party wishing to prevent depletion of its wildlife populations from international trade

${ }^{\circ}$ a Party may find that trade is facilitated in its species for which trade is permitted, based on the products having received international approval for trade (this is explored further in the economic effectiveness section of this paper) 
${ }^{\circ}$ only by joining can a country influence the listing decisions and the evolution of the innovative measures in the treaty

In reality, the membership in the treaty is impressive, such that most of the world is covered, and most consumer and producer countries are Party (see Annex 1). Furthermore, Parties are continuing to join the Convention. As such, the evidence reveals that the Convention succeeds in facilitating international co-operation to regulate the international market.

Secondly, one may consider whether the Convention as a whole facilitates international co-operation to regulate the international market. Again, this must be answered in the positive, considering the impressive success of the various CITES committees and the COP in deciding how specific cases should be dealt with, as well as undertaking new initiatives. These mechanisms also de facto act as negotiating vehicles for disputes between Parties.

\subsubsection{Does the Convention Provide Clear Rules?}

While the original scheme in the Convention provided for a relatively simple set of rules, the past 22 years of evolution has witnessed a tremendous growth in the complexity of the treaty. However, the motivation behind these developments has been a desire to make the treaty more workable, clearer and more scientifically based.

In addition, since so much of CITES is now based on the resolutions and decisions taken at COPs, the recent effort to consolidate resolutions contributes to greater understanding of the rules. Although, as mentioned above, the precise legal status of the COP resolutions and decisions is unclear, the fact that they are influential may in part due be to the nature of COP process leading to their enactment, in that it allows for successful negotiation on how the treaty should be interpreted and applied. It must also be noted that to date no formal dispute between Parties has been lodged relating to the interpretation or application of the treaty provisions. However, more needs to be done to clarify the status of resolutions and decisions. This was recognised by the decision at the tenth COP that the next report on infractions would clearly distinguish between violations of the Convention and non-compliance with resolutions.

Thus, although a significant commitment of resources and political will is necessary to implement the package of treaty measures effectively, it can be said that CITES does succeed in basically setting forth a clear set of rules. At the same time, the continued efforts to streamline and clarify the treaty are welcome.

\subsubsection{Prevention of Abuse and Non-Compliance}

By regulating trade in listed species, CITES also works, of course, to combat illegal trade in wildlife. The basic approach to achieve this objective has been the institution in the case of Appendix I species of a dual system of controls, with permits based upon scientific findings required from both the importing 
and exporting States. In addition, several importing countries, notably those of the European Union, Australia and the United States have adopted stricter national measures (see section 4.2.4), pursuant to Article XIV of the Convention, to establish such a dual system also for their imports of Appendix II and III species.

Problems of illegal trade are highlighted in the Review of Alleged Infractions and Other Problems of Implementation of the Convention, prepared by the Secretariat for meetings of the COP. Among the problems reported in the review prepared for COP 10 (Doc. 10.28) were: acceptance of invalid documents, mischaracterization of trade as non-commercial, issuance of more export permits than permitted by a quota, failure to nominate a Scientific Authority, insufficient border controls and infractions relating to fraud.

\subsubsection{Illegal Trade with Non-Parties}

By creating a set of rules relating to trade in listed species with non-Parties (and those Parties who enter reservations), CITES seeks to prevent such trade from undermining the objectives of the regulated market. Given the high number of Parties to the Treaty, it would appear that the need for concern as to the impact of trade with non-Parties has diminished, although it has not disappeared.

\subsubsection{Illegal Trade between Parties}

As noted above, the Standing Committee has recommended that action be taken against Parties in cases of serious non-compliance. Such sanctions usually occur as a single-, or multi-CITES species trade ban. For example, total "trade bans" were instituted against the United Arab Emirates in 198590; Thailand in 1991-92 and Italy in 1992-3. The United Arab Emirates withdrew from the Convention in 1987 following the recommendation of the trade ban. It adopted new legislation to conform with CITES and re-acceded to the Convention in 1990, whereupon the ban was removed by the Standing Committee. In the case of Thailand, the recommended ban, imposed by the Standing Committee in 1991 because of insufficient legal provisions to implement the Convention was lifted in 1992 following the adoption of amendments to the Thai Wild Animals Protection Act and a field inspection by the CITES Secretariat. In the case of Italy, a ban was recommended in June 1992 by the Standing Committee because of enforcement difficulties; it was suspended a few months later in February 1993 and was finally lifted in April 1995, after new legislation was adopted.

Efforts have also been made in recent years to encourage Parties to develop effective national legislation to implement the Convention. The IUCN Environmental Law Centre and TRAFFIC USA have been involved in analysing the state of Parties legislation to implement the Convention. At the tenth COP, it was agreed that a concerted effort will be made to induce Parties to improve their national legislation. among the actions decided, was the possibility of refusal by other parties to trade in CITES- listed species with those Parties which (a) do not have legislation which meets the requirements for CITES implementation, (b) have not reported any improvements in their legislation in accordance with Decision 6(a) of COP 9, and (c) are engaged in significant amounts of trade in CITES species. 
To address fraud and other abuses, several mechanisms have been introduced over the years to enhance the integrity of this system including the use of security paper, stamps and comparison signatures to avoid abuse and counterfeiting.

As part of the effort to enhance enforcement of the Convention, the Secretariat was requested by Resolution Conf. 2.6 (Rev.) to maintain co-operation with ICPO-INTERPOL. This was echoed in Resolution Conf. 9.8 which called for additional co-operation (also with the World Customs Organisation), for the appointment of additional officers within the Secretariat to deal with enforcement and for the creation of regional law-enforcement agreements. In 1996 a Memorandum of Understanding was concluded between the World Customs Organisation and the CITES Secretariat and also between the CITES Secretariat and ICPO-INTERPOL However, a proposal at the tenth COP to create a Working Group on Illegal Trade in CITES Specimens was defeated.

\subsection{Are the Trade Measures Effective in Preventing Species from Being Over- Exploited through International Trade?}

This section restricts itself largely to a discussion of how the species conservation aspects of the trade measures might best be evaluated. The principles that would underlie a full evaluation of the Convention are assessed (5.2.1). However, it is not only international trade that contributes to causing extinctions of species, and possible causal factors other than those under the purview of the Convention are outlined in (5.2.2). This is followed by, a discussion of how to define and measure success or failure in the context of the Convention (5.2.3).A cursory evaluation of the effectiveness of listing species on the different Appendices of the Convention would suggest that considerable conservation success has attended the listing of some species or species groups, while little success has attended other listings. Two contrasting examples are examined, namely the success of listing many spotted cats in Appendix I to prevent trade in their skins, and the failure of listing all rhinoceros species in Appendix I to prevent international trade in their horn. These two examples are examined in some detail in (5.2.4) and (5.2.5) to set the scene for other cases that are examined in less detail (5.2.6). This section ends with what effectively amounts to a self-assessment of the effectiveness of the Convention by its Parties, through examining the changes in the listing of species on the Appendices since the Convention came into force (5.2.7).

\subsubsection{General Considerations}

There are several thousand taxa listed in the Appendices of CITES including both species and higher taxa (see Wijnstekers 1995). Their sheer number, and the complexity of the Convention and the associated issues, renders a full evaluation of the effectiveness of the trade measures very difficult. Unsurprisingly, a full evaluation of the effectiveness of the trade measures adopted under the Convention has not proved possible to date. Past initiatives have included the study by Environmental Resource Management (ERM, 1997) carried out at the request of the Parties to determine How to Improve the Effectiveness of the Convention. Whilst the Parties adopted the majority of recommendations of the 
ERM study, there was criticism of the study from various quarters, primarily on the grounds that it was not based on independent assessments.

Nor indeed will a full evaluation of the effectiveness of the Convention be possible through this study. Instead, the approach adopted here is to discuss some of the complexities that would be involved in such an evaluation, in order to point the way forward for future studies. Apart from the sheer number of listings that would need to be evaluated, several other very important issues present themselves.

A possible test of the effectiveness of the Convention would be to speculate what would have happened if there had not been a Convention. Whilst this is largely an hypothetical question, insights may be gained by looking at the management of wildlife resources which are outside the controls of CITES. Useful examples here might include the commercial timber and fisheries trades, which have not been under CITES controls and which representatives of these industries argue are under management by their own industries and so do not require CITES oversight. However, the indications of sustainability of these trades are not good: Commercial fisheries for a number of fish species have collapsed over the years and there are fears about the over-exploitation of certain timber trees. These examples, coupled with the view of resource economists that the best short term economic strategy is to mine a resource to extinction (Clark 1976), suggest that the Convention has an important role to play in regulating the overexploitation through trade, of the species listed in the Appendices.

Rarely can the effectiveness of CITES be isolated from other factors which affect levels of international trade. For example, the decreases in the purchases of cat skins in the 197Os and the decrease in ivory purchases in the late 1980s and early 1990's were associated with large public awareness campaigns which helped to reduce demand for both these products. In turn, the example of the African Elephant is also pertinent to the dynamic nature of the effectiveness of CITES, in showing that the Convention has the potential to adopt different approaches to conservation when faced with various types of pressure. The Appendix I listing of the African Elephant in 1989 appears to have reduced the levels of poaching of many populations (Dublin, Mulliken and Barnes 1995). However, despite these apparent short term gains, the long term outlook for the elephant is not so clear. Management of elephants requires considerable revenue expenditure throughout elephant range states (Leader-Williams and Albon 1988), yet spending on conservation has been decreasing in real terms (Dublin et al. 1995). As the human population in Africa continues to grow, competition for land and conflicts with wildlife will also increase, such that greater inputs and opportunity costs will be required to maintain the wildlife estate. In such circumstances an Appendix I listing may not be the most effective measure for the holistic conservation of for elephants. It could conceivably prevent over exploitation through legal trade, but as in the case of rhinoceros, the survival of African elephants could still be threatened by illegal trade and loss of habitat to alternative forms of land use. The Convention would be powerless to halt reductions of elephant numbers through human/animal conflict and habitat destruction, unless it dealt creatively with elephant conservation to find a mechanism for generating support from local people.

Some of the issues outlined above are insuperable in the context of this analysis, and are not considered further in this evaluation. 


\subsubsection{Factors Affecting the Effectiveness of CITES}

The Convention regulates international trade, but, species become extinct for many reasons other than international trade. Most recorded extinctions have arisen from a series of factors known as the Evil Quartet that include: habitat destruction and fragmentation; introduction of alien species; overkill, that may be for local use as well as international trade; and chains of extinction, where one species upon which another depends goes extinct (Diamond 1989). Declining status may also occur as a result of ineffective conservation policies acting more locally than the regulation of international trade, for example poor law enforcement around, and low budget devoted to a particular protected area (see LeaderWilliams and Albon 1988). Nonetheless, the effects of these other agents should be taken into account by national CITES Authorities in determining whether an export will be detrimental to the survival of the species.

Furthermore, an evaluation of the effectiveness of trade measures in securing the conservation status of species, would require consideration of other possibly confounding factors that might contribute towards a change in their status. For example, a bird such as a turaco (Tauraco spp.), harvested for a relatively low volume, high value international trade (see PAWM 1996) might be principally affected by habitat loss through deforestation, rather than trade per se (see Collar et al. 1994). As habitat is lost and population size declines, there will be fewer birds to harvest for trade. If the species is listed in an Appendix of the Convention, (all species of turaco are included in Appendix II (see Wijnstekers 1995)), any attempt to fully evaluate the effectiveness of that listing would need to take into account both the effect of that trade measure, as well as any changes in the rate of deforestation.

Hence, the following issues are discussed in the next sections:

$\circ \quad$ how to define success in the context of CITES;

$\circ \quad$ which measures of trade and species status to use; and,

$\circ \quad$ how to avoid confounding variables in defining success.

\subsubsection{Defining and Measuring Success or Failure}

An evaluation of the effectiveness of the trade measures under the Convention requires an acceptable definition of effectiveness. Such an evaluation could be considered both from an operational perspective and/or from a more biological and conservation perspective. From an operational perspective, effectiveness could be considered by :

i) examining the effectiveness of wording and operation of the Convention itself; and

ii) assessing the effectiveness of the Parties in implementing the Convention.

The contrast between these two options will be highlighted, through the comparison of the success of the Convention with spotted cats (5.2.4), its failure with the rhinoceros (5.2.5), and the varying successes and failures with other species (5.2.6). 
The case of the international trade in cat fur highlights a major conservation success for the Convention achieved through a combination of the efforts of importing nations and of pressure group advertising focused on consumers. In the case of rhinos, increasingly stringent resolutions were passed to encourage both importing and exporting Parties, and non-Parties to implement the strict measures of the Convention.

From a more biological and conservation perspective, the effectiveness of the trade measures in the Convention could be assessed by considering:

i) the wider viewpoint of achieving successful conservation of the species listed, or

- ii) the narrower viewpoint of achieving success in the stated objectives of the Convention, i.e. protection of species from over-exploitation through international trade.

These two options may not necessarily be mutually inclusive. For example, the collared peccary, Pecari tajacu (formerly Tayassu tajuca), is listed in Appendix II of the Convention, and that listing may be playing an important role in regulating the volume of international trade in their hides, both legal and illegal. However, the main hunting pressure on collared peccaries comes from commercial enterprises such as timber and oil companies, whose employees depend on game meat as a major source of food (Bodmer et al 1996). Furthermore, the species is heavily consumed locally and its products are sold on domestic markets (Redford and Robinson 1991). In this instance, an evaluation might conclude that the Convention was successful in playing its mandated and rightful role in regulating international trade, but that the wider objective of regulating international trade was not securing the status of the species in the wild. This is an important divergence to understand, because many regard the CITES Convention as the premier convention of wildlife conservation, expected perhaps to achieve above and beyond its mandate.

Taking first the narrow viewpoint of looking at the success of trade measures in achieving the objectives of the Convention, a full evaluation would require consideration of different factors that might have affected the success of listing individual species for each of the three appendices separately, because each provides different levels of regulation for the specimens of species placed upon them.

Appendix I includes species that are threatened with extinction and in which commercial trade is prohibited. Therefore, strict interpretation of the Convention provides at least two clear indices by which trade measures for species placed in Appendix I might be considered successful:

- in the immediate and short term, if international commercial trade in the species (that by placing it in Appendix I is now illegal) ceases; and, 
- in the long term, if the status of the species recovers successfully from the effects of international commercial trade to the extent that it is no longer threatened with extinction. By definition, a successful outcome should result in the movement of that species off Appendix I.

Appendix II includes species that are not yet threatened with extinction, but may become so unless international trade in their parts or derivatives is regulated. International commercial trade must be carried out at levels that are not detrimental to the survival of that species and at levels that are commensurate with its role in the ecosystem. All exports must be accompanied by a permit. Therefore, strict interpretation of the Convention provides at least three indices by which trade measures for species placed in Appendix I might be considered successful:

- in the short term, levels of international trade in that species should be quantifiable and open to inspection by all exporting and importing nations, and enforcement should become easier, thereby reducing levels of illegal trade.

$\circ \quad$ in the long term, if the status of the species does not deteriorate further such that it becomes threatened with extinction from the effects of international commercial trade. By definition, a successful outcome should result in the species remaining on (or even moving off) Appendix II, while a failed outcome would result in the inclusion of that species in Appendix I.

$\circ \quad$ in the long term, that dependant species remain at levels at which the ecosystem can function normally.

Appendix III contains species that national authorities wish to list and for which they seek the assistance of other Parties to regulate trade.

- in the short term, levels of international trade in that species from the range State listing the species should be quantifiable and open to inspection by other exporting and all importing nations, and enforcement should become easier, thereby reducing levels of illegal trade.

$\circ \quad$ in the long term, if the status of the species does not deteriorate further such that it becomes threatened with extinction in that range state from the effects of international commercial trade. By definition, a successful outcome should result in the species remaining on (or even moving off) Appendix III, while a failed outcome would result in the inclusion of the population of that range state for that species in Appendix I or II.

In practical terms, any standardised indices for quantifying illegal trade, by its very nature, are difficult to achieve for any species. Furthermore, the role of dependant species in the ecosystem, as required in the listing for Appendix II, is very hard to assess. Even documenting levels of legal trade between importing and exporting nations has proved hard to achieve. It is of course an important success of the Convention that there are any data at all on levels of international trade in the CITES database. Equally, it is important to recognise that the deficiencies and problems that occur with these data. Among the problems are the following (eg Johnson 1989): 
- The effectiveness of the implementation of the Convention varies from country to country. Some have not enacted domestic legislation to implement or to conform to the Convention. Even scrupulous examples of implementing legislation may have difficulties. Problems with forged documentation occur frequently. The accuracy, frequency and format of "annual reports", are highly variable. Thus the origin of specimens or the purposes of trade may not be completed, and descriptions of the type of specimen are not necessarily consistent.

- The scope of the Convention is necessarily limited to international trade, so the data only relate to international as opposed to domestic trade. Furthermore, the data do not necessarily reflect the volume harvested to produce the international trade, taking no account for example of mortality at capture.

$\circ \quad$ Different customs agencies use different units of measure, for example weight or number, which hinders clarity when the data are compiled. Furthermore, country of origin may be treated differently, so that it is not always possible to source imports and exports and cross-check them against each other.

- Illegal trade, apart from some seizures, is not reported through the CITES database.

- Not all countries are a Party to CITES, and trade between such countries is not reported to CITES. Thus such countries can be important consumers, or act as laundering operations, without this necessarily being reflected in the data on trade volumes. However as the number of Parties increases this becomes less of a problem

During the early years of the Convention, many of these problems were acute. However, with better record-keeping and cross-checking by Parties in future, the indices on trade levels in the CITES database would appear to offer the most promise of a tangible set of measures with which to evaluate trade measures for two of the Appendices.

Another requirement of the Appendix II listing is that levels of trade must not be detrimental to the survival of that species, and this in turn raises the need of comparing trade volumes against some measure(s) of population performance to make any meaningful non-detriment finding.

In terms of the wider viewpoint, any success in regulating trade through CITES should, inter alia, produce some improvement in status of the species or taxa in the wild. In turn, changes in status and trade levels should result in changes in listing on the Appendices. However, even attempting to assess the change in status of many species has proven very difficult. There are relatively few species for which extensive and systematic numerical counts are available. A process of revising the criteria by which species are listed in Appendix I and II (Resolution Conf. 9.24), and those by which species are listed in Red Data books as Critical, Endangered or Vulnerable, was undertaken from 1992 to 1994 (IUCN 1995) in order to place these criteria on a firmer scientific basis than was previously the case. While designing the criteria has provided some controversy, the limiting factor in applying the criteria remains 
the variable quality and type of data that are available on status of species in the wild. Even species that are among the best known and studied in the wild, such as the African elephant Loxodonta africana, are hard to count accurately in certain habitats such as rain forest, and it is arguable if an accurate estimate of a trend of change in their numbers has yet been achieved (Said et al. 1995). Furthermore, most species have never been counted throughout part or all of their range (Baillie and Groombridge 1996). Thus, the criteria allow for use of various other parameters such as changes in area of range and extent of distribution (Resolution Conf. 9.24; IUCN, 1995). One of the problems, however, of having recently revised the criteria is that it is not possible to use the resulting listings of 1988 and 1996 as indices of change. Thus, there have been some changes in the listing of birds in different categories of threat between 1988 and 1996 that result from a genuine worsening of status. Equally, other changes in listing arise from factors such as better knowledge, the different process of listing, and so on (see Collar, Crosby and Stattersfield 1994).

\subsubsection{How to Avoid Confounding Variables in Defining Success.}

To tease out the direct contribution of the CITES trade measures to changes in trade patterns and conservation status of the species listed in the various appendices, a multivariate analysis would be necessary. A possible matrix of factors that address the points raised in the various sections above could be constructed along the lines suggested in Table 5. For illustrative purposes, hypothetical data are entered for different explanatory variables for a few hypothetical species listed in Appendix I of the Convention. If an index of success or failure was available for each species listed in different appendices, it would be possible to undertake appropriate statistical analyses that teased out important factors in explaining the effectiveness of measures regulating international trade through the Convention.

The combination of needing to consider confounding factors that may affect the effectiveness of the trade measures, and the difficult issue of achieving a measure of effectiveness for each species, makes the task of providing an independent evaluation of the trade measures impossible at this time.

\subsubsection{The Effectiveness of the Convention With Spotted Cats}

\subsubsection{Wild Cats And The Fur Trade}

There are 36 species of wild cat, ranging in size from the tiger to the $1.5 \mathrm{~kg}$ rusty spotted cat. Wild cats are found in every continent except Australia and Antarctica (Nowell and Jackson 1996). Cat skins have been used in many traditional communities for a long time. However, there was growing concern in the 1960s and early 1970s about the appearance of many pelts of the larger cats, primarily tigers, leopards, jaguars, snow leopards, in the boutiques of North America and Europe. Estimates of annual imports into the United States and Europe in the late 1960s indicate that pelts of over 10,000 leopards, 15,000 jaguars, 3,000-5,000 cheetahs and 200,000 "ocelots" (including other similar small species such as margay and oncilla) reached the market annually (Fitzgerald 1989; Nowell and Jackson 1996). Conservationists feared this lucrative trade in large cat skins, then worth an estimated US\$ 30 million (Myers 1973), could drive many species towards extinction. In 1971, the International Fur Trade Federation and two conservation organisations, IUCN and WWF, strongly recommended that its 
members should adopt a voluntary moratorium on trade in skins of three large cats, namely tiger, snow leopard and clouded leopard. The Federation also funded status surveys of certain fur-bearing cats in South America and Africa. These surveys concluded that the international fur trade had led to unsustainable hunting pressure in many areas (Koford 1976; Myers 1975, 1976).

\subsubsection{Wild Cats And The Convention}

Concern over the effects of this trade in fur was a primary stimulus for developing the Convention by conservationists, who believed that international co-operation was essential for protecting many spotted cats from over-exploitation through international trade. Once the Convention entered into force in 1975, all felids were listed in Appendix I or II where they currently remain, with a few changes in their listing since then (Table 1). Once all the large cats exploited for their skins were placed in Appendix I, thereby prohibiting their skins from international commerce, the traders in importing nations focused on the smaller species in Latin America (Nowell and Jackson 1996). Trade in "ocelot" pelts was already at high levels in the 1960s, and caused the demise of many ocelot populations in the wild. Thus the attention of traders in the late 1970s to early 1980s switched to other small species in the "ocelot" group South America, such as margay, oncilla and Geoffroy's cat, the skins of which were often smuggled with false paperwork through various free ports (Nowell and Jackson 1996). The available customs figures for all countries in 1977 suggested a trade of between 570,000 and 650,000 skins, which was believed a considerable underestimate of the true total because many countries lacked customs data (Anon. 1978). At this time, there was still also considerable difficulty in documenting the extent of the trade in cat skins, and this led to calls for governments to submit regular annual trade reports and the creation of a centralised database to monitor the trade.

Since 1978, the data available from this central CITES database has shown a steady decline in cat skins that have been sold on international markets. The trade reported to CITES of all Felidae fell from some 450,000 skins traded in 1978 to some 12,000 skins in 1993 (Figure 1a). This decline in number also shows a marked switch away from the South American small spotted cats in the "ocelot" group (Figure 1b), which supplied around $45 \%$ of the world trade in 1978 to only $1.3 \%$ in 1990, and close to zero in 1993. Instead, the supply since the 1990s has been based largely on four species living in the northern hemisphere (Figure 1b). These species, and the volumes of world trade that they supplied in 1990, comprised the bobcat (15.6\%), the Canadian (6.3\%) and Eurasian (2.8\%) lynxes, and the leopard cat from China $(73.8 \%)$.

The majority of the current trade in cat skins is believed to be legal (Nowell and Jackson 1996), but there is still a largely unquantified illegal trade in skins of the large cats in many range States. A number of illegal markets are reputedly found in the major cities of countries that receive many tourists, including Greece, Kashmir and Argentina. Some of these skins may be from animals that are killed for reasons other than supplying the international trade in fur coats. Equally, others may be part of a targeted internal trade in furs that it is beyond the mandate of CITES to regulate, although such sales are often covered by domestic legislation (Nowell and Jackson 1996). 
Despite these illegal markets, and with the current success of the listings of cat species on the Appendices of the Convention, the population of only one species of spotted cat has recently been believed threatened by illegal trade in their skins (Nowell and Jackson 1996). This population of leopard cats from China, listed in Appendix II of CITES (Table 1), was a recent focus of heavy legal trade. There has been a large volume of trade in this species since 1976, with an average annual trade volume of some 86,000 skins from 1976-1990, which had declined to a total of some 8000 skins by 1992. This population was included in the Significant Trade process (see 5.2.5) in 1992, and trade has ceased pending the completion of a status survey that will determine whether the population can withstand further harvest and at what levels.

The spectacular conservation success that has been achieved in the case of the spotted cats and the use of their skins has in large measure been due to advertising campaigns run by pressure groups in importing nations. These have caused many wearers of fur coats to switch to synthetic alternatives, such that potential poachers of spotted cats have no markets to supply. Law enforcement officers in importing countries and the relevant fur trade associations have also played an important role. Therefore, the measures taken under, and in association with, the Convention have been very successful in producing conservation benefit for many tropical species, by reducing the threat of extinction from the international fur trade that they faced in the 1960s and 1970s (Nowell and Jackson 1996). Nevertheless, there have also been a number of possibly negative consequences. A particular concern is the economic consequence of directing the most recent trade in furs from bobcat, lynx and leopard cat mainly towards benefiting northern hemisphere nations (Figure 1b). Indeed, with the recent inclusion of China's leopard cat in the Significant Trade Process, the trade in furs from bobcat and lynx is almost exclusively directed towards developed North American and European countries. Therefore, many species of spotted cat no longer provide local people in developing countries in the tropics with any incentive for their conservation, apart from through two innovative measures directed at the leopard and cheetah .

A related issue is that one species of large cat still faces considerable threat from international trade in another product that so far the Convention has failed to regulate (Nowell and Jackson 1996). The tiger is being systematically poached for its bones to supply the traditional Chinese medicine market (Mills and Jackson 1994), and this species poses the Convention as great a challenge as the rhinoceros family.

\subsubsection{The Apparent Ineffectiveness Of The Convention With 3 Out Of 5 Species Of Rhinoceros}

5.2.6.1 Rhinos And The Horn Trade There are five living species of rhinoceros. Three species, Sumatran, Javan and Indian rhino

The international trade in rhino horn has a long history. An early record was use of rhino horn as a medicine by the Chinese during 200 B.C.-200 A.D. (Martin and Martin 1982). During the Ming and Ching dynasties, the Chinese also carved rhino horns into beautiful cups, plates, bowls and figurines. However, westerners long believed that rhino horn was used primarily as an aphrodisiac, but this myth was exploded in the early 1980s (Martin and Martin 1982). Some rhino horn is indeed consumed as an 
aphrodisiac, but this is limited to use by the Gujaratis in India. Rhino horn has had two far more important uses in terms of volume traded in recent times. First, horn and other rhino products such as blood, skin and urine, are an important constituent in traditional medicines and potions used to reduce fevers, headaches and other illnesses in the Far East. Such medicines are used primarily by the Chinese, but also by Burmese, Thais and Nepalis. In contrast, the Japanese and Koreans also learned to use rhino horn in medicines through early cultural links with the Chinese, but do not use other rhino products. Rhino horn is generally sold in the Far East in one of two forms, first as "raw" horn by traditional pharmacists who make up the medicine for individual customers from horn made in their shops, and second as a constituent in manufactured medicines. Furthermore, "Fire" (Asian) horn is believed more efficacious than "Water" (African) horn and therefore Asian horn is considerably more expensive (Martin \& Martin, 1982, Nowell, Chyi and Pei 1992). Thus both African and Asian rhino horn are used widely throughout the Far East both by indigenous people but particularly by the resident Chinese communities found in most Far Eastern countries (Martin 1983). In addition, confiscations in Los Angeles, San Francisco and Brussels attest to the use of rhino horn by Chinese communities in Western countries. Second, Yemenis have used African rhino horn since at least the 8th century to make handles for traditional daggers, known as jambias. Daggers are important status symbols in the cultural life of Yemeni men. In contrast to other materials used for dagger handles such as water buffalo horn, rhino horn handles improve in appearance and lustre with age (Martin, Vigne and Allan 1997).

\subsubsection{Rhinos And The Convention}

Concern over the effects of the trade in horn was, like the trade in spotted furs, a primary stimulus for developing the Convention by conservationists. When the Convention entered into force, rhinos and their products were among the first species to be placed in Appendix I and II (Table 2). Three species, the Sumatran, Javan and Indian rhinos, and one sub-species, the northern white rhino, were placed in Appendix I in 1975, while one species, the black rhino, was placed in Appendix II. All Rhinocerotidae were placed in Appendix I in 1977, therefore banning international trade in the whole family of rhinos and their products from that date.

Despite these listings, the formerly numerous black rhino has continued to plummet from an estimated 65,000 to 2400 over the past two and a half decades (Figure 2a), and has become locally extinct within at least 18 range States in Africa. The once numerous and wide-ranging Sumatran rhinoceros has probably undergone no less spectacular a decline, but this has been less well documented due to the difficulty of counting this species in rainforest habitats. Nevertheless, it is estimated that Sumatran rhinos have declined from an estimated 600-1000 in the early 1990s to perhaps 300 in 1995 (Foose and van Strien 1997). There have been continued population increases of the Indian rhino and the southern white rhinos since their listings on the Appendices of the Convention. However, these increases continue trends that had been set in motion in the early 1900s, when small and well-protected reserves were established in India and South Africa to prevent then remnant populations from going extinct, with spectacular success that appears to BE unrelated to actions taken under the Convention. Despite the increases in these two taxa, the point remains that the global population of all species of rhinoceros has probably declined from perhaps 75,000 in the early 1970 s to some 11,000 rhinos today. The main cause of this loss has been the continued illegal trade in rhino horn, both to the Far East for medicines 
and to the Middle East for dagger handles (Leader-Williams 1992). After the Appendix I listings, the price of African rhino horn rose dramatically in all consumer markets (Figures 2a, 3a, 3b), and illegal trade in both African and Asian horn has continued despite the international ban (Figure 3c).

The failure of the Appendix I listing, initially to save Kenya's population of black rhinos, stimulated further efforts from the Parties through the adoption of resolutions (Wijnstekers 1995). This series of resolutions (Table 3) plot a gradually changing philosophy to the international ban in rhino horn trade. Initial concern centred on the various major markets for rhino horn that occurred in countries such as Taiwan and Yemen that were not Parties to CITES (Wijnstekers 1995), and therefore outside the controls operating on international trade in rhino horn. Furthermore, certain Parties continued to sell stocks of rhino horn held by relevant government and parastatal wildlife authorities. Therefore, Resolution Conf. 3.11 was approved in 1981 (Table 3) and called on nations that were not Parties to CITES also to take measures to prevent the international trade in rhino products, and called for a moratorium on the sale of all government and parastatal stocks of rhino horn, and that any stocks should be recorded in annual reports to the Convention. Subsequent to the adoption of this resolution, the illegal killing of black rhinos in Africa continued unabated with outbreaks of poaching occurring in Tanzania, Zambia and Central African Republic (Cumming et al. 1990), contributing further to the continental decline in this species (Figure 2a).

The obvious failure of Resolution Conf. 3.11 prompted the adoption of Resolution Conf. 6.10 in 1987 (Table 3). This resolution called for immediate, drastic and even stricter measures to be taken by Parties to curb an illegal trade in rhino horn that had no respect for international boundaries. Furthermore, concern was also expressed at stockpiles of rhino horn held by respective authorities, which had stimulated theft and further horn entering illegal markets. Therefore Resolution Conf. 6.10 urged all Parties to completely prohibit all sales and trade, whether internal or international, in rhinoceros parts and derivatives, particularly horn, excluding non-commercial movement of hunting trophies. Furthermore, all Parties were urged to destroy all government and parastatal stock of rhino horn with supporting contributory funds from external aid sources to be used for rhino conservation in the state concerned. Other measures that were urged comprised: issuing instructions to all law enforcement agencies to be particularly alert to smuggling of rhino horn; to increase penalties for individuals and companies convicted of relevant offences; and, to take firm action against middlemen and poachers involved in cross-border poaching and trafficking of horn. Additionally, since Resolution Conf. 3.11 was being ignored by several countries, Resolution Conf. 6.10 recommended that Parties use all appropriate means, including economic, political and diplomatic, to exert pressure on countries continuing to allow trade in rhinoceros horn. Therefore, this resolution broke new ground by urging and recommending actions that were well outside the remit of the Convention to regulate international trade. Nevertheless, many range States again ignored Resolution Conf. 6.10, and did not destroy their stockpiles of rhinoceros horn, and nor indeed was any compensation forthcoming to promote the destruction of stockpiles. Furthermore, several key consuming nations failed to implement domestic legislation to curb the rhino horn trade. Black rhinos in Zimbabwe were the next to suffer (Milliken, Nowell and Thomsen 1993), and illegal horn continued to be available in the market place (Figure 3). 
By 1992, the governments of South Africa, Zimbabwe and Namibia began to express dissatisfaction with the performance of the international ban on trade in rhino horn, and concluded that a controlled legal trade in rhino horn might be a better option. Both Zimbabwe and South Africa held considerable stocks of horn attained through seizures from traders, through collection of horn from dead animals, and in the case of Zimbabwe through dehorning operations undertaken to enhance the protection of rhinos. At the 1992 Conference of the Parties, South Africa proposed to down-list its white rhino population to Appendix II and Zimbabwe proposed to downlist both its black and white populations to Appendix II. These proposals were rejected. The dissatisfaction with the Appendix I listings generated further contradictory actions between the 1992 and 1994 Conferences of the Parties, and several major changes in direction at the 1994 Conference of the Parties.

Three main actions were undertaken between the 1992 and 1994 Conference of the Parties. First, the United States government threatened four consuming nations with sanctions under a piece of domestic legislation known as the Pelly Amendment. This legislation empowers the US President to suspend any wildlife and fisheries trade between the USA and any country considered responsible for diminishing the effectiveness of an international treaty designed to protect any threatened or endangered species. Governments of consumer nations responded to this pressure from the US by passing some domestic laws and intensifying efforts to control illegal trade, but this served only to drive trade further underground and to raise the illegal prices charged for rhino horn (Mills 1993). The second action was that UNEP held a meeting in Nairobi in 1993 to raise funds for rhino conservation, there having been no external aid for rhino conservation in response to Resolution Conf. 6.10. At this meeting, some US\$ 60 million was requested in emergency funds over the next 3 years, but only some US\$ 5 million was pledged. At this same meeting, South Africa again expressed its belief that a controlled legal trade in rhino horn offered a potential solution, because sales of legally held stockpiles could provide a substantial source of revenue to conservation agencies that the international community was patently unwilling to provide. The third action was that efforts were finally made to seek the views of the traditional Chinese medicine community about how they viewed their healing role relative to the threat posed to rhinos and other endangered species included in their medicines.

At the 1994 Conference of the Parties, South Africa again proposed to down-list its white rhino population to Appendix II. However, even though the downlisting was agreed, an annotation confined this to trade in live specimens and in hunting trophies only (Table 2), and this innovative measure is assessed in section 6.3.4.1. Therefore, even though one rhino population was transferred to Appendix II, the international ban on trade in rhino horn remained in place. Nevertheless, a far-reaching resolution (Resolution Conf. 9.14) was adopted that recognised many of the problems in rhino conservation and that resulted in the repeal of Resolution Confs. 3.11 and 6.10. Resolution Conf. 9.14 urges the following: those Parties that have legal stocks of rhino horn to identify, mark, register and secure all such stocks; all Parties to implement adequate legislation including internal trade restrictions, aimed at reducing illegal trade in rhinoceros products; range States to be vigilant in their law enforcement efforts and to place increased emphasis on the prevention of illegal hunting and early detection of offenders; that law enforcement co-operation between states be increased in order to curtail trafficking in rhinoceros horn; the consumer states to work with traditional-medicine communities and industries to 
develop strategies for eliminating the use and consumption of rhinoceros parts and derivatives. Resolution Conf. 9.14 also directed the Standing Committee to continue to pursue actions aimed at reducing illegal trade, ensuring that all such actions are accompanied by evaluations of their effectiveness, through the use of standardised indicators, and that policies guiding interventions are responsive to the outcomes of evaluations and modified accordingly. The resolution also recommends that each range State develop for its rhinoceros population a recovery plan that inter alia: is appropriate for the situation in that country; will not adversely affect rhinoceros conservation in other range States; and, includes provisions for the re-investment of revenues derived from use of rhinos that is consistent with the Convention, in order to offset the high costs of their conservation. Finally, Resolution Conf. 9.14 urges potential donors to assist with funding the efforts of range States to implement their recovery plans, and the Global Environment Facility to fund the protection of rhinoceros populations within the context of broadly-based projects for the conservation of biological diversity.

Between the 1994 and 1997 Conferences of the Parties, the Lusaka Agreement came into force with the aim of promoting enhanced co-operation between a number of African countries in their law enforcement efforts. At the 1997 Conference of the Parties, South Africa yet again attempted to set in motion measures that would lead eventually to a controlled legal trade in rhino horn, but this proposal was again rejected. South Africa, conserving as it does some 70 to $80 \%$ of the global population of rhinoceros, continues to remain concerned about incentives for rhino conservation, particularly for private land owners who conserve some $15 \%$ of South Africa's rhinos. Meanwhile, the black rhino in Africa appears to have stabilised at a continental population of around 2500 (Figure 2a), but this species, the northern white rhino and two Asian species of rhinos remain critically endangered (Baillie and Groombridge 1996).

The case of the rhinoceros shows that the Appendix I listing failed to stop either trade or poaching (Figures 2,3). Indeed, the raised stakes caused by making international trade illegal was evidenced by soaring prices for rhino horn in consumer markets (Figure 2a), that in turn may have stimulated poaching in range States where rhinos were inadequately protected and where the incentive structure favoured poachers rather than conservationists (Milner-Gulland and Leader-Williams 1992). However, even an intuitively obvious comparison of data on population decline and rising prices of horn (Figure 2) masks a number of complexities that need to be addressed in evaluating the apparent failure of the Convention with the rhinoceros family. The most obvious question is whether the decline in black rhino numbers, the start of which pre-dated the entry into force of the Convention (Figure 2a), would have been faster or slower without the Convention. This question cannot be adequately answered with the currently available data, although many economists believe that the Convention has been responsible for regulating the extinction process in rhinos (Swanson 1994; 't Sas Rolfes 1995). Another issue is that certain important consuming nations like Taiwan and Yemen were not Parties to the Convention at the time many rhinos were being lost in the late 1970s and the 1980s, and the role that this might have played cannot be determined with any certainty.

Whatever the answer to this imponderable question, the rhinoceros family has certainly played an important role in developing thinking within the workings of the Convention, and extension of its 
mandate to roles other than purely dealing with issues of international trade, to consider wider issues of conservation. The resolutions adopted for the rhinoceros family have served as a model for the thinking that has been devoted to other groups of species, where success has not been fully evident, including tigers and bears.

\subsubsection{Effectiveness With Other Species}

\subsubsection{Non-Human Primates}

The international trade in non-human primates has apparently been curtailed significantly since the Convention came into force, and a number of export bans were imposed (Table 4). There has been a marked reduction in the number of non-human primates imported to developed countries each year. For example, the United States imported 113,714 monkeys and apes in 1968, but this number had dropped to 13,148 by 1983 (Wolfheim 1983; Mack and Mittermeier 1984). A decline in the pet trade of neotropical primates during the last decade can be attributed mainly to the imposition of export bans by source countries, enforcement of import restrictions by user countries and a decreased demand for primates in biomedical research (Mack and Mittermeier 1984; Mittermeier, Kinzey and Mast 1993). However, the Convention can only be as effective as the countries that implement it, and some countries follow its requirements more carefully than others (Mittermeier et al. 1993).

\subsubsection{Bears}

The giant panda (Ailuropoda melanoleuca), sun bear (Helarctos malayanus), sloth bear (Melursus ursinus), spectacled bear (Tremarctos ornatus), the Himalayan brown bear (Ursus arctos isabellinus), the Asiatic black bear (Ursus thibetanus), and the brown bear (Ursos arctos) populations of Mongolia, Bhutan and China have all long been listed in Appendix I of the Convention. All other species of bear are now listed in Appendix II. Although over 40,000 North American brown bears are shot annually by trophy hunters and although trade in galls from these bears is legal in a number of states, very few gall bladders have been recorded in the CITES database (McCracken, Rose and Johnson 1995). This suggests that trade deriving from a legal source of specimens may be conducted in the absence of permits, and hence illegally. The price of bear galls was thought to be increasing from 1991 to 1995, but recent information from Russia and South Korea suggests that the price has stabilised (Mills and Servheen 1991; Mills, Chan and Ishihara 1995; Chestin, in litt, 1995). Currently, the price of bear bile in China has dropped dramatically since 1991 (Mills and Servheen 1991; Mills, Chan and Ishihara 1995). The Parties agreed that calls for the inclusion of the brown bear populations in Appendix I, for "look-alike" reasons, would not necessarily be helpful for bear conservation, and rejected such a proposal at the tenth COP. Instead Resolution Conf. 10.8 on the conservation of and trade in bears was adopted which called on Parties to strengthen legislation, and enforcement, but also to strengthen dialogue between players in the trade, encourage funds for research and increase public awareness.

Although prices for bear bile appear to be decreasing, there is very little information on status of bears in Asia, and it is too early to evaluate the effectiveness of CITES for bear populations. 


\subsubsection{The Trade In Wild Birds With Reference To Macaws}

Exotic birds have been traded internationally in large numbers since at least the mid-19th century (Mulliken, Broad and Thomsen 1993). Large numbers of wild-caught birds have been supplied by Africa, Asia, and Central and South America to overseas markets, especially those of Europe and the United States, throughout this century. The international trade increased in size and species diversity as shipping times were reduced through use of steam and then air transport. The pastime of keeping wild birds for pleasure is common throughout much of the world, giving rise to the international trade in millions of wild-caught birds each year (Mulliken, Broad and Thomsen 1993). A number of nongovernmental organisations and some national governments have expressed concern that trapping wild birds to support foreign pet markets may be depleting certain wild avian populations.

Over 2600 species of birds have been recorded in international trade during the past 20 years. However, accurate trade volumes for most species are unknown, owing to varying or non-existent import and export reporting requirements. Documentation of international trade in species listed in the CITES Appendices is more extensive than that of trade in non-CITES species. However, even CITES trade figures may not accurately reflect total trade volumes. Information available from the United States, the United Kingdom and the three major exporting countries of Senegal, Tanzania and China, indicates that the majority of birds in trade are passerines, or songbirds (Order Passeriformes). However, the vast majority of passerine species are not listed in the Appendices of the Convention, and so the songbird trade is poorly documented. Psittacines form the next largest group of birds in international trade. With all but two psittacine species included in the Appendices of the Convention, trade figures for this order are relatively comprehensive compared to those for passerines. Since the early 1990's the net CITES reported trade in wild caught psittacines suggests that overall total trade reported to the CITES database has been decreasing (Table 4).

Among psittacines, over 100,000 macaws have been traded internationally from the early 1980s to early 1990's (Thomsen and Brautigam 1991; Mulliken and Thomsen 1995). As a result, many wild populations have declined, with trade combining with habitat loss to bring some species to the point of local extinction. However the scale of international trade in wild macaws appears to have decreased significantly in recent years, almost certainly due to increased trade controls in both range and consumer states, with the greater availability of captive raised birds also likely to have played a part. Gross trade in macaws escalated from approximately 14,000 birds in 1981, the first year that parrots were listed in Appendix II, to over 21,000 birds in 1983, the last year that exports were allowed from Bolivia, the country exporting the greatest number of macaws to international markets during the early 1980s. Trade averaged just over 8,000 birds during the following three years, then sharply declined in 1987 . The decrease was directly attributable to a temporary ban on parrot exports by the government of Guyana in 1986, and the subsequent setting of national trade controls including export quotas in mid1987. Trade remained relatively stable from 1988 to 1991, then declined slightly in 1992.

Unfortunately, the continued demand for and unsustainable trade in macaws despite the measures of the Convention and national trade restrictions illustrates the difficulty of ensuring the effectiveness of the Convention. 
A total of seven macaw species have been transferred from Appendix II to Appendix I since 1981, a further indication of the problems faced by Parties seeking to maintain trade within sustainable levels, and to prevent illegal trade; and a number of species have been exported from declared countries of origin that are not range States for the species. The hyacinth macaw, Anodorhynchus hyacinthus, provides a good example of these problems. The remaining population of between 5000 and 10,000 hyacinths are largely restricted to Brazil, with a population of approximately 300 birds found in neighbouring Bolivia. Even though Brazil banned the export of nearly all species of wildlife in 1967, many hyacinths were laundered through other countries such as Bolivia, Paraguay and even the Philippines. A total of some 2000 hyacinths were traded internationally from 1981 to 1992, despite the restrictions in Brazil and their listing in Appendix I of the Convention in 1987 (see Mulliken and Thomsen 1995). However, it seems likely that the CITES controls helped to slow the decline of some species( Mulliken, pers. comm).

\subsubsection{Marine Turtles}

Large quantities of turtle meat, shell and leather products were formerly imported to Europe and North America. It was estimated that over 15,000 green turtles, Chelonia mydas, were imported into England from the Caribbean in 1878. During the 20th century, the United States imported substantial quantities of $C$. mydas products from a variety of Caribbean and Latin American countries, reaching some 200 tonnes in 1974. However, once the Convention entered into force, sea turtles have been accorded increasing levels of protection, culminating in the inclusion of the entire family of Cheloniidae in Appendix I in 1981. The uniform implementation of the Convention by EU countries has forced France and Italy to withdraw their reservations on sea turtles. As a result, there has been very little evidence of continuing international trade in green turtle meat (Groombridge and Luxmoore 1989). This evident success in curtailing of international trade in turtle meat has greatly reduced the threat to C. mydas populations from international trade. However, turtle products are probably traded in greater quantities than any other commodities supposedly protected under Appendix I, and the major problem is commercial domestic trade that it is not within the purview of the Convention to regulate.

International trade in hawksbill turtle, Eretmochelys imbricata, shell still gave considerable cause for concern in 1989 (Groombridge and Luxmoore 1989). Although imports to Europe and North America had been reduced to virtual insignificance, largely by the implementation of the Convention, the trade in the Far East may have accounted for more hawksbills than were ever consumed by the traditional western markets. Imports of bekko into Japan show an interesting pattern with marked increases in imports in 1973 with the drafting of the Convention and in 1979 immediately before the Convention was ratified by Japan. On signing the Convention, Japan took out a reservation on trade in hawksbill products and adhered to a self imposed import quota of around 30 tonnes of raw bekko annually. Prior to Japan joining the Convention, 55\% of Japan's imports came from Parties to the Convention, but this had decreased to $44 \%$ of imports by 1983 , and to only $16 \%$ of imports by 1986 . Hence, the enforcement of the Convention apparently caused Japan to change its suppliers of bekko; latterly Japan withdrew its reservation and ceased imports of bekko. At the recent tenth Conference of the Parties, Cuba submitted a proposal for a limited trade in bekko which would have re-opened the trade with 
Japan, but this proposal was defeated. In many range States, international trade in E. imbricata shell appears to have decreased although domestic use still continues. It remains to be seen what effect the measure of developing guidelines for marine turtle ranching will have.

\subsubsection{Reptile Skins}

The scale of the reptile skin trade appears to have been similar in the 1930's to that prevailing today (Jenkins and Broad 1994). Indirect evidence indicates that the trade may have grown to much higher levels in the late 1950s and early 1960's. Each year, at least 10 million reptiles are processed for the international reptile skin trade. The majority are taken from the wild in tropical countries. The Convention has effected at least one important difference between the 1930's and present day, in that more complete data are available on the scale of the reptile skin trade. Whilst the reporting requirements of the Convention have resulted in the accumulation of a large body of data on international trade in listed species, it is still far from complete. Illegal trade, poor and inconsistent reporting and trade in non listed species and between non Parties or Parties with reservations for that species, mean that the trade picture is inevitably incomplete. In contrast to the net CITES reported trade data for live primates and birds, the net CITES reported trade in live reptiles appears to have been increasing from 1977 to 1995 (Table 4).

\subsubsection{Plants}

A huge number of plants are included in the Appendices of the Convention (see Wijnstekers 1995), but plants have tended to attract less attention under the Convention than animals. This is despite the fact that the harmful effects of over collection of wild plants has long been recognised. As early as 1911, the Swiss Canton of Zug enacted legislation banning the collection of some spectacular alpine plants such as lilies and edelweiss. Germany has had similar legislation since 1936 and Mexico banned the export of native wild plants for trade over 50 years ago.

At the present time, over 200 plant species are listed in Appendix I of the Convention. Although a few are timber species, the great majority are plants that are under threat from collecting for horticulture, mostly orchids, cacti and cycads. A further 17,000 to 25,000 species of plant are listed in Appendix II (the number is uncertain because the whole orchid family is listed in Appendix II, and botanists are uncertain how many species are in this family). Other families listed in their entirety include the cactus family, two families of cycads and two of tree ferns.

Customs officers face great difficulty in identifying many plant taxa (Jenkins and Oldfield 1992). Nevertheless, enforcement of the Convention for plants has improved considerably in many countries since the mid 1980s, but the illegal trade in certain species of wild plant listed in Appendix I still continues, for example in Pitcher plants Saracenia rajah, cycads and orchids (Jenkins and Oldfield 1992).

\subsubsection{Changes In Listings In The Appendices As A Measure Of CITES Effectiveness}


This analysis is based on the argument that the provisions of Article IV.3, (the requirement for the socalled "non-detriment" findings) are essential for achieving the aims of the Convention with regard to preventing species from becoming threatened with extinction as a result of utilization incompatible with their survival. According to this reasoning, the majority of transfers of species from Appendix II to Appendix I can therefore be considered as an example of the failure of the Convention (Wijnstekers, 1995). However, even this line of reasoning is open to interpretation, given the fact that CITES does not have jurisdiction over many of the extinction processes that may affect species in international trade, and the fact that the threatened status of some species may not be recognised until they become candidates for Appendix I listing.

This preliminary analysis examines the numbers of species and higher taxa that have been added to, deleted from or transferred between, Appendices I and II in ten successive Conferences of the Parties held from 1976 to 1997 (see successive Proceedings of the Conference of the Parties in Anon. 1977 to 1996). The analysis is considered very preliminary because it simply takes the approach of summing the numbers of additions to, removals from, or transfers between, Appendices I and II for all species and higher taxa listed in the Proceedings. The analysis does not follow the detailed rules laid down for considering interspecific and intraspecific relationships to ensure independence of data (see for example Clutton-Brock and Harvey 1977) that would be necessary for a detailed analysis of this kind. Nor does it control in any way for the effects of the remaining evil triplet of extinction factors. A more detailed analysis would attempt to determine whether the primary cause of worsening status was due to factors under the control of the Convention or due to other factors. If the worsening status was found to be due to factors outside the control of CITES, then these examples should be excluded from the analysis.

Various assumptions are made for this analysis that extend and expand upon the statement Wijnstekers (1995) that "Every transfer of a species from Appendix II to Appendix I can be regarded as an example of the failure of the Parties to fulfil their obligations under the Convention". For the purposes of this analysis, the successful outcome of listing might include recovery of the listed species or higher taxa, and its consequential downlisting, either through transfer from Appendix I to Appendix II, or its deletion from the Appendices. An unsuccessful outcome of listing or of attempts to put in place conservation measures might include transfer to an Appendix providing more protection. The data for the total numbers of additions, deletions or transfers (but excluding those made as a result of the innovative measures as discussed in section 5, at successive Conferences of the Parties have been summed for all taxa in Table 6a. The data for the total additions, deletions or transfers have been summed for different taxonomic groups in Tables 6b-e. Various summaries of these data are shown graphically as follows: all upward movements for different taxonomic groups at successive Conferences of the Parties (Figures 4), all downward movements as before (Figure 5), and the total number of different kinds of movement summed from 1976 to 1997 (Figure 6).

These data indicate that there have been many more movements to increase regulation than to decrease regulation (Table 6a, Figure 6). The largest number of transfers to Appendices providing more regulation was made at the first Conference of the Parties in 1976, perhaps to correct any errors made 
at the Plenipotentiary Conference. However, even allowing for such thinking very early in the life of the Convention, the total number of movements towards greater regulation has invariably exceeded, and sometimes greatly so, those towards less strict regulation at every successive Conference of the Parties (compare Figures 4a and 5a). Furthermore, this difference still held in 1987 and 1997 (see Table 6a and Figure 5a), when the ten-year review of the Appendices was undertaken based on recommendations made in 1977 (see Wijnstekers 1995). From Table 6a it is evident that the number of transfers from Appendix II to Appendix I has been larger than the number of transfers from Appendix I to Appendix II in all years bar the first COP in 1976 and the most recent COP in 1997.

The changes in listing have always contained high numbers and proportions of both mammals and birds (Table 6 and Figures 4b, 5b). This point is particularly important if any changes in listing are considered in proportional terms, both relative to the total numbers of species of mammals and birds that occur in or are threatened in the full range of mammalian and avian taxa, and relative to total numbers of species of reptile and other groups such as amphibians and fish. A similar bias towards mammals and birds is evident in the Red List of Threatened Animals (see Baillie and Groombridge 1996). Furthermore, according to the World List of Threatened Birds,-(see Collar et al. 1994) a total of 1111 species of birds are considered threatened, comprising a total of $11 \%$ of the world's known avifauna. However, only $2.6 \%$ or 29 of these threatened species are affected primarily by trade (without specifying "international") and commercial egg collecting (see Figure 6 of Collar et al. 1994). In contrast, Appendix I of the Convention lists over 150 species. This difference would be worth exploring further for various groups, particularly as the classification of threatened species proceeds further.

This preliminary assessment of changes in listing suggests that the status of many species included in the appendices is worsening, as assessed by the Parties themselves in making amendments to the appendices (see arguments by Wijnstekers 1995 quoted above). Consequently, it may be that the Convention is not effective for these species. Alternatively, the conservation status of all species could be generally worsening, and more strongly protective measures may be important to ensure that international trade does take its place alongside all those other factors that threaten populations of fauna and flora. Whatever the answers to these complex questions, the Convention has undoubtedly made great strides towards monitoring the levels of international trade, to regulating trade levels for many species and also towards implementing innovative measures that aim to prevent an inexorable movement of species to higher appendices.

\subsection{An Evaluation of the Innovative Measures in the Convention from the Species Conservation Perspective}

\subsubsection{An Evaluation of Captive Breeding and Artificial Propagation}

Captive breeding of Appendix I species allows commercial trade in captive bred specimens to proceed as if the species were in Appendix II. Therefore, this measure offers several competing and perhaps contradictory possibilities. First, it allows the possibility of a legal trade that can be monitored through the CITES permit system. Second, it offers potentially attractive conservation benefits by reducing take 
from the wild and establishing parental stock in captivity. Third, it allows a legal trade to mask an illegal trade unless marking, monitoring and registration measures are enforced very carefully. Fourth, it offers the captive breeders in exporting countries a large share of any benefits of trade. Fifth, it may remove the benefits of trade from local communities that once harvested the species to supply the trade, thereby removing incentives for habitat conservation.

The most recent data available on captive breeding operations of Appendix I species are found in Notification to the Parties \#940 of 1996 and \#981 of 1997. Nevertheless, the Secretariat notes that the data therein are those received with the application for inclusion, and therefore may not necessarily be up-to-date. Sixteen species included in Appendix I are bred in a total of 59 captive breeding operations that occur within the jurisdictions of 15 Parties (Tables 7a, 7b). The Asian boney-tongue, the peregrine falcon, saltwater crocodile and gyrfalcon occur in most operations, and the other 11 species are bred in from one to three operations. Species of birds occur in operations that are generally out of range, while most crocodilians and the Asian boney-tongue are generally bred within their range (Table 8a). Each Party generally supports operations that specialise in particular species (Table 8b). A number of these operations were established well before the Convention came into force, but once the species were included in Appendix I, approval was sought to register as a captive breeding operation, so as to be able to continue commercial trade in those species. The majority of the species now included in the register (11 ex 16) were already established in captivity when the Convention came into force, but very few (3 ex 16) were being exported by 1975. Therefore, only five more species have been established in captive breeding operations, but 11 more have been exported since the Convention came into force (Figure 6a). In contrast, the number of operations that have been established since the Convention came into force have increased greatly, as have the numbers of operations that have exported (Figure 6b). However, there is a long lag time between establishment and export (Figure 7).

On this basis, captive breeding measures have allowed the establishment and export of species held in captivity. Therefore, there may be some conservation benefit in preventing the export of specimens caught directly and illegally from the wild, but there are no data available to show whether this is correct. A related point is that the benefit derived from breeding the resource has in many cases moved out of the range State (Table 8a), and in almost all cases out of the control of local people living among the resource (see Thorbjarnarson 1992 for arguments about different forms of crocodilian utilisation).

Listing of certain plant species in Appendix I of the Convention seems to encourage artificial propagation of rare plants (Oldfield 1987; Jenkins and Oldfield 1992). The trade in orchids has been facilitated, both through flasked seedlings and hybrids, and by the nursery registration scheme for growers of Appendix I species (Hagsater and Dumont 1997). However, an important issue for all plants is that Parties often do not record whether the specimens that are imported or exported are wild collected or artificially propagated, making any formal evaluation difficult.

The time frame for the current study does not allow for full evaluation of these various issues for the range of Appendix I species with registered captive breeding operations or that are artificially propagated. Indeed, the data with which to evaluate many of these possibilities for the full range of 
species will be lacking, including for animals. However, some of the points made above will be illustrated for one Appendix I species for which captive breeding has been attempted.

\subsubsection{Captive Breeding of the Asian Boney Tongue (or Arowana) Scleropages Formosus}

Taxonomy and biology: S. formosus is a large mouth brooding species of freshwater fish that occurs in SE Asia. An adult may reach $1 \mathrm{~m}$ in length. S. formosus reaches sexual maturity at 4-5 years of age and produces small numbers, around 30-90, of young once per year. Several colour varieties have been described including green, yellow and red (sometimes described as 'golden'). It is not known if these are only varieties, if they have a possible sub-specific or specific status, or if populations are polymorphic or geographically variable (Roberts in litt). However, the Kapuas River in West Kalimantan has the red variety in its upper drainages, the yellow variety in its middle reaches, and the coastal districts hold varieties variously described as green, white and black (Luxmoore 1990). There are possibly two related species around Australia and New Guinea, S. leichardti and S. jardini.

Status and distribution: $S$. formosus had a wide distribution throughout rivers and swamps in south-east Asia, from Thailand to Indonesia and Vietnam, preferring peaty water in areas of tropical rainforest. However, the distribution of the species is believed to have declined considerably, mainly as a result of habitat destruction, including use of toxic agents in Vietnamese habitats, through dredging for rubies in Thailand, through fire and plantation agriculture. The species has also been harvested both for local consumption and the aquarium trade and, because of its late maturity and low fecundity, it is likely to suffer from localised over-harvesting. However, no formal population estimates or trends in population size are available with which to examine any changes in status that might have occurred due either to habitat loss or to over-harvesting. The species is still believed to be common and widely distributed in swamps of Kalimantan and Sumatra. Estimates of catch sizes in the 1970s suggested 20,000 were taken annually in West Kalimantan but this is not verifiable. Important concentrations of the red variety of $S$. formosus remain in Kalimantan, but are becoming more scarce to obtain as a result of its preference by Chinese fish fanciers. In contrast, green and yellow varieties remain more common. Despite its uncertain status, the IUCN Red List includes the species as Endangered (Baillie and Groombridge 1996).

Protection status: S. formosus was listed in Appendix I of CITES in 1975. Exports from Indonesia were therefore illegal from 1978, when Indonesia ratified CITES, until 1989 when Indonesia obtained a downlisting to Appendix II for a limited quota (Anon. 1991). The population of Indonesia was again included in Appendix I in 1994 (Anon. 1996). However, in domestic legislation, the species has been protected in Indonesia since 1980,: the private taking, possession or commercial trade in this species is prohibited. Fishing can only be undertaken for scientific research or collecting breeding stock. Much of the current range of the species in Indonesia occurs in protected areas.

Utilisation: S. formosus was an important local food in the 1970s. Ethnic Chinese believe the fish bestows good luck, and demand from neighbouring Chinese communities has supplanted local custom. Chinese most favour the red and the yellow varieties, as they are thought to bring the greatest luck. Japan reported legal imports of over 2200 S. formosus that were supposedly captive-bred in 1982 
(Matsumura and Milliken 1984), including 2000 from Indonesia that Indonesia claimed were not captive bred or accompanied by an export certificate (see Table 9). There has also been a flourishing illegal trade since 1970, that was evidenced by increasing seizures from the early to mid 1980s on a smuggling route from Indonesia to Hong Kong and other entrepots for import to China (Anon. 1987, 1989). Some $20 \%$ of wild caught specimens die before reaching the market. A flourishing aquarium trade also exists in Thailand. While the source of these specimens was unclear in the late 1980s, it was suspected they were captive bred (Roberts in litt, 1989).

Singapore claimed the first success at captive breeding of green arowana in 1981 at Sembawang (Joseph et al. 1986). Another four companies in West Kalimantan were registered to breed $S$. formosus in captivity in the early 1980s. However, they were found to be a front for marketing fish caught from the wild, and their registration was withdrawn (Luxmoore 1990). Indonesia achieved the downlisting of S. formosus from Appendix I to Appendix II in 1987, based on a proposal for captive breeding without a specified quota, and in 1989 with a desired export quota of 2500 (Anon. 1988, 1991). In their proposals, Indonesia proposed that no fish over $30 \mathrm{~cm}$ in length should be taken from the wild to form the parental stock; only specimens that were captive bred should be traded; and, $10 \%$ of captive bred animals would be released into the wild. This downlisting was not believed successful, and the Indonesian population of S. formosus was again listed in Appendix I in 1994 (Anon. 1996).

The current situation is that 16 operations for breeding an Appendix I species have been registered for S. formosus (Table 9a), one in Singapore, two in Malaysia and 13 in Indonesia (Notification to the Parties \#940 of 1996 and \#981 of 1997). The Singapore operation was established in 1981 and first exported in 1994. The two Malaysian operations were established in 1978 and 1980, and first exported in 1994. The 13 Indonesian operations were established from 1984 to 1994, and 9 of them have begun to export from 1992 to 1995 . The captive breeding operations in Indonesia disclosed holding a breeding population of 3747 fish and a total stock of 33,394 fish in captive breeding operations.

The available data from the CITES database does not help clarify whether the registration of captive breeding operations has been a successful measure for S. formosus (Table 9). There have been imports of specimens declared as captive bred from producer states since 1982, and the numbers imported from 1993 have exceeded numbers of exports declared by those same producer states. Therefore, it is unclear whether trade of actual captive bred specimens pre-dated the time that operations in producer states began to export, or whether supposedly captive bred specimens were wild-caught and exported illegally. The captive breeding operations all note that their specimens will be marked with transponders, and the use of such technology would appear vital if this innovative measure is to be effective.

\subsubsection{An Evaluation of Ranching}

Ranching has been applied exclusively to the crocodilian family. The technique of ranching is one that ideally suits the life history this family (Craig, Gibson and Hutton 1992). Adults are generally long-lived, 
slow to reach sexual maturity and experience low mortality of some 5-6\% annually. Therefore, a harvest of large adults above the natural mortality rate may remove a proportion of breeding animals from the population that can result in a population decline. In contrast, the eggs and juveniles of this family experience very high mortality of around $98 \%$ annually. Therefore, removing up to $92 \%$ of eggs and juveniles from the wild, when well regulated and conducted effectively, can have less impact upon the wild population than removing breeding adults.

This family comprises 23 extant species of tropical and sub-tropical aquatic reptiles, the status and knowledge of which varies widely (Thorbjarnarson 1992). Crocodiles had been hunted extensively for their hides for over a century before the Convention came into force. Overhunting, coupled with more recent problems of habitat loss, had resulted in most of the 23 species of crocodile becoming endangered, depleted or declining in numbers by the early 1970s, and some species on the brink of extinction. Excessive exploitation was rampant, regulated harvest almost non-existent, and illegal trade in crocodile products the norm. Efforts to conserve crocodilians began with in situ protection in certain range States in the 1960s. Most species (17 ex 23) of crocodilian were included in Appendix I in 1975, and the remainder were included in Appendix II (Table 10). However, members of the IUCN Crocodile Specialist Group increasingly believed that crocodiles would only be conserved in the long term through sustainable use programmes that provided conservation benefits to wild populations, rather than by protection of wild populations alone. Therefore, the development of conservation programmes for the species of crocodilians originally listed in Appendix I have been at the forefront of developing innovative measures under the Convention. As a result of these efforts, several populations of the Nile crocodile and the saltwater crocodile, and one species, the American alligator, have been subsequently transferred to Appendix II (Table 10). In contrast, only one species, the American crocodile has been transferred to Appendix I, a situation that is markedly different to the analysis of movements between Appendices for all species (Figure 4). As importantly, the status of many species has improved in the wild (Thorbjarnarson 1992), and many crocodilians are no longer considered threatened (Table 10). The time frame for the current study does not allow for an overall evaluation of ranching for the full range of crocodilian species originally listed in Appendix I . However, some of the salient points in evaluating ranching operations will be illustrated for one species of crocodilian.

\subsubsection{Ranching of the Nile crocodile, Crocodylus niloticus}

Status and distribution: The Nile crocodile is one of 12 species in the genus Crocodylus. It is the largest member of the genus and the best known biologically. It is sexually dimorphic and males of $6 \mathrm{~m}$ in length have been recorded. Females become sexually mature at $2.5 \mathrm{~m}$ and lay 50-60 eggs which they guard until after hatching (Thorbjarnarson 1992). The species is widely distributed throughout subSaharan Africa, now occurring in some 40 countries, but has become locally extinct in four countries, and is depleted in a number of others (Thorbjarnarson 1992). However, IUCN do not currently list the species as threatened or even near threatened (Baillie and Groombridge 1996), although in 1990 the species was listed as vulnerable. Large populations remain in certain countries, for example Zimbabwe with around 50,000, Tanzania with perhaps 100,000; and crocodiles are still widespread in many drainages in countries such as Zambia, Mozambique and Kenya (Thorbjarnarson 1992; Hutton and Games 1992). 
Protection status: The Nile crocodile receives full protection in many of the countries in which it occurs. However, control killing is usually sanctioned when this is carried out by wildlife authority staff, and sport hunting is allowed in several countries (Thorbjarnarson 1992).

Principal threats: The Nile crocodile suffers from illegal hunting, often carried out as a result of loss of life and limb, and property of local people. Furthermore, crocodiles also suffer from habitat degradation along their main watercourses, many of which occur outside of protected areas in areas shared with people (Thorbjarnarson 1992).

Assessment of the innovative measures: Ranching was intended to achieve two important complimentary actions. First, the development of ranching industries aimed to shift crocodile exploitation towards that part of the life cycle most able to sustain harvest (see Craig et al. 1992), and away from the killing of breeding-size adults. Second, the development of ranching aimed to provide a continuous economic value for crocodiles occurring outside protected areas, in which egg and hatchling collection could be under the control of and benefit to local communities. An objective of ranching is to make a direct linkage between maintaining a healthy wild population in its natural habitat, and deriving economic benefits from that population (Thorbjarnarson 1992). This is in direct contrast to farming or captive breeding, which usually isolate the management of their stock from maintaining healthy wild populations. For ranching to be considered effective, it would need to facilitate the commercial trade in ranched as opposed adult wild specimens, to promote habitat conservation and the status of crocodiles, and to reverse the listings of the Nile crocodile in Appendix I.

The appropriateness of originally listing the Nile crocodile in Appendix I of the Convention has often been questioned given the widespread distribution and large populations of crocodiles remaining in many areas of Africa (see Hutton and Games 1992). Success has generally attended the downlisting of Nile crocodile populations in Africa through a combination of export quotas and ranching (Figure 8a) and few populations have been returned to Appendix I. The approach to ranching was pioneered in Zimbabwe, whose population of Nile crocodiles was transferred to Appendix II in 1983, pursuant to Resolution Conf. 3.15. The populations of nine other range States (Cameroon, Congo, Kenya, Madagascar, Malawi, Mozambique, Sudan, Tanzania and Zambia) were transferred to Appendix II in 1985 on the basis of export quotas for wild specimens, pursuant to Resolution Conf. 5.21. A tenth range state, Botswana, joined those countries with export quotas in 1987. By 1989, the populations of four range States, Botswana, Malawi, Mozambique and Zambia, were transferred to Appendix II on the basis of a ranching proposal. A further two range States, Ethiopia and Somalia were granted export quotas in 1989. By 1992, populations of another three range States, Ethiopia, Kenya and Tanzania, were transferred to Appendix II on the basis of a ranching proposal, while Madagascar and Somalia were granted export quotas. However, some reverses occurred as the populations of Cameroon, Congo and Sudan, that had been granted export quotas since 1985, were once again listed in Appendix I. In 1994, Uganda was granted an export quota, while the population of Somalia, granted an export quota, became the fourth to return to Appendix I. In 1997, the populations of Madagascar and Uganda were transferred in the basis of a ranching proposal. Thus the populations of ten range States have made 
the transition from an Appendix I listing to an Appendix II population listed on the basis of a ranching proposal, submitted pursuant to Resolution Conf. 3.15. In contrast, four range States have attempted but failed to make that transition (Figure 8a).

This apparent success in transferring crocodile populations to Appendix II for ranching purposes, masks certain problems that can be illustrated by the contrasting situation in Zimbabwe and Tanzania (Figure 9). No quota has been placed against the population of Zimbabwe since 1983. With large numbers of crocodiles in well-managed ranches, the status of Zimbabwe's wild population is considered secure against any offtake of adults from nuisance crocodiles and those taken for sport hunting. Eggs and hatchlings collected for ranching operations by local communities from land under their management through CAMPFIRE provide a continuous source of revenue that reduces the incentive for local communities to target nuisance animals. Zimbabwe has consistently exported large numbers of ranched skins alongside those exports of many fewer adult skins from the wild and from sport hunting (Figure 9a, 9b). In contrast, Tanzania has by and large failed to make the transition from a range State requesting an export quota to one conserving its crocodile population based on ranching. Tanzania has been offered large export quotas of wild specimens, varying from 1000 in 1985 increasing to 2000 in 1987, as the basis on which to provide the necessary investment for ranching operations (Figure 8b). While an export quota of 4000 rising to 6000 ranched specimens was granted for 1991 and 1992, the wild quota was successively reduced from 1100 to 300 wild specimens (including a quota of 100 sport hunted) from 1990 to 1994 to provide further incentives to initiate successful ranching, for which Tanzania approved a policy in 1993 (Department of Wildlife 1993). However, the ranching quota has hardly been used. Instead, Tanzania has since 1994 requested increasing quotas of wild specimens (Figure $8 \mathrm{~b}$ ), on the basis that many nuisance animals cause considerable loss of life and property, and has exported mainly skins from the wild and from sport hunting (Figure 9c). Thus, Tanzania hovers between the status of country with a large wild population more precariously conserved on the basis of export quotas for wild shot specimens, while also ostensibly promoting policies to initiate the more biologically safe option of a ranching operation (Department of Wildlife 1993).

Equally, Tanzania and other countries with populations recently transferred to Appendix II on the basis of a ranching proposal all face the vagaries of the world market for ranched skins, over which they have no control. This appears to be a declining market that has been successfully cornered by Zimbabwe, with little room for the entry of new players. In contrast, the market for large adult skins appears more consistent and more valuable, and Tanzania amongst others continues to exploit this market with its exports. Thus local communities living among crocodile populations receive no incentive for crocodile management through the collection of eggs and hatchlings, while the harvesting of long-lived adult crocodiles poses more of a biological threat to the population (see Craig et al. 1992). On this basis, ranching has achieved considerable success with the Nile crocodile, particularly for Zimbabwe and in terms of downlisting a species that was inappropriately listed at the outset. However, it does not appear likely that ranching will provide the answer for populations in every country.

\subsubsection{An Evaluation of the Effectiveness of Appendix I Quotas}




\subsubsection{The Trade in Leopard Trophies and Skins}

Distribution and status: The leopard, P. pardus, is the most widely distributed wild cat (Nowell and Jackson 1996). Its main stronghold is in sub-Saharan Africa (Martin and de Meulenaer 1988), where it is not listed by IUCN as threatened. Other populations of leopard also occur in north Africa and southwest Asia and eight different sub-species are listed either as Endangered or Critical by IUCN (Baillie and Groombridge 1996).

In sub-Saharan Africa, leopards occur in all habitats with over $50 \mathrm{~mm}$ of rain annually, and can penetrate drier areas along rivers. Thus the leopard occurs in both rainforest and in semi-arid desert habitats, and occurs throughout all the range States of sub-Saharan Africa (Nowell and Jackson 1996). There have been numerous attempts to count leopards through Africa and to determine their overall status (eg Myers 1976), but this task is made exceedingly difficult by the secretive habits and wide distribution of the leopard. A density and rainfall model suggested that there may be some 714,000 leopards throughout sub-Saharan Africa (Martin and de Meulenaer 1988). This might well be an overestimate, but there is consensus that the leopard is not endangered, but only subject to local depletion through exploitation and loss of habitat. The largest population may occur in Democratic Republic of Congo, formerly Zaire, with over 100,000 leopards, while other large populations are believed to occur in Tanzania, Mozambique, Zambia and Angola (see also Nowell and Jackson 1996).

Protection status: The leopard is protected by national legislation across much of its range in subSaharan Africa. However, a number of countries allow legitimate trophy hunting (see below), while others that do not permit hunting do permit the killing of problem animals, either by landowners or government authorities.

Principal threats: The fur trade in the 1960s and 1970s once posed a local threat to the leopard in areas where they were baited (see Nowell and Jackson 1996). However, the collapse in the market due to changing public opinion and the international trade regulation under CITES have removed this threat (see 6.2.1).

The wide distribution of the leopard encompasses much land that has no formal protection status, and the leopard appears very tolerant of habitat modification and occurs in the vicinity of settled areas (Martin and de Meulenaer 1988). Therefore, the current threats to leopards occur primarily through degradation of habitat where livestock graze and the persecution of leopards that threaten livestock. On this basis, countries with healthy populations of leopards and developed trophy hunting industries have allowed hunting of leopards as a means of earning revenue to provide incentives to encourage leopard conservation (Martin and de Meulenaer 1988; Nowell and Jackson 1996).

Assessment of leopard quotas: The quota for leopard trophies and skins was designed to reduce the threat of persecution of leopards outside protected areas by facilitating the derivation of economic benefits from hunting leopards to act as an incentive for conservation. The quotas initially adopted by the Conference of the Parties in 1983 applied to seven range States, and this has now increased to encompass eleven range States (Table 10). Therefore, the trade in leopard specimens from these 
countries is not subject to the provisions of Article III of the Convention, and import permits are not required, prior to the granting of export permits.

For the quota to be considered effective, it would need to facilitate the commercial trade in hunted trophies for the range States which have quotas, and to produce increased benefits for those co-exiting with leopards outside protected areas, and that in turn improves the conservation status of leopards on that land. Unfortunately, there do not appear to be any available data that assess the last point. In other words, it has not been possible to determine whether the conservation status of leopards has changed as a result of the innovative measure because there are no consistent data describing trends in leopard populations. Furthermore, there is little data available to assess whether hunting has benefited those people co-existing with leopards.

In order to determine if the quota has facilitated commercial trade, it is necessary to examine long term trends in the trade of leopard specimens from data collated from records of imports (Figure 10). This is because several major exporters did not return CITES Annual Reports during certain periods from 1975 to 1995, and therefore export or net trade data would contain many gaps and omissions. Data for the imports of leopard have been divided into those imported as skins and as trophies from all the African range States that have been given quotas. However, numbers of skulls imported have not been included because the skulls and skins from the same animal often appear to be reported in trade separately. There was a trade in leopard skins and trophies before the quota was adopted in 1983 (Figure 10a). However, the records of imports showed a higher proportion of skins than of trophies during the period 1975 to 1982 . Since the innovative measure was introduced there has been a steady increase in numbers of skins and trophies that have been imported. In addition, a higher proportion of the specimens has been described as trophies rather than as skins. The purposes of the imports have not been recorded systematically but those records that are available suggest a higher proportion of the records was recorded as personal effects before 1983, whereas more were described as hunted specimens after 1983. An important benefit of the quota has been removing the requirement for prior grant of an import permit. This appears particularly important in the context of imports to the US, where many of Africa's trophy hunters originate, and where controls under domestic legislation through the Endangered Species Act might otherwise make imports more difficult. However, since the early 1990s, a higher proportion of imports has been recorded from other importing countries, particularly those in continental Europe.

In summary, the leopard quota would appear to have facilitated the carefully controlled trade in trophies of a large cat listed in Appendix I that is an important component of the African safari hunting industry and from which economic incentives can be derived. Although firm data on population trends are lacking there is no indication that the leopard quotas have been detrimental to the survival of the species.

\subsubsection{An Evaluation of Trade in Live Specimens and Hunting Trophies of Cheetah}

Distribution and status: The cheetah, A. jubatus, is distributed primarily throughout the drier parts of sub-Saharan Africa, where its status is listed as Vulnerable by IUCN (Baillie and Groombridge 1996). Small populations of cheetah also exist in north Africa and south-west Asia and, although their 
taxonomic affinity is not resolved (Nowell and Jackson 1996), these populations are listed as Endangered and Critical, respectively, by IUCN (Baillie and Groombridge 1996). Cheetahs have become locally extinct in many of their former range States, including Afghanistan, Egypt, India, Jordan, Libya, Pakistan, and Saudi Arabia. However, populations of cheetah are still believed to occur in 31 range States (Baillie and Groombridge 1996; Nowell and Jackson 1996).

In sub-Saharan Africa, cheetahs are sighted most frequently in open grassy plains, but they also make extensive use of bush, scrub and open woodlands, although they are not associated with forest habitats. Cheetah numbers have been variously estimated at 15,000 in 1977, 25,000 in 1984 and 9,000-12,000 in 1991 (Nowell and Jackson 1996). The two largest meta-populations of cheetah are believed to occur in east Africa (Kenya and Tanzania) and southern Africa (Namibia, Botswana, Zimbabwe and Zambia).

Protection status: The cheetah is fully protected and hunting is prohibited by national legislation in many range States in sub-Saharan Africa (Nowell and Jackson 1996).

Principal threats: Cheetahs in sub-Saharan Africa appears to face three principal threats. First, cheetahs are known to exhibit a very high level of genetic homogeneity, but there is no evidence that reproduction in the wild is compromised (Caro and Laurenson 1994). Thus monomorphism in cheetahs attracts much attention amongst conservation biologists, but its implications for the management wild populations are not evident (Nowell and Jackson 1996). Second, cheetahs suffer from inter-specific competition from other large carnivores within protected areas. More powerful carnivores such as lions, leopards and hyenas limit cheetah abundance by killing cubs and by driving cheetah off kills (Caro 1994). Where other large carnivores have largely been eliminated, such as private ranchland in Namibia and on pastoral land and farmland in Kenya, cheetahs flourish at higher densities. However, this gives rise to their third threat. The survival of cheetah outside protected areas is affected by conflicts with people over livestock predation. In Namibia, the cheetah is believed to be the most important predator of livestock on both commercial and communal farms, and such predation is higher where the natural prey base has been removed and livestock is the only alternative (Nowell and Jackson 1996). The large litter size of cheetahs may render them relatively resilient to eradication compared with other large carnivores, but their decline on Namibian ranchland in the 1980s was attributed to persecution (Morsbach 1987). As there is little hope of preventing the destruction of cheetah on private lands, Namibia, South Africa and Zimbabwe have pursued a strategy of permitting trophy hunting of cheetahs on private land, with the goal of encouraging landowners to accept profits from cheetahs on their land instead of destroying them.

Assessment of the innovative measures: The innovative measure was designed to reduce the threat of persecution of cheetahs on private land by facilitating the derivation of economic benefits from hunting and selling live cheetahs. The quotas adopted by the Conference of the Parties in 1992 applied to three range States comprising Namibia, Zimbabwe and Botswana (Table 7), but did not include South Africa. Furthermore, the trade in cheetah specimens is subject to the provisions of Article III of the Convention, 
therefore requiring both export and import permits. This is in contrast, for example, to the quota for trophies of leopards, now in Appendix II and therefore not requiring import permits.

For the innovative measure of cheetah quotas to be considered effective, it would need to facilitate the commercial trade in live cheetah or in hunted trophies for the range States with quotas, and to produce increased benefits for the ranchers who hold populations of cheetahs on their land, that in turn improves the conservation status of cheetahs on that land. Unfortunately, there do not appear to be any available data that assess the last two points. In other words, it has not been possible to determine whether the conservation status of cheetahs on private land has improved since the decline noted in Namibia since the 1980s (see Morsbach 1987). In order to determine if the quota has facilitated international trade, it is necessary to examine long term trends in the trade of cheetah specimens from data collated from records of imports. This is because the major exporter, Namibia, did not regularly return CITES Annual Reports until recently, and therefore export or net trade data would contain many gaps and omissions. Data for the imports of cheetah have been divided into those sold live and those imported as skins and trophies. Furthermore, imports are tallied in the following categories: Namibia; South Africa; Zimbabwe and Botswana combined; and all other range States combined, mainly comprising sales between European and North American countries (Figure 11).

There was a steady increase in the recorded numbers of live sales to 1988, and a decline thereafter to 1992. Most of the live sales for the period 1976 to 1992 were from Namibia (46.5\%), but there were also many sales from South Africa (24.5\%), and between other range States (27.2\%) (Figure 11a). Since the quota measure was adopted in 1992, live sales appeared to increase in 1993 and 1994 but to decline again in 1995 (although the decline in 1995 may have been due to incomplete receipt of Annual Reports by WCMC). Sales over this period were almost equally divided between South Africa $(38.6 \%)$ and Namibia (37.3\%), with many sales (22.1\%) still occurring between other range States (Figure 11a). Zimbabwe and Botswana did not feature strongly in the live trade. The purpose of the live sales or the origin of the specimens was not recorded consistently, either before or after the adoption of the innovative measure. Even after the adoption of the measure, for a total sample of 61 records, the majority $(88.6 \%)$ of the recorded purposes from the main exporting states in Africa were for zoos and breeding in captivity, while very few (4.9\%) were for commercial trade $(\mathrm{N}=61)$. Furthermore, for a total sample of 43 records, the majority $(81.4 \%)$ of the recorded sources from the main exporting states in Africa were from captivity, with relatively few $(18.6 \%)$ from the wild.

There were relatively few recorded imports of cheetah skins and trophies from 1976 to 1983, apart from a large consignment of skins imported from Ethiopia in 1980 (Figure 11b). A very large volume of skins was imported from Namibia in 1984, and the totals declined thereafter, until there was evidence of a slight rise in 1991 and 1992. Most of the recorded skins and trophies imported for the period 1976 to 1992 were from Namibia (79.3\%), but there were also sales from South Africa (6.3\%), Zimbabwe and Botswana (3.5\%), and between other range States (11.1\%) (Figure 11a). Once the innovative measure was adopted, there was a further fall in 1993, and then evidence of a slight rise in 1994 and 1995. Imports over this period were dominated by exports from Namibia (71.9\%), with an increasing share from Zimbabwe and Botswana (14.6\%) and some imports still recorded from South Africa 
(4.5\%) and between other range States (8.9\%) (Figure 11a). As with live sales, the purpose of skin and trophy imports or the origin of the specimens was not recorded consistently, either before or after the adoption of the innovative measure.

On the evidence available for imports of live cheetah and of skins and trophies, the quota measure appears to have had little beneficial effect. There was a flourishing trade in live cheetahs and in hunting trophies before the quotas were adopted and no strong indication that implementation of the quota measure has facilitated further trade. Furthermore, one range State which does not have a quota (South Africa) continues to be a major player in trade in live cheetahs, while two countries with quotas (Zimbabwe and Botswana) play little role in the overall trade. However, a fuller assessment of this innovative measure should also include assessing whether greater net financial benefits have accrued to private ranchers in Namibia, through say increased trophy fees, and whether the status of cheetahs on private land has improved since the 1980s. In addition, this innovative measure may require longer than three years for an effect to be noticed.

\subsubsection{Annotations}

5.3.4.1 An Evaluation of Trade in Live Specimens and Hunted Trophies of Southern White Rhinos in South Africa

Distribution and status: The southern white rhino, Ceratotherium simum simum, occurred throughout the savannah regions of South Africa, but never occurred south of the Orange River. In historic times, the northern limit of this sub-species was the Zambezi River, and southern white rhinos occurred in what are now Namibia, Botswana, Angola, Swaziland, Zimbabwe and Mozambique. The historic range of southern white rhinos has remained isolated from that of northern white rhinos by some $2000 \mathrm{~km}$, at least since historic times and perhaps for as long as 2 million years. Hence, the two sub-species are both taxonomically and genetically distinct (Cumming et al. 1990).

Reports suggest that 20,000 or more white rhinos may have occurred in South Africa in 1800. However, white rhinos were hunted throughout the 19th century in southern Africa, for their horn, for sport and for their meat, hides and valuable fat that were particularly favoured by European settlers. The pressure was so sustained that the southern white rhino was eliminated from most of its range from 1830 to 1870 . However, a few white rhinos were later found in the former Natal, and given protection in 1895 (Player and Feely 1960). Their recovery during the course of this century is the major success story of rhino conservation. Population numbers have increased dramatically, to a global population of around 7500 in 1995 . The southern white rhino is now the most numerous taxon of rhino, and no longer considered threatened (Baillie and Groombridge 1996). Many new populations have been established, both in protected areas and on private land in South Africa, and outside South Africa (Cumming et al. 1990).

Protection status: The southern white rhino receives the highest legal protection possible through the various provincial legal instruments in South Africa, and through national legislation in other major range 
States such as Zimbabwe, Namibia and Kenya. However, all wildlife in South Africa, Zimbabwe and Namibia is res nullius, thereby promoting the involvement of private landowners in rhino conservation ('t Sas-Rolfes 1990).

Principal threats: The major potential threat facing southern white rhinos is from poaching, but South Africa's population has only suffered lightly from this fate. Within South Africa, the major constraint to continued population growth is shortage of suitable land, as many protected areas are small and at or close to carrying capacity. Therefore South Africa has been relying increasingly heavily upon private landowners to conserve rhinos, from which the land owners in turn seek economic benefits ('t SasRolfes 1990).

Assessment of the annotation for Southern-white rhino: The annotation recognises that southern white rhinos in South Africa are no longer endangered, and facilitates the derivation of economic benefits from hunting and selling live rhinos, particularly on private land, which holds some $16 \%$ of South Africa's white rhinos. The trade in specified white rhino specimens from South Africa is no longer subject to the provisions of Article III of the Convention, and the prior grant of import permits are not required. For the annotation to be considered effective, it would need to facilitate the international trade in live animals and hunted trophies, and in turn to improve the conservation status of white rhinos, particularly on private land. It is still rather early to assess a measure adopted only in 1994, relative to the data available on levels of trade.

Live white rhinos were initially sold by the Natal Parks Board to the private sector at fixed, below market prices to encourage wildlife use among land owners. Equally, these rhinos could not all be accommodated by South Africa's nature conservation agencies within existing protected areas (Anderson 1993). This policy continued until 1987, when it was found that many rhinos on private land had been lost, many through hunting or sale to other owners. It appeared there was no incentive to conserve white rhinos on private land, particularly as the safari hunting fee increased ('t Sas-Rolfes 1990, 1995), and the system was abused by many property owners. Natal Parks Board reviewed its procedures for allocating white rhinos in 1988, and began offering white rhinos on auction from 1989, like other provincial authorities in South Africa (Figure 12a). However, Natal Parks Board has also continued to offer some white rhinos at fixed prices.

Numbers of white rhinos sold increased from 1986 to 1991, as a result of increased numbers sold at auction by Natal Parks Board, and of an increasingly dry period (Figure 12a). Numbers auctioned from 1992 to 1995 still remained high, but no rhinos were sold by Natal Parks Board at fixed price in 1995, the year after the adoption of the annotation. The mean auction price was increasing in actual and real terms before Natal entered the auction market in 1989. Auction prices, whether in actual or real terms, reached their peak in 1989 and 1990, then began to fall, with evidence of a slight rise again in 1995, the year after adoption of the annotation (Figure 12b). Over the 10 year period 1986-1995, sales have raised the equivalent of over US\$ 4 million in real terms. Many of the rhinos sold live feed into the hunting industry. 
A best estimate suggests that approximately 820 to 840 white rhinos were hunted in South Africa from 1968 to 1994 (Adcock and Emslie 1994). Some 497 rhinos were hunted from 1968 to 1987 , equivalent to approximately 25 rhinos per year, or an average hunting rate of some $0.93 \%$ relative to the South African population (Figure 12c). Some 347 rhinos were hunted from 1987 to 1994 but, with an increasing population of white rhinos throughout South Africa, this resulted in a lower average hunting rate of $0.81 \%$ (Figure 12c). Both hunting rates are clearly sustainable, and the white rhino population has continued to increase throughout the period that live sales and trophy hunting have been practised (Cumming et al. 1990). Some 650 rhinos hunted on private land from 1968 to 1994 could have generated around US\$ 15 million in real terms. Thus, hunting of white rhinos is seen as an important tool that helps population management in state protected areas by removing surplus animals from populations that are at carrying capacity, that provides private land-owners with an incentive to take rhinos onto land that might otherwise be used for cattle, and that generates considerable income through live sales by parastatal wildlife authorities to re-invest in the conservation of their areas (Adcock and Emslie 1994).

The limited evidence available shows that South Africa was practising the sale of live animals and of trophy hunting on a sustainable basis before the annotation was adopted. Considerable funds are generated for conservation through both these activities, and hunting plays a vital role in maintaining white rhinos on private land that would otherwise be dedicated to livestock. It remains to be seen whether the annotation further promotes the improving status of white rhinos.

\subsubsection{Annotations - An Evaluation of Trade in Cloth and Wool Sheared from Live Vicuna}

Distribution, utilisation and status: The vicuna, Vicugna vicugna, inhabits the high regions of the Andes, between 3000 to $4600 \mathrm{~m}$ of altitude. There are two geographic subspecies of the vicuna, the more southerly V.v. vicugna and the more northerly V.v. mensalis. The vicuna currently occurs in four range States, comprising: Argentina, Bolivia, Chile and Peru (Torres 1992). Some 2 million vicuna were estimated to have occurred in the Andes when the Spanish colonialists arrived. The Incas had practised an ideology that favoured conservation and sustainable utilisation of vicuna products (Koford 1957). Only a few vicunas were slaughtered in ritual ceremonies, but vicunas were caught regularly in corrals for shearing. Wool was used for certain types of special clothing, and hair was favoured for fine cloaks used magic-religious rituals performed to ensure the success of pasturing activities high in the Andes (Torres 1992). Upon arrival of the Spanish colonialists, the Inca system of management broke down, and during three centuries of colonial domination, the vicuna population was greatly reduced by hunting. By the 1950s, less than 400,000 vicunas remained. In the late 1960s, there were fewer than 2000 vicunas in Bolivia, Chile and Argentina combined, and some 10,000 in Peru. An important concentration centred on the south of Peru, where the Pampas Galeras Reserve was established in 1965, and which successfully began the recovery of the species (Otte and Hofmann 1981). By 1990, Peru held almost 100,000 vicunas, including many outside protected areas (Torres 1992). However, serious poaching in the early 1990s reduced this population by an estimated $50 \%$, but it has since recovered to some 75,000 animals. Chile, Bolivia and Argentina all have smaller populations of vicuna, with numbers distributed both inside and outside protected areas. At its present global population size, the vicuna is not considered threatened (Baillie and Groombridge 1996). 
Protection status: Legislation specifically regulating or banning the hunting possession, or trading of vicuna has been passed by all Andean countries. A co-operative agreement entitled Agreement for the Conservation and Management of the Vicuna was signed in 1979 by the four range States and Ecuador, based on historical records from the last century indicating the existence of some form of camelid (Torres 1992).

Principal threats: Poaching of vicunas for their valuable wool still provides the main threat to the species. With many vicunas living outside protected areas, and increased competition for grassland, future conservation of the species can only be achieved if local communities whose land is being used to raise vicunas receive tangible benefits from their conservation (see Rabinovich, Capurro and Pessina 1991).

Assessment of the annotation: The measure of allowing trade in wool sheared from live animals, and cloth and products therefrom, is intended to provide local communities with tangible benefits for conserving vicuna outside protected areas, without killing the animals. For the measure to be considered effective, it would need to facilitate the commercial trade in wool and wool products, and in turn to improve the conservation status of vicunas, particularly outside protected areas. The annotation means that export of the specified products does not require the prior grant of an import permit.

The adoption of the annotation in 1987 initially gave rise to preparations for international trade in wool and its products in each range State. Records of CITES reported trade from 1988 to 1994 mainly recorded re-exports of old stock. However, Peru and Chile only began to export cloth and hair directly to consuming nations in 1995 . Therefore, it is too early to assess whether the annotation has been successful in its aims. Nevertheless, it holds considerable promise of economic benefit for local communities through shearing wool (see Rabinovich et al. 1991), with all four current range States signed up to the measure and acting through a co-operative management regime. 


\subsubsection{An Evaluation Of The Significant Trade Process}

This process is perhaps the most important innovative measure that has been adopted since the Convention came into force. This is because the successful implementation of the provisions relating to Appendix II is critical to the overall and long-term success of the Convention (Wijnstekers 1995).

\subsubsection{Significant Trade in Animal Species}

There have been three phases in the implementation of Resolution Conf. 8.9. Each phase has begun with the selection of species by the Animals Committee and with desk studies carried out by WCMC, IUCN and TRAFFIC. Draft reports were sent to each range State for comment, and the final reports were sent to all Parties for information. On the basis of these reports, the Animals Committee formulated recommendations which were sent to the States concerned according to the following schedule: first phase in June 1992; second phase in January 1994: and third phase in March 1996.

The Significant Trade Process has involved 106 species and 5 higher taxa, totalling 111 species and higher taxa combined. The process involved 27 species or higher taxa in Phase 1, 74 species or higher taxa in Phase 2 and 10 species or higher taxa in Phase 3 (Figure 13a). As with amendments to the Appendices (Figures 4, 5), the Significant Trade Process has been heavily biased towards birds and mammals (Figure 13b). However, a higher proportion of reptiles was considered in the Significant Trade Process than for amendments to the Appendices. As with the amendments to the Appendices, there were also very few species considered from other groups, comprising two species of amphibian, three species of insect and two species of mollusc. A noticeable absentee from the Significant Trade Process was any species of fish. In part, this paucity of fish, amphibian, insect and mollusc species reflects a similar lack of representation in the appendices.

The inclusion of a species or higher taxon in the Significant Trade Process can result in recommendations from the Animals Committee for several range States. Thus 138 recommendations had been formulated by March 1997, and these involved a total of 45 range States (counting the satellites of the former USSR as one range state). The countries that have attracted most recommendations under the Significant Trade Process, include Indonesia, Argentina, Tanzania, Malaysia, China, Togo, Ghana, Philippines and Madagascar, that have each attracted several recommendations (Figure 13c). This tightly clumped distribution comprises Parties that have significant export volumes and are known to have had difficulty in implementing the Convention. Thus the Significant Trade Process, besides aiming to reduce the need for the transfer of species from Appendix II to Appendix I, also assists the Parties to improve implementation of the Convention more generally.

The Animals Committee have made various recommendations to the range States concerned in Phases 1 and 2, but, recommendations for Phase 3 are still being formulated. Therefore, an assessment of the action taken for animals under the Significant Trade Process can only be made for Phases 1 and 2 (Figure 14). By March 1997, over 65\% of the recommendations had been implemented or part 
implemented to the satisfaction of the Secretariat, for the species and range States involved in Phase 1. Some field surveys were initiated, no quotas were set, but two range States prohibited exports in the species concerned. There were only two total failures that resulted in the listing of species in Appendix I (namely Goffin's cockatoo Cacatua goffini from Indonesia and red-vented cockatoo $C$. haematuropygia from the Philippines). Furthermore, there were seven instances, in which the Standing Committee recommended the suspension of imports, comprising $18.4 \%$ of the total cases in Phase 1 . Unsurprisingly, a lower proportion (48\%) of recommendations had been implemented or part implemented for the species and range States involved in Phase 2 by March 1997. However, a number of export quotas were set following the recommendation of the Standing Committee (11\% of cases) for those species involved in Phase 2, whereas none had been set in Phase 1. Another important difference between Phases 1 and 2 was that many more range States decided to curtail or prohibit their exports (26\% vs 5\%). Indonesia in particular moved from a situation where the Standing Committee recommended the suspension of imports in Phase 1 to a situation where the country decided to limit its exports in Phase 2. Again there were two total failures that resulted in the listing of species in Appendix I (red panda, Ailurus fulgens from China and Egyptian tortoise, Testudo kleinmanni from Egypt). However, there was a lower proportion of instances where the Standing Committee recommended the suspension of imports, comprising only $9 \%$ of the total cases in Phase 2, compared with $18 \%$ in Phase 1.

The results of the Significant Trade Process for animals to date suggests that this measure has been very important in assisting Parties to maintain species in Appendix II (compare Figures 5 and 14). Furthermore, the Significant Trade Process engages those responsible for overseeing the Convention, and their associated non government partners such as WCMC, IUCN and TRAFFIC, in interactive dialogue with the Parties concerned, well before the final decision to transfer the species to Appendix I is taken. On the basis of its performance to date and this limited analysis, the Significant Trade Process appears very effective.

\subsubsection{Significant Trade in Plant Species}

There are great difficulties with identification of plant species that lead to problems in reporting of import and exports (Jenkins and Oldfield 1992). Another important issue is that Parties often do not record whether the plants are wild collected or artificially propagated. In turn, this means that the data in the CITES database relating to plants is often very incomplete. Hence, a recent report of the Plants Committee to the tenth Conference of the Parties noted that the unreliability of the data on plant trade in the CITES database meant that a Significant Trade Process similar to that for animals was not appropriate. However, the Plants Committee is adopting an approach for collecting information on the status of species to compare with such trade data as is available to determine which groups of plants may be traded at unsustainable levels. Consequently, the effectiveness of this measure for plants is not yet clear. 


\subsection{An Analytical Framework for Assessing the Effectiveness of CITES Measures in Economic Terms}

A demand and supply analysis is used to build a framework for assessing the effectiveness of the trade and innovative measures in attaining the objectives of the Convention (see section 3). The CITES approach is essentially to regulate the quantity and source of a species in international trade through various trade and innovative measures. The CITES regulations in turn produce economic incentives and disincentives to trade, to which the market responds. To determine whether CITES measures provide the appropriate economic incentives to achieve the objectives of the Convention, this analytical framework uses demand and supply functions and price elasticities. This framework provides a foundation for a later practical analysis of the incentive compatibility of CITES measures in individual listing cases.

Trade occurs when there is a demand for a good that can be matched by a supply. By identifying which variables affect the demand and supply sides of trade, it is possible to analyse whether the measures in CITES are an economically effective means of influencing trade in listed species. This section describes the demand and supply approach. Subsequent sections then use this approach to establish an analytical framework for the various trade measures.

\subsubsection{Demand Side}

The quantity demanded is the quantity of a good that consumers will choose to buy at a given price. As the price of the good falls, the quantity demanded for the good rises, until the market is saturated. The demand curve $(\mathrm{D})$ in Figure 15 gives the quantity demanded $(\mathrm{Q})$ for each price $(\mathrm{P})$. A change in the price of the good results in a movement along the demand curve. For example a decrease in price from $\mathrm{P}_{1}$ to $\mathrm{P}_{2}$ leads to an increase in quantity demanded from $\mathrm{Q}_{1}$ to $\mathrm{Q}_{2}$. (It is important to note at this point that the functional relationship is $\mathrm{Q}=\mathrm{f}(\mathrm{p})$.) In economics, by convention, the dependant variable, $\mathrm{Q}$, is placed on the horizontal axis while the independent variable, $\mathrm{P}$, is placed on the vertical axis.

Factors other than price may also affect the position of the demand curve, and could include: consumer income, the prices of other goods (and services), human population pressure, lifestyles and consumer choices, the necessity for import permits, or the use of the good as an asset. Changes in these factors can result in a shift of the demand curve.

For "normal" goods, a rise in the consumer income results in a shift to the right in demand -- as is depicted in Figure 16. At any given price the quantity demanded increases -- reflected by the increase from $\mathrm{Q}_{1}$ to $\mathrm{Q}_{2}$ at a price of $\mathrm{P}_{1}$. Other goods may be "inferior" implying that the demand will decline (say 
from $D_{2}$ to $D_{1}$ ) with rising incomes. For example, as income rises some communities may shift from wild medicines to synthetic medicines.

A change in the price of other goods can also shift the demand curve. The direction of the shift resulting from the change in price of another good depends on the relationship between the two goods. For example, the demand for crocodile skins may be influenced by the price of alligator skins. If the price of alligator skins falls then consumers may choose to substitute alligator skins for crocodile skins and therefore the demand for crocodile skins shifts inward (to the left). Alligator and crocodile skins are in this case substitutes. In other cases an increase in the price of another good may have the opposite effect. The demand for trophy hunting of a listed species, for example, may shift to the right with a fall of the price of airline ticket prices. The fall in ticket prices makes the trophy hunting package cheaper. Trophy hunting and airline tickets are complements. It is important to know the relationship between the various goods to determine how a change in price will shift demand.

Population composition and consumer taste are two other factors which shift the demand curve. A change in the composition of a population also effects the demand curve. For example, if it is the elderly who constitute the demand for a medicine derived from a listed plant and the population is ageing then over time the demand curve for the medicine will shift to the right. A change in tastes can also shift the demand curve. For example, a move away from the use of fur in the fashion industry shifts the demand curve for mink skins to the left. Marketing campaigns can be used as a tool to shift demand for fur and may, one day, reduce the quantity demanded to zero at any price.

\subsubsection{Supply Side}

The supply referred to in this analysis is the supply of the goods traded on the international market. It is not the overall quantity of species that exist in the world. Quantity supplied is the quantity of a good that producers would be willing to sell at a particular price. As the price of a good rises, so does the quantity supplied, until the resource is exhausted. The supply curve shows the quantity of a good that the individual or group will supply at each price. A change in price will result in a movement along the supply curve (see Figure 17).

Like the demand curve, the supply curve can shift for a number of reasons. In the case of the supply of goods derived from wild species these factors may include a change in the price of inputs, a change in technology, a change in the natural habitat, and a change in the CITES regime.

A higher price in the inputs of a good derived from a listed species results in a shift inwards (to the left) of the supply (Figure 18). For example, a higher price for chemicals used in the processing of hides results in a reduced quantity supplied at each price. CITES regulations also influence the price of inputs. For instance, an export permitting system introduces a new 'input' into the process of getting the good to the market thereby shifting the supply curve to the left. 
Improved technologies, such as the introduction of 'target picture' hunting of big game in Southern Africa, result in a shift to the right of the supply curve for game hunting assuming that the new technology is a perfect substitute. Target picture hunting gives a picture of the animal in the gun's target and enables the hunter to shoot the animal in the picture without harming the live animal. Thus the game hunting supply curve shifts to the right because a single animal can be hunted many times over.

On the other hand, the supply curve of goods derived from listed species is likely to shift to the left if there is a loss of natural habitat. This is because the loss of habitat is likely to result in a decline in the population of the species to supply the market at any given price. Such an effect may be countered by an increase in supply due to increased accessibility (i.e. from road building).

\subsection{Demand and Supply}

In a competitive market, demand and supply work together to determine the market clearing price and the quantity traded. Mapping the supply curve and demand curve on the same graph reveals the market price for a good which is the price at the intersection of the two curves or $\mathrm{P}^{*}$ in Figure 19. This intersection is the equilibrium point $(\mathrm{E})$, which has as its co-ordinates the equilibrium price $\left(\mathrm{P}^{*}\right)$ and the equilibrium quantity $\left(\mathrm{Q}^{*}\right)$. When the market reaches this equilibrium point it clears. But changes can and do occur, as we have seen above. CITES is a deliberate attempt to interfere with the markets in goods derived from listed species. Demand and supply analysis provides a useful framework for determining the possible consequences of this interference.

\subsubsection{Price Elasticity of Demand}

One factor which must be taken into account in determining the impacts of shifts in the demand and supply curves is the price elasticity of demand. The price elasticity of demand indicates the nature of the relationship between changes in price and changes in quantity and is an important concept used throughout the demand and supply analysis. The price elasticity of demand is the percentage change in quantity demanded relative to the percentage change in price. This is expressed in the formula:

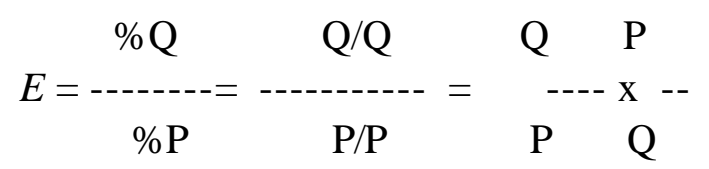

In this formula $E$ is the price elasticity of demand, $\mathrm{Q}$ is the change in quantity, $\mathrm{P}$ is the change in price, $\mathrm{P}$ is the price, and $\mathrm{Q}$ is the quantity. The price elasticity of demand is in fact a negative number because of the inverse relationship between changes in price and changes in quantity demanded. However, to simplify this presentation, we use the absolute value.

The concept of elasticity can be clarified with an example. Figure 20 depicts a linear demand curve for rhino horns with several price/quantity ratios. At a price of 36 (hundred dollars), the quantity demanded is 0 . When the price drops to 30 , the quantity demanded increases to 4 . When the price drops to 6 , the 
quantity demanded increases to 20 . Seven such combinations of prices and quantities are lettered A-G in Figure 20. Each of these points has a different price elasticity which can be derived by inserting the numbers into the above formula.

The elasticity for $\mathrm{A}$ is infinity (), for $\mathrm{B}$ it is 5 , for $\mathrm{C}$ it is 2 , and so on. Figuring the elasticity for each point (given in Table 11) it becomes obvious that the elasticity decreases as we go down the demand curve. More precisely, the elasticities at the upper part of the curve are greater than one, at the midpoint (point $\mathrm{D}$ in Figure 20) the curve elasticity is 1, and the elasticities in the lower part of the curve are less than one. Therefore points at the top of the curve (such as B) are elastic, and points at the bottom (such as E) are inelastic.

These elasticities are important for understanding the likely market response to quantity restrictions. This is perhaps most easily understood by looking at changes in the total revenue. Total revenue (TR) is price times quantity (PxQ). The TR at A it is 0 , at B it is 120, at C it is 192, and so on (see Table 11). Total revenues are maximised at the midpoint where the price elasticity is 1 . Total revenues increase with a decrease in price where the elasticity is greater than 1 because the percentage change in quantity demanded is greater than the percentage change in price. In other words, the consumers respond to a price drop by spending more money. Total revenues increase with an increase in price where elasticity is less than 1 because the percentage change in quantity demanded is less than the percentage change in price. In this case, the consumers do not respond to a price increase by spending less money. This response is inelastic.

Table 11: Price Elasticity of Demand and Total Revenue

\begin{tabular}{|c|c|c|c|c|}
\hline Point & $\mathbf{P}$ & $\mathbf{Q}$ & $\mathbf{E}$ & TR \\
\hline $\mathrm{A}$ & 36 & 0 & & 0 \\
\hline$B$ & 30 & 4 & 5 & 120 \\
\hline $\mathrm{C}$ & 24 & 8 & 2 & 192 \\
\hline$D$ & 18 & 12 & 1 & 216 \\
\hline E & 12 & 16 & 0.5 & 192 \\
\hline$F$ & 6 & 20 & 0.2 & 120 \\
\hline$G$ & 0 & 24 & 0 & 0 \\
\hline
\end{tabular}


Throughout this study an inelastic demand curve is represented by a nearly vertical line as is depicted in Figure 21. Tracing this almost vertical line to the price axis it becomes obvious that this curve essentially represents the lower half of the demand curve -- which is the inelastic portion of the curve. An elastic demand curve is represented in the opposite way -- as a nearly horizontal line (see Figure 22) reflecting the portion of the curve above the midpoint or the elastic portion of the curve.

The nature of the good is likely to influence the elasticity of its demand. A good which has many substitutes is likely to have an elastic demand curve because consumers will more readily drop it for another good. On the other hand, a good which is not readily substituted is likely to have an inelastic demand curve (i.e. traditional medicine such as rhino, tiger, bear)

The following sections apply the demand and supply tools explained above to develop an analytical framework for assessing the effectiveness of CITES trade measures. CITES uses a number of measures to regulate the international trade in listed species or goods derived from listed species. These include a trade ban, an export and import permit system (Appendix I), an export permit system alone (Appendix II listing), and an export permit system for a single country (Appendix III listing). Each of these measures affect demand and supply in a slightly different way.

\subsection{Analysis of the Effectiveness of CITES Appendix I Measures in Economic Terms}

This section outlines an analytical framework for two measures within Appendix I: (1) a trade ban on commercial goods and (2) an export and import system for non-commercial goods.

\subsubsection{Trade Ban}

International trade in Appendix I species for commercial purposes is prohibited. The demand and supply prior to the ban is represented in Figure 23 by $S_{1}$ and $D_{1}$ which gives the equilibrium price and quantity $\mathrm{P}_{1}$ and $\mathrm{Q}_{1}$. Imposing the ban results in an elimination of legal demand, which shifts the demand curve to the left from $D_{1}$ to $D_{2}$ - assuming that some people prefer not to buy illegal goods. $D_{2}$ thus represents the continued demand to buy in a now illegal market. Without effective enforcement of the ban, the supply curve represented by $S_{1}$ remains unchanged. Some enforcement leads to a shift to left of the supply curve depicted as $S_{2}$, because enforcement raises the input costs of supplying the good. Total enforcement of the ban results in a vertical supply curve along the price axes, meaning that there is no quantity available at any price. It is important to point out that the situation of total enforcement, though theoretically possible, is very rarely achieved.

As the graph demonstrates, with the shift of the demand curve from $D_{1}$ to $D_{2}$ the equilibrium quantity drops from $\mathrm{Q}_{1}$ to $\mathrm{Q}_{2}$. Therefore the ban results in a drop in quantity even without enforcement. Some enforcement results in yet another drop in the equilibrium quantity to say $\mathrm{Q}_{3}$ as a consequence of the 
shift to the left of the supply curve. Total enforcement will result in a quantity equilibrium of zero (0). In short, a ban on its own only pushes a market under ground. Enforcement is needed to close down the trade.

The elasticities of the supply and demand curves greatly affect the magnitude of the changes in equilibrium quantity. The first shift of the demand curve from $D_{1}$ to $D_{2}$ results in a decrease in equilibrium quantity from $\mathrm{Q}_{1}$ to $\mathrm{Q}_{2}$. The magnitude of this decrease depends in part on the price elasticity of supply. (Price elasticity of supply is a similar concept to the price elasticity of demand presented in the previous section.) As is depicted in Figure 24, an elastic supply curve results in a significant decrease in quantity demanded. On the other hand, an inelastic supply curve, as depicted in Figure 25, results in a much smaller decrease in quantity demanded. Thus variable costs, and fixed costs which govern the supply curve dictate the impact of the shift in demand on the change in equilibrium quantity.

The second shift in the curves - the shift of the supply curve to the left - also reduces the equilibrium quantity and the magnitude of this change depends on the price elasticity of demand. For instance, an elastic demand curve corresponds with a significant decrease in equilibrium quantity (from $\mathrm{Q}_{2}$ to $\mathrm{Q}_{3}$ in Figure 26) where an inelastic demand curve corresponds with a significantly smaller drop in equilibrium demand (Figure 27). Thus the nature of the good (eg. whether it is readily substituted or not) determines the impact of enforcement efforts in changing the equilibrium quantity. Enforcement is more cost effective for goods with an elastic demand curve.

Combining the shifts in demand and supply we see that the ban and enforcement efforts are most effective in lowering quantity traded when both the demand and supply curves are elastic. On the other hand, a ban will be less effective if both of the curves are inelastic. This is demonstrated in Figure 28 and 29.

Total revenues indicate some of the incentives implicit in the market. In Figure 30, the total revenue of a market without the ban is equal to $P_{1} Q_{1}$ (i.e. $P_{1}$ times $Q_{1}$ ). The total revenue with some enforcement of the ban is equal to $P_{3} Q_{3}$. There is, of course, no revenue with total enforcement of the ban since there is no legal or illegal market. The elasticity of the curves combined with the magnitude of the shift of the curves determines if the total revenues rise or fall.

With an elastic demand curve total revenue will fall no matter the magnitude of the shift in the supply curve. For instance, total revenues for crocodile skins which are easily substituted by alligator skins will fall so long as there is some enforcement. This means that there is little incentive to supply the crocodile skins on the market. This is depicted in figures 30 and 31 .

In the case of a good with an inelastic demand curve the magnitude of the shift in the supply curve is crucial in determining whether total revenues rise or fall. Total revenues to illegal traders, rise when the ban is well enforced (i.e. a large shift in the supply curve), but fall if there is little enforcement (i.e. a small shift in the supply curve). Therefore perversely there may be more incentive to supply the good on a black market where enforcement is strong. These scenarios are depicted in figure 32 and 33. 
Further one important difference between the total revenue derived from legal trade $\left(\mathrm{P}_{1} \mathrm{Q}_{1}\right)$ versus illegal trade $\left(\mathrm{P}_{3} \mathrm{Q}_{3}\right)$ irrespective of the elasticity of the curves, is that some of the revenue from $\mathrm{P}_{1} \mathrm{Q}_{1}$ can be captured for conservation purposes but none of the revenue from $\mathrm{P}_{3} \mathrm{Q}_{3}$ can officially be channelled towards conservation. This is because the revenues in $\mathrm{P}_{3} \mathrm{Q}_{3}$ are the revenues of an illegal market. Depending on the structure of the illegal market, however, those revenues may informally be channelled into conservation in any case. For example, a local land owner profiting from the illegal trade in a species coming from his land may have an incentive to conserve that species. But a poacher harvesting a species off government owned land does not have that same incentive.

In addition to this loss of a possibility for official revenue, the ban also imposes enforcement costs. Enforcement is necessary to shift the supply curve to left. The further the government wishes to shift the supply curve, the higher their enforcement costs. If these costs are being met through the use of the conservation budget (i.e. if enforcement and other conservation efforts are linked through a shared budget) then higher enforcement perversely may actually serve to hinder the conservation of the species. For example, assume a country needs to spend US\$10,000 on enforcing a ban on orchids which reduces the quantity of orchids on the market by 100 . If this US\$10,000 comes from the conservation budget and the reduction in this budget results in poor habitat management, these could be a subsequent loss of say 150 orchids. By enforcing the ban, in this case, the government has lost 50 orchids. The lower the costs of enforcement and the more elastic the demand the more worthwhile it is for the government to pursue total enforcement of the ban. A ban is less effective if enforcement costs are high and demand is inelastic because the change in equilibrium quantity is small and the high potential rewards strong incentive to trade illegally.

However, this scenario may be complicated by the fact that by instituting a global ban on that commodity, enforcement costs are actually reduced, as enforcement officers will know that when a trade ban is in place, any trade in the species is highly likely to be illegal. Indeed this is the rationale behind the co-operative nature of CITES, that by working together, the Parties make trade regulation more efficient. Consequently, to test these models, it will be necessary to have some data on the economics of CITES enforcement.

Some may argue that the type of enforcement will effect the revenues available for conservation. For instance, a penalty may be seen as providing some revenues. But in order for the penalty to be paid the offender may continue trading. Hence a penalty system may be essentially supported by the trade system. On the other hand imprisonment halts the trade by taking the illegal suppliers out of the market. But imprisonment increases enforcement costs and provides no direct revenue.

It is obvious from this analysis that there are a myriad of factors which influence the effectiveness of a ban on the international trade and conservation status of the species. Of key importance to the trade is the price elasticity of demand and supply, the taste for illegal goods, and the costs of enforcement. Of importance to the effectiveness of the ban on influencing the conservation status of a species is the relationship between the costs of enforcement and the conservation budget. Additionally it should be 
noted that a major drawback of such a ban is that it applies equally to those countries investing and those not investing in conservation of the specified species. Therefore Appendix I listing may generate perverse incentives by treating all producer states equally, despite their different conditions and efforts to conservation.

\subsubsection{Export and Import Permit for Appendix I Listed Species}

An Appendix I listing also allows for non-commercial trade in goods with the requirement of export and import permits based on a non-detrimental finding. This section analyses the effectiveness of an export and import permit process in reducing the quantities traded. Another issue of importance but which will not be addressed in this study, is the problematic concept of a "non-commercial trade". Is a sale to a zoo in North America or a research laboratory in Europe commercial or non-commercial? In an increasingly globalised, market-based economy, both zoos and laboratories operate more and more on a commercial basis.

As is depicted in Figure 34, the introduction of the export and import permit process shifts the supply curve to the left from $S_{1}$ to $S_{2}$. This is because the supplier suffers new costs as result of time and efforts given to the process and uncertainty of acquiring a permit. The supply curve may shift even further to the left if the supplier must pay for the permit. Therefore the equilibrium quantity initially shifts from $Q_{1}$ to $Q_{2}$ and the price rises from $\mathrm{P}_{1}$ to $\mathrm{P}_{2}$. For instance, the difficulties of obtaining import permits for elephant trophies may have reduced the quantity demanded, as evidenced by the fact that trophy quotas have not been fulfilled in recent years. The magnitude of these changes in quantity and price depend on the elasticity of the curves. But no matter the elasticities, the export and import permit process at this stage is effective in lowering the quantity traded in the market.

If such a process, however, is effective in guaranteeing that the goods traded are not detrimental to the survival of the species or, that the process essentially certifies that the goods are 'green goods', then the demand for these goods may well increase. This is reflected by a shift in the demand curve to the right from $D_{1}$ to $D_{2}$, increasing the equilibrium price from $P_{2}$ to $P_{3}$ and the equilibrium quantity traded from $Q_{2}$ to $\mathrm{Q}_{3}$.

The elasticity effects the magnitude of the changes in quantity and price, but also the size of the shift of the demand and supply curves which dictate whether the end equilibrium quantity is greater or less than the original equilibrium quantity before the listing. For instance a small shift in the supply curve matched by a large shift in the demand curve would result in a greater end equilibrium quantity. In this case the trade measures would increase rather than decrease the quantity traded. This is demonstrated in Figure 35. In all cases, however, the equilibrium price rises with the shifts in the demand and supply curves.

Additionally, as is shown in Figure 36, if the market is not allowed to adjust to the equilibrium price $\mathrm{P}_{3}$ by increasing the quantity traded from $Q_{2}$ to $Q_{3}$ then after the shift in the demand curve from $D_{1}$ to $D_{2}$ consumers would be willing to pay $\mathrm{P}_{4}$ for the $\mathrm{Q}_{2}$ quantity resulting from the original shift in supply to $\mathrm{S}_{2}$. 
At this high price suppliers, including the government, ultimately may be willing to supply $\mathrm{Q}_{4}$. In this case the high price may provide a perverse incentive to issue more permits, than is truly non-detrimental.

Further, referring to the scenario where the market is allowed to adjust to the increase in demand (due to the 'green good' effect under this scenario), there is also a potential for the government to capture some of the revenue from the price increase from $\mathrm{P}_{1}$ to $\mathrm{P}_{3}$. This revenue could be used for conservation efforts thereby increasing the conservation status of the species in the country. This opportunity to raise revenues through the export of species, however, may undermine the non-detrimental finding efforts because there is now an additional incentive to increase the quantities of permits issued. Such a scenario, however, has been anticipated by CITES, and in the case of Appendix I species, the export permit system is checked by the import permit. Additionally the CITES Standing Committee can impose strict sanctions on countries who issue more permits than is deemed non-detrimental. Sanctions for non-compliance can be seen as CITES-related trade measures and are discussed in more detail in section 6.8 .

Generally, the costs involved in issuing export and import permits (i.e. non-detrimental findings and administration) are paid by the respective governments or sometimes through international donor aid. Therefore governments are generally missing out on the opportunity to collect revenues from those who benefit from the trade and are able to cover these costs.

This section has highlighted some important factors which must be integrated into a detailed economic analysis of the effectiveness of the ban and export and import permit process of Appendix I. The nondetrimental finding stipulation for the export and import permit process essentially functions as a quota because it limits the amount of permits issued. Therefore this analysis is also similar to the quota analysis addressed in section 6.1.

\subsubsection{Export Permit for Appendix II Listed Species}

An effectiveness analysis of Appendix II trade measures is similar to the above-mentioned Appendix I export and import permit analysis. The only difference is that Appendix II does not have a double security approach based on export and import permit. This means that the incentive to issue more export permits than is deemed non-detrimental may go unchecked. Some countries (Australia, EU countries, Japan, USA), however, are implementing 'stricter domestic measures' to require an import permit for trade in certain species listed under Appendix II. In these cases the economic analysis is identical to the analysis described above on export and import permits.

The trade restriction on look-alike species, is equivalent to an Appendix II listing and may reduce enforcement costs by simplifying the identification process. But from an economic perspective it is necessary to compare the reduction in enforcement costs to loss of revenue from trade in species to determine if this measure is economically sound.

\subsubsection{An Export Permit under Appendix III Listing}


An Appendix III listing subjects one country's population to an export permit process, while other populations of the same species remain in free trade but with new documentation and requirements. When a species is listed under Appendix III, the supply curve on this market may shift to the left from $S_{1}$ to $S_{2}$ as the costs of permitting etc. for one geographic supplier, may increase and hence the supply available for that price decreases. As depicted in Figure 37a the shift to the left in the supply curve results in an increased price (from $\mathrm{P}_{3}$ to $\mathrm{P}_{2}$ ) and therefore increases pressure for an illegal market. The demand curve may also shift to the left from $D_{1}$ to $D_{2}$ because of people's preference not to buy illegal goods. This shift moves the equilibrium price to $\mathrm{P}_{3}$ thereby easing the pressure for an illegal market. The impact of an Appendix III listing by a country will, of course, depend on its 'market share' of the species in trade and on its ability to influence the behaviour of other actors in the market.

\subsection{Effectiveness of Innovative Measures in this Economic Framework}

This section outlines an analytical framework to determine the effectiveness of innovative measures in meeting the CITES objective. As explained above, innovative measures include captive breeding, ranching, quotas, split listing, annotations, marking and registration, financial contributions and technical co-operation, sanctions, and reservations. Each of these measures affect demand and supply in different ways.

\subsubsection{Captive Breeding and Artificial Propagation}

An exception to Appendix I allows Parties to commercially trade in Appendix I species which are not taken from the wild but which are raised through captive breeding or artificial propagation. Artificial propagation is effectively captive breeding for plants and therefore will follow the same analysis as the one given here. From an economic perspective Resolution Conf. 8.15 is noteworthy as it recognises that breeding a species in captivity for commercial purposes can be an economic alternative to domestic livestock production in its places of origin and can thus provide an incentive for the rural population in those places to develop an interest in its conservation. As demonstrated below, captive breeding may reduce the market price which may then take away the incentive to poach animals from the wild. This is because the lower market prices would not compensate the poacher for the risk they take of being caught.

However there has been some concern with regard to the actual conservation benefits arising from captive breeding. For instance, the IUCN/SSC Crocodile Specialist Group (CSG) recognises that ranching generally provides greater conservation benefits than captive breeding [Messel and Ross, 1992]. The demand and supply analysis highlights some of these concerns.

The demand and supply analysis for captively-bred species is slightly different from the demand and supply analyses done thus far. This is because goods derived from captively-bred species compete as substitutes for the wild species. For this reason the analysis uses two graphs simultaneously. In Figure 
37 the graph for the wild species is on the left and the graph for the captively-bred species is on the right.

Captive breeding is a innovative measure for species listed in Appendix I meaning that the supply and demand for the species prior to the introduction of a captive breeding programme is illegal. We have drawn the supply curve in the wild (illegal) trade graph of Figure 38 so that it reflects only some or no enforcement of the ban.

The introduction of the captive breeding programme creates a legal market for the good represented by the right-hand graph in Figure 39. This market influences the illegal market in the good from the wild species by shifting the illegal demand curve to the left (to $\mathrm{D}_{2}$ ). This is because it is assumed that some consumers now prefer to buy the legal good - thereby lowering the number of consumers in the illegal market. Therefore the wild (illegal) equilibrium price and quantity fall to $\mathrm{P}_{2}$ and $\mathrm{Q}_{2}$. At this point in the analysis captive breeding programmes appear to be effective measures for reducing pressures on the wild species because the introduction of a substitute (captivity-bred) good reduces the demand for wild species.

But this reduction in the demand for the illegal good may not be the full effect of a captive breeding programme on the markets. The introduction of captive breeding may give consumers the signal that it is now acceptable to purchase goods derived from the species. Indeed, if consumers think that their purchases will help fund conservation efforts they may even purchase more. This 'green good' effect shifts the demand curve for the captively-bred species to the right (from $\mathrm{D}^{*}{ }_{1}$ to $\mathrm{D}{ }_{2}$ ), raising prices from $\mathrm{P}^{*}{ }_{1}$ to $\mathrm{P}{ }_{2}$ on the captive breeding market. Tracing this new price over to the wild (illegal) market we discover a discrepancy between the legal and illegal prices $\left(\mathrm{P}^{*}{ }_{1}\right.$ to $\left.\mathrm{P}_{2}{ }_{2}\right)$ which creates an incentive for expanding the illegal market.

The elasticity of the captive breeding supply curve $\left(\mathrm{S}^{*}\right)$ also has an important role in the impact of the 'green good' effect. If significant capital investment is required for the start-up of a captive breeding programme - making the captive breeding supply curve highly inelastic as is depicted by ( $\mathrm{S}^{*}$ ) in Figure 38- there may be a significant jump in the price. This causes increased pressure on the wild (illegal) market. Over time, however, the captive breeding supply curve is likely to become more elastic (as is depicted in Figure 39) because suppliers are able to react to the signals of the increased demand. Therefore the price increase on the captive breeding market will be significantly less and the pressure on the wild (illegal) market will ease over time.

If the captive-bred supply curve is significantly inelastic in the short run, this poses a difficult situation for governments. Faced with the short term increase in price and the related increase in pressure on the wild (illegal) market, and expecting the decrease in this pressure over time governments can: (1) increase short term enforcement efforts, or (2) help the captive breeding suppliers expand their capacity more quickly.

The decision will depend on many factors, including: 
the breeding patterns of the species in question (it will be more difficult to increase the captive breeding capacity for a species which breeds infrequently or with small litters than for a species which has many large litters),

the risk of extinction due to increased poaching (enforcement will be more important for species which are likely to become extinct from the initial short term pressure on their wild population), and

the costs of enforcement in the wild (illegal) market.

\subsubsection{Ranching}

First mentioned with the adoption of Resolution Conf. 3.15, ranching addresses some of the concerns arising from captive breeding operations. Ranching operations are different from captive breeding programmes in that they rely directly on the wild population for stock (eggs and young), whereas captive breeding programmes are self-enclosed and function independently form the wild population [Wijnstekers 1995]. Supporters of ranching argue that captive breeding may not be feasible for certain species because of high species mortality and intensive capital requirements. Critics of ranching argue that ranching operations stimulate an illegal market and that they are too focused on an individual location or operation.

Ranching, like captive breeding, creates a substitute good for the wild Appendix I listed species. Therefore, the analysis involves a two market diagram (Figure 40) depicting the wild (illegal) trade in the left-hand graph and the ranching market in the right-hand graph. The introduction of a ranching scheme results in a shift to the left of the demand curve $\left(D_{1}\right.$ to $\left.D_{2}\right)$ on the wild (illegal) market because of people's preference for legal goods. Like the captive breeding market, the 'green good' effect may shift the demand curve to the right (from $D^{*} 1$ to $D^{* 2}$ ) in the ranching market. This raises the ranching prices from $\mathrm{P}^{*} 1$ to $\mathrm{P} * 2$, putting pressure on the illegal market.

An interesting difference between the captive breeding and ranching markets is the interface between the artificial (captive breeding and ranching) and wild habitats. The ranching habitat is more closely linked to - and may even be a part of - the wild habitat where captive breeding is most often entirely separate from the wild habitat (whether the government or the rancher owns thehabitat). This is demonstrated in Figure 41. The implication of the ranching habitat's position within the wild habitat is exposed when there is investment for expanding capacity for ranching. The rancher - reacting to the increased demand in his ranching market - may expand his capacity by investing in more habitat (or by lobbying the government for increased habitat) - shown by concentric circles around the ranching process in Figure 41. This reaction shifts the ranching supply curve to the right (from $S^{*} 1$ to $S^{*} 2$ ), lowering the ranching price to $\mathrm{P}^{*} 3$ which eases pressure on the wild (illegal) market. Some of this expansion may also further effect the supply on the wild (illegal) market. This is because the expanded habitat may make it easier for suppliers on the illegal market to obtain their goods - thereby shifting the wild (illegal) supply curve to the right - from $S_{1}$ to $S_{2}$. This lowers the price on the wild (illegal) market to $P_{3}$ thereby increasing the discrepancy between the ranched and wild prices $\left(\mathrm{P}_{3}\right.$ and $\left.\mathrm{P}_{3}\right)$ and again applying more pressure on the wild (illegal) market. 
The rancher's ability to keep poachers (suppliers on the wild market) from claiming goods from his newly maintained habitat will influence how far the wild (illegal) supply curve shifts out. If a rancher is able to increase habitat protection and deter poachers from infringe on this newly protected habitat then the wild (illegal) supply curve would not shift out at all. This means that the expaned protection of the habitat through ranching will have eased the pressure on the wild (illegal) market because the ranched price will have fallen from $\mathrm{P} * 2$ to $\mathrm{P} * 3$ and the wild price will remain at $\mathrm{P}_{2}$. A clear system of property rights would likely make it easier for a rancher to keep poachers from the new habitat, so the extent to which a ranching system effects the wild (illegal) market will be influenced by the property rights system. Additionally, some ranching permits have reintroduction clauses, which will streamline the natural population but are also likely to effect the market. Such linkages between the artificial and wild habitat do not exist for captive breeding.

\subsubsection{Quotas for Species listed in Appendix I}

As depicted in Figure 42, without a quota system, the market establishes $\mathrm{P}_{1}$ and $\mathrm{Q}_{1}$ as the equilibrium price and quantity. A quota limits the quantity to $\mathrm{Q}_{2}$ creating the 'kinked' supply curve $\mathrm{S}_{2}$. At the quantity $\mathrm{Q}_{2}$ suppliers are willing to supply the good for $\mathrm{P}_{2}$. At this price, however, the quantity demanded for the product is $\mathrm{Q}_{3}$. This discrepancy between the quantity supplied $\left(\mathrm{Q}_{2}\right)$ and quantity demanded $\left(\mathrm{Q}_{3}\right)$ at $\mathrm{P}_{2}$ creates a shortage. This shortage creates upward pressure on the price. This is because consumers are willing to pay $\mathrm{P}_{3}$ for the good there is an incentive for trade on the illegal market.

Without any enforcement of the quota system $\mathrm{S}_{1}$, beyond $\mathrm{Q}_{2}$, is now the supply curve of the illegal market and $S_{2}$ is the supply curve of the legal market. The government has two options for addressing the illegal market. The government can either work towards shifting the supply curve left by raising the input costs (for example, through increased enforcement) or work towards shifting the demand curve left (for example, by influencing consumer tastes).

As depicted in Figure 43, strengthening enforcement shifts the supply curve to the left to $\mathrm{S}_{3}$. This reduces the equilibrium quantity to $\mathrm{Q}_{4}$ and raises the equilibrium price to $\mathrm{P}_{4}$. Ensuring that no more goods are exported than are allowed by the quota would entail strengthening enforcement to the point where the (illegal) supply curve crosses the demand curve at the quota quantity, i.e. a shift to $\mathrm{S}_{4}$. This raises the equilibrium price to $P_{3}$ and keeps the equilibrium quantity at the desired $Q_{2}$.

Shifting the supply curve to left so that the quantity on the (legal and illegal) market equals the amount allowed under a quota system may entail significant enforcement costs. But unlike the case of an Appendix I ban, with a quota system there is potential for obtaining revenues from the trade. In the case of the ban there can be no official revenues because there is no official trade. In the case of quotas there is a potential for official revenues because some trade is allowed. This trade could be taxed and revenues could be used for enforcement or other conservation purposes. Noting that a price of $\mathrm{P}_{2}$ is sufficient to ensure a supply of the $\mathrm{Q}_{2}$ quota, and that consumers are willing to pay a price of $\mathrm{P}_{3}$ for this quantity. The government could tax the difference $\left(\mathrm{P}_{3}\right.$ to $\left.\mathrm{P}_{2}\right)$ and apply this to enforcement and other 
conservation efforts. From this perspective a quota system is more effective than a ban and is likely to be more effective at raising the conservation of the species.

Total revenues derived from a quota system are important in determining how much the government can obtain. Whether total revenues rise or fall depends again on the elasticity of the demand curve. As is depicted in Figure 44, total revenues rise with a very inelastic curves, because $0 \mathrm{P}_{1} \mathrm{X}_{\mathrm{Q}_{1}}$ is less than $0 \mathrm{P}_{2} \mathrm{Y} \mathrm{Q}_{2}$. This means that the government could obtain more revenue from trade after imposing the quota than it could before the quota system was in place. This money may finance enforcement or conservation efforts which improve the conservation status of species. The logic here is the same as the logic behind taxing tobacco and alcohol. Because the demand for these goods is inelastic, the government is likely to gain significant revenues through taxing them.

On the other hand, the total revenue in the case of an elastic demand curve will fall with the introduction of the quota (see Figure 45) because $0 \mathrm{P}_{1} \mathrm{X} \mathrm{Q}_{1}$ is greater than $0 \mathrm{P}_{2} \mathrm{Y} \mathrm{Q}_{2}$. This means that the government is not able to obtain as much funding from the trade and therefore is more likely to lose money on enforcement efforts. The case for using quotas is stronger for a good which has an inelastic demand than for a good which has an elastic demand.

Elasticities also tell a story about the costs of reducing quantity traded. For instance to reduce the quantity traded by five units of a species will cost more in the case of an inelastic demand curve than in an elastic demand curve. This is because the shift of the supply curve involved in reducing the quantity traded with an inelastic demand will be greater than the shift in the supply curve with an elastic demand.

A second option open to governments for reducing illegal trade is to influence the demand for the good. As is depicted in Figure 46, changing consumer tastes shifts the demand curve from $D_{1}$ to $D_{2}$, which results in a fall in the equilibrium quantity from $\mathrm{Q}_{1}$ to $\mathrm{Q}_{4}$. For illegal demand to be completely snubbed out the demand curve must be shifted to $\mathrm{D}_{3}$ so that it meets the supply curve at the set quota $\left(\mathrm{Q}_{2}\right)$. But by shifting the demand curve for the species under a quota, the government gives up the opportunity to collect revenue. Thus the expenditures for influencing demand are not met by an opportunity for increased revenues.

Of course, these options of shifting demand and supply do not pose an 'either/or' scenario for governments. Shifting the demand and supply curves simultaneously results in a fall in the equilibrium quantity. The most efficient way to address illegal trade may very well be a combination of enforcement and public education. However, the CITES approach does not usually address the demand for the good but - as is evident from this analysis - shifting the demand curve is potentially a useful tool for increasing the effectiveness of quotas.

\subsubsection{Split-listing}


Under Article I (a) of CITES "species means any species, subspecies, or geographically separate population thereof". This definition allows for split-listing, which means that certain populations of one species could be listed in one Appendix and other populations of the same species on another Appendix. In some cases this flexible mechanism allows for commercial trade in species which before was prohibited and in these cases it can function as an incentive for the active management of populations. With Resolution 9.24 (Annex 3), the Parties resolved that listing a species in more than one Appendix should be avoided due to the enforcement problems it creates. In the case that split-listing is agreed, this should generally be based on national or continental populations, rather than subspecies.

Applying the demand and supply analysis to split-listing involves a similar technique to that used for ranching operations and captive breeding, because split-listing effectively divides a species into populations which compete as substitute goods. The analysis in 6.4.1 describes the effectiveness of split-listing a population to a less restrictive trade status - from Appendix I to Appendix II (downlisting). The analysis in section 6.4.2 assesses the effectiveness of up-listing a species population from Appendix II to I.

\subsubsection{Transfer from Appendix I to Appendix II}

Figure 47 depicts two graphs - the left-hand graph represents trade in the Appendix I listed population and the right-hand graph represents trade in the Appendix II population of the same species. It is assumed that there is some illegal trade in the Appendix I listed species (i.e. partial enforcement) therefore the supply curve is $S_{1}$. With the transfer to Appendix II of one population of the species the supply curve for the illegally traded populations shifts to the left - to $S_{2}$ because one of the suppliers falls out of the illegal market. This results in a fall of equilibrium quantity and price to $\mathrm{Q}_{2}$ and $\mathrm{P}_{2}$ in the Appendix I market. The demand curve also may shift to the left to $\mathrm{D}_{2}$ because of the preference for legal goods. Thus the equilibrium quantity falls ultimately to $\mathrm{Q}_{3}$ and the equilibrium price falls to $\mathrm{P}_{3}$.

On the side of the Appendix II listed population, trade is legal. The demand for the legal good may shift to the right because of the 'green good' effect (i.e. formerly suppressed demand enters the market). This raises the equilibrium price to $\mathrm{P}^{*} 2$ and the equilibrium quantity to $\mathrm{Q}^{*} 2$ on the legal market. Tracing this higher legal price over to the illegal market's price axis there may be a significant differential between the legal and illegal equilibrium prices. This could create a price pressure which may expand the illegal market.

One interesting aspect of split-listing is its effect on the conservation status of the two populations of the same species. Figure 48 depicts the two populations as separate circles. The two circles are isolated because the two populations must be isolated geographically for them to be split-listed. Split-listing the species creates an opportunity for governments to obtain revenue from commercial trade of the downlisted population. If these revenues are used for conservation for that population then the status of that population of the species is likely to improve - represented in Figure 48 by concentric circles around the down-listed (Appendix II) population. This results in a shift to the right of the supply curve of the downlisted population because the input costs fall. This results in a fall in the equilibrium price which reduces the price pressure on the illegal market. 
It is important to note, however, that while the status of the down-listed population is improving, there are no revenues generated to improve their conservation status of the Appendix I population. Thus while the conservation status of the down-listed population may improve, the conservation status of the more endangered or at risk population may not benefit from the down-listing process. Thus perversely, splitlisting may not improve the status of the most threatened population.

\subsubsection{Transfer from Appendix II to Appendix I}

In the case of moving one population from Appendix II to I (up-listing) there is essentially a single market for the species prior to the transfer. As depicted in Figure 49 the transfer of one population to a more protective trade status results in a shift to the left of the Appendix II supply curve to $\mathrm{S}_{2}$, because there are fewer species to trade (i.e. input costs rise). This increases the equilibrium price to $\mathrm{P}_{2}$ thereby creating pressure for an illegal market in Appendix I species. Again, the demand curve shifts to the left to $\mathrm{D}_{2}$ because of the preference not to buy illegal goods. This results in a fall of the equilibrium price to $\mathrm{P}_{3}$ which reduces pressure for the illegal market. As in the case of down-listing, the split-listing will not provide new revenues for the conservation of the more threatened population.

\subsubsection{Annotations}

Annotations are effectively a mechanism for tailoring the package of trade and innovative measure for a listed species. An annotation can be given to a species already listed in Appendix I, II, or III or to a species that is being added to any of the Annexes. The annotation may be comprised of any one of or any combination of the measures so far discussed. For example, the African elephant annotation in the split-listing discussion at COP 10 (June 1997) is very specific and includes details on: which uses are applicable for each country with a down-listed population (for instance, Zimbabwe is the only country which can export hides); the time at which trade in ivory can be resumed (18 March 1999); and the countries which are allowed to import (Japan).

On the other hand, the annotation for the hairy armadillo establishes this species as an Appendix II listed species with a zero annual export quota. The variety of applications for annotations means that no single analysis can be completed for the annotations mechanism. Rather, an analysis needs to be conducted for individual annotations. It could be based on the analyses conducted thus far. The case of the White rhino given below demonstrates such an approach.

\subsubsection{Trade in Live Specimens and Hunted Trophies of Southern White Rhinos in South Africa}

A demand and supply analysis of the case of the white rhino requires three graphs because there are effectively three markets - (i) the legal market for live rhinos and trophies from white rhinos from South Africa; (ii) the illegal market for parts from white rhinos from South Africa; (iii) the illegal trade in any goods derived from white rhinos in other range states. 
These markets are interdependent and are displayed in Figure 50. The introduction of the annotation (i.e. legal trade) for South Africa is expected to increase the number of white rhinos in South Africa by encouraging more land-owners to stock the species. The positive nature of the measure is intended to ensure that few rhinos reach the illegal market and it could be argued that the supply curve for the illegal trade in parts of white rhinos from South Africa to will shift to the left, to $\mathrm{S}_{2}$. This results in a lower equilibrium quantity of $\mathrm{Q}_{2}{ }_{2}$ and higher equilibrium price of $\mathrm{P}_{2}$. Tracing this new equilibrium price $\left(\mathrm{P}^{*}{ }_{2}\right)$ over to the illegal market in other range states it is clear that at this price suppliers in that market are willing to supply $\mathrm{Q}_{2}$. If this price increase is significant, it could result in an increased incentive for that illegal market. However, the illegal trade in South Africa has always been low relative to that in other parts of Africa and it seems that countries such as South Africa, Zimbabwe and Kenya where rhinos are closely guarded cannot be accused of fuelling illegal trade elsewhere as a result of their currently effective protection efforts.

Going back to the legal trade in live white rhinos or trophies, the South African government is able to derive some revenue from the total revenue $\mathrm{P}_{1} \mathrm{Q}_{1}$. This revenue could go into increased enforcement or other conservation measures. Yet the annotation increases pressure for illegal trade in the other range States where the governments are unable to derive any revenues for increased enforcement costs. So while the conservation status of the species in South Africa may very well improve because of the annotation, the status of the species in other populations could be hindered by the annotation.

\subsection{Financial Contributions and Technical Co-operation}

Financial contributions and technical co-operation are important innovative measures because they promote adherence to and implementation of the Convention - in the sense that they make it possible for countries to implement the Convention.

The first major financial innovation arose in 1978 as CITES faced a financial crisis which resulted from the UNEP Governing Council's decision to phase out financial support for CITES. This led to an amendment of Article XI conferring financial powers to the COP and permitting the establishment of a special CITES Trust Fund with a current annual budget of approximately US\$ 4 million.

Besides the regular contributions to the CITES Trust Fund, the CITES Secretariat received US\$ 4 million external contributions from 33 donors during the period of October 1994 to December 1996. Approximately half of this was spent on species-related projects (i.e. species surveys in the context of the significant trade review) and the remaining amount was spent on routine activities such as capacity building, enforcement and support to technical committees. All together 54 projects were carried out. From this fund approximately half was allocated to Africa and the remaining was spent to support other projects of global importance.

Additionally, CITES relies on bilateral and multilateral funds. As noted by the OECD study (1997) "bilateral aid flowing to projects directly related to CITES implementation has been relatively small". However several donors, both official and private, have contributed substantial financial and technical 
assistance directly to the range states through projects such as public education and outreach, population studies, or more generally related to wildlife trade (i.e. anti-poaching and institution building efforts).

There is limited multilateral funding for CITES. OECD (1997) notes, that "apart from one or two projects, CITES has not benefited from multilateral financial and technical assistance, despite calls to international aid agencies in general by the COPs to support Convention related activities (e.g. on tigers in Resolution Conf. 9.13) or the GEF in particular (i.e. Resolution Conf. 9.2 which "invites all Parties to support, through their representatives in UNEP, UNDP and the World Bank...for additional funding of CITES projects by the Global Environment Facility"). The sole GEF financed project (with technical support from CITES Secretariat, TRAFFIC and WWF) is in Gabon and it aims to involve local communities in the monitoring of wildlife and consequently assess the impact of trade on these species in order to develop sustainable trade strategies. Its emphasis lies on assigning economic value to the species and provide economic incentives for their long term survival.

In addition, numerous NGOs have provided financial and technical assistance to the CITES Parties over the years.

\subsection{Sanctions}

Sanctions are used as a measure to encourage Parties to enforce and implement CITES and have been applied to Parties for non-compliance with CITES. In short, under sanctions a Party can lose its right to trade in one or several species. This is effectively a split-listing where those species are subject to an uplisting for the sanctioned country. Therefore the economic analysis follows the up-listing analysis.

\subsection{Reservations}

A reservation allows Parties who do not agree with an amendment or listing to opt out of its enforcement. A Party may enter a reservation to conduct trade in any species included in Appendix I, II, or III. In such cases, trade with this Party is treated like trade with a non-Party. Reservations are usually used by Parties to make a point that the listing of the species does not qualify biologically or legally. Due to the large number of signatories to CITES there are now only a limited number of nonParties that a Party adopting a reservation could easily trade with.

In the case of a reservation for an Appendix I species, the economic analysis would be similar to that of the down-listing version of split-listing where the left hand graph represents a ban and the right hand graph represents legal trade with non-Parties. The reservation analysis differs from the down-listing analysis in that there is no shift to the right of $\mathrm{D}^{*} 1$ (see Figure 51) because there is no green good effect since the species is listed by all other Parties in Appendix I. Therefore there is no price pressure for an illegal market. Additionally the government with the reservation can collect revenues from the legal trade 
and these revenues could be invested in conservation which may in the end shift the supply curve to the right to $S^{*} 2$. This results in an even lower price for the good which may alleviate the illegal market.

\section{ECONOMIC IMPACT ANALYSIS OF CITES}

There are currently 143 signatories to CITES, thus there must be some incentive for being a Party to CITES. This section uses a benefit-cost approach to assess the feasibility of implementing CITES from a Party perspective and points out the benefits and costs to a country signing and enforcing the Convention.

\subsection{The Benefits of Being a Party}

The benefits of the Convention stem partly from the value of the species conserved, but also from the ability to influence international trade in species, possible reduced costs in enforcement, and the value of international co-operation. In addition to these benefits there is also the consideration of aid provided through financial contributions and technical co-operation which was addressed in section 6.

Measuring the benefits derived from the value of the species requires a systematic and thorough approach. Total valuation is the assessment of the total economic contribution, or net benefits, to society of the species (Barbier, Acreman, and Knowler 1997). Total economic valuation is a method of measuring all of the values an individual, group, or society hold for a species. Further information on total economic valuation is available in most environmental economic texts including Economics of Natural Resources and the Environment by David Pearce and Kerry Turner (1990).

In addition to benefits resulting from the use or non-use values of the species, there are benefits inherent to the Convention process which accrue to Parties. One such benefit relates to the value of influencing the process of determining where species are listed (i.e. Appendices I, II, or III) and therefore which trade measures they are subject to. The value of this benefit can be measured by determining the value of trade, which occurs as a result of signing the Convention. It is important to note that this benefit exists largely because non-Parties no longer have influence over their own trade in endangered species because of the significant membership to the Convention. Additionally, it is worthwhile noting that pressure to join CITES may arise from the interest of private sector members who wish to embark on trade of a species .

In addition to the benefit of maintaining the value of species, Parties may also gain from the Convention through reduced enforcement costs. A major incentive to co-operate internationally to regulate trade, 
must be that this reduces enforcement costs is some instances. For example for Appendix I listed species it could be argued that by making all commercial trade in such species illegal, the enforcement costs may be reduced as differentiation between legal and illegal trade is no longer problematic.

\subsection{The Cost of Being a Party}

The costs of being a Party to the CITES Convention can be broadly divided into two groups for the purposes of this paper. First, there are the costs of implementing and enforcing the Convention. Second, there are the costs involved in foregoing income from trade prohibited by the Convention.

\subsubsection{Costs of Implementing and Enforcing the Convention}

A Party shoulders numerous costs in implementing and enforcing the Convention. These are referred to often throughout the demand and supply analyses in Sections 6.3 and 6.5 and are discussed in more detail in this section. Article VIII and IX stipulates the minimum conditions of being a Party. Under these conditions a Party is required to designate a Management and Scientific Authority, prohibit inappropriate trade, design legislation for these prohibitions, maintain records, and prepare reports. These requirements are developed in more detail in Box 3.

With these minimum conditions it is possible to estimate the lowest direct cost implications resulting from being a Party. The costs involved will vary, however, from country to country depending on many factors including how many listed species exist in the country, or if the country is predominately an exporting, conduit, or importing country. In general, biodiversity-rich countries (e.g. Tanzania) are likely to have higher costs on the supply side of regulating international trade while 'taste diverse' countries (e.g. China) are likely to have higher costs on the demand side of regulating international trade. Further, because of the structure of international transport systems, (e.g. the importance of Johannesburg International Airport on limiting African supply to Asian demand), some countries will have large conduit costs irrespective of the place in either the demand or supply of the listed species.

However, it is important to note that although CITES places a large number of requirements on countries, many of these institutions and the requirements for legislation and enforcement would be necessary for any country wishing to manage its wildlife estate without the benefits of international cooperation, which CITES brings.

\subsubsection{The Cost of Foregoing Income from Trade}

In addition to the direct costs of implementing and enforcing the Convention, there are secondary costs of lost revenues from trade. These costs are referred to throughout the demand and supply analyses and are examined here in more detail measure by measure. However, it should be remembered that whilst lost trade revenue will penalise countries which have managed that resource successfully, the countries whose biodiversity is under threat should actually benefit from a short term loss of trade revenue, by being able to re-build their wildlife populations. 


\subsubsection{Bans}

As pointed out earlier, a ban in trade of an Appendix I listed species results in a loss of potential revenue for the government but entails significant costs in enforcement. This may result in the reduction of other conservation efforts in the country. Working with limited resources, those wildlife departments face a trade off between enforcement and other conservation efforts. Similar trade-offs face customs departments on monitoring the illegal trade of wild species and other goods such as narcotics and weapons. A study of wildlife department and customs budgets could reveal how these trade-offs are addressed on the ground and could assess whether enforcement budgets impinge on conservation budgets. Alternatively, by opting for international co-operative action a wildlife department may reduces its enforcement costs relative to what it would have had to spend to enforce its national legislation in the absence of international co-operation. Such a study may find that some Parties pay for enforcement through their customs or military budgets, in which case it is unlikely that increased enforcement costs will result in lower conservation or other activities spending.

\subsubsection{Export-Import Permits}

Generally, most governments appear to shoulder the majority of the costs of awarding export and import permits, but governments could charge for the permit and thereby obtain revenue from the process. The pricing system could be set up so that the price of the permits reflects the costs of establishing the non-detrimental status of the specimen. This means that the price of the permits could be used to cover overhead costs of periodically assessing the status of the species, establishing and maintaining databases, and paying an individual or individuals to conduct the paperwork involved in issuing the permit.

Additionally, the price of the permit could be used as a method of rationing the permits. When there is a shortage in a good (in this case a permit), the distributor must decide who is given the opportunity to buy it. This they can do on a first-come first-serve basis or through favouritism or discrimination. None of these is an efficient method of distribution. By allowing the permits to carry a price the distributor (government) could auction the permits to the highest bidders. Thus the government would obtain the highest possible revenues. Another source of revenue for governments is through custom taxes levied on fauna and flora.

From an economic perspective it would be inefficient not to collect these revenue because those who gain from the permit (i.e. the importers) are willing to pay for the services. But because they do not share any costs for the permit, they may ask for more permits than is economically efficient. The counter argument for this is that if the government started selling the permits rather than giving them away, there may be incentive to distribute more permits than is non-detrimental. But this incentive still exists without selling the permits (because importers are willing to pay for the permits) but it is driven onto a black market.

\subsubsection{Export Permits}


The export permit process for an Appendix II listed species is similar to the export-import process of an Appendix I species. So again there is the possibility of earning revenue from the trade through the pricing of permits, and this is increasingly becoming the practice.

\subsubsection{Quotas}

A government can still earn revenues for conservation and enforcement with a quota system but whether those revenues rise or fall depends on the price elasticity of demand. As is discussed in Section 6.3 and depicted in Figures 23 and 24, total revenues rise with an inelastic demand curve and fall with an elastic demand curve. Therefore the government could collect more revenues by placing a quota on a good which has a very inelastic demand, but would not be able to collect as much by placing a quota on a good with an elastic demand.

\subsection{2..5 Captive Breeding}

Captive breeding also allows governments to collect revenues for conservation and enforcement. Again this can be done through a charge for the permits involved or through a tax on the good as it leaves the country. The tax revenues are proportional to the amount of total revenues derived from the industry and therefore would rise with the 'green good' effect on demand displayed in Figure 26.

\subsection{2..6 Ranching}

Ranching provides a similar scenario to captive breeding for government revenues but government expenditures on conservation efforts may be eased by a ranching scheme. This is because ranchers have incentives to maintain more habitat and therefore embark on conservation efforts of their own. Thus, in theory, more of the government revenues could be shifted to enforcement to address the shift to the right of the supply curve depicted in Figure 40 which results from lower input costs for illegal traders.

\subsubsection{Split-Listing}

Down-listing a population of a species from Appendix I to II results in the opening of a market for one region. This allows the government in that region to obtain revenues from the trade in the species but keeps other regions from obtaining revenues. The result is likely to be increased investment in conservation and enforcement efforts in the region where the species already has a better conservation status. Up-listing a population of the species results in the closure of one region's market while the other regions' markets remain open. This would have the same effect on the conservation efforts of the populations.

\subsection{2..8 Appendix III Listing}

An Appendix III listing has some interesting connotations for government revenues. The Party listing the species essentially imposes enforcement costs on the other countries. This is because other Parties are required to check imports of an Appendix III listed species to determine if they originated from the country listing the species. Additionally, of course, the country is subjecting trade in this species to an export permit process which carries the same implications for revenues as the Appendix II listing.

\subsubsection{Annotations}


Annotations provide the opportunity for tailoring the measures under the Convention to the situation of the species. Therefore they may or may not provide the opportunity to obtain revenues through charges for the permit process and through taxes on the total revenues in the trade. The analysis for these costs and benefits would have to be done for each annotation individually. Annotations can turn the treaty into a more effective and efficient mechanism because they allow each case to be handled individually.

In summary, even through CITES does not focus on the economic implications of its trade and innovative measures, these measures do have financial implications. If managed properly, some of the measures can be applied in a manner that will generate revenues for administering CITES and even to finance other conservation activities. Other measures, however, imply significant costs with little chance for collecting revenues. More attention to the financial implications of the various measures is needed to ensure that the costs of being a Party to CITES are not perceived to exceed the benefits. 


\section{Bibliography}

't Sas-Rolfes, M.J. (1990). Privatising the rhino industry. Free Market Foundation Paper, No 900501: 1-42.

't Sas-Rolfes, M.J. (1995). Rhinos: Conservation, Economics and Trade-Offs. Institute of Economic Affairs, London.

Adcock, K. and Emslie, R.H. (1994). The role of trophy hunting in white rhino conservation, with special reference to Bop parks. In: Rhinos as Game Ranch Animals (Ed. B.L. Penzhorn and N.P.J. Kriek), pp. 35-41. South African Veterinary Association, Onderstepoort.

Anderson, J.L. (1993). Management of translocated white rhino in South Africa. Zoological Society of San Diego, San Diego.

Anon. (1977). Proceedings of the first meeting of the Conference of the Parties. Report to Secretariat, Convention on International Trade in Endangered Species of Wild Fauna and Flora.

Anon. (1978). The international trade in Felidae 1977. In: 1978 Annual Report of the CITES Secretariat (Ed. pp. 264-293. CITES Secretariat, Lausanne.

Anon. (1980). Proceedings of the second meeting of the Conference of the Parties. Report to Secretariat of the Convention, Convention on International Trade in Endangered Species of Wild Fauna and Flora.

Anon. (1982). Proceedings of the third meeting of the Conference of the Parties. Report to Secretariat of the Convention, Convention on International Trade in Endangered Species of Wild Fauna and Flora.

Anon. (1984). Proceedings of the fourth meeting of the Conference of the Parties. Report to Secretariat of the Convention, Convention on International Trade in Endangered Species of Wild Fauna and Flora.

Anon. (1986). Proceedings of the fifth meeting of the Conference of the Parties. Report to Secretariat of the Convention, Convention on International Trade in Endangered Species of Wild Fauna and Flora.

Anon. (1989). Proceedings of the sixth meeting of the Conference of the Parties. Report to Secretariat of the Convention, Convention on International Trade in Endangered Species of Wild Fauna and Flora. 
Anon. (1991). Proceedings of the seventh meeting of the Conference of the Parties. Report to Secretariat of the Convention, Convention on International Trade in Endangered Species of Wild Fauna and Flora.

Anon. (1994). Proceedings of the eighth meeting of the Conference of the Parties. Report to Secretariat of the Convention, Convention on International Trade in Endangered Species of Wild Fauna and Flora.

Anon. (1996). Proceedings of the ninth meeting of the Conference of the Parties. Report to Secretariat of the Convention, Convention on International Trade in Endangered Species of Wild Fauna and Flora.

Barbier, Edward, Joanne Burgess, Timothy Swanson \& David Pearce. (1990). Elephants, Economics and Ivory. London: Earthscan Publications Ltd.

Batchelor, Anne (1988). The Preservation of Wildlife Habitat in Ecosystems: Towards a New Direction under International Law to Prevent Species Extinction. Florida International Law Journal, volume 3/3, p. 307-339.

Barnes, James I. (1996). Changes in the Economic Use Value of Elephants in Botswana: The Effect of International Trade Prohibition. Ecological Economics, volume 18/3, p. 215-230.

Bodmer, R.E. (1996). Oryx,

Bräutigam, Amie (1989). CITES: A Conservation Tool: A Guide to Amending the Appendices to the Convention on International Trade In Endangered Species of Wild Fauna and Flora. Washington: IUCN / SSC Trade Specialist Group.

Burgess, Joanne C. (1994). The Environmental effects of Trade in Endangered species. In Organisation for Economic Cooperation and Development, The Environmental Effects of Trade. Paris: OECD.

Burton, John A. (1981). Comments on the Annual Report by the Federal Republic of Germany on its Implementation of CITES. TRAFFIC Bulletin, volume 3/3, p. 36-40.

Burns, William C. (1990). CITES and the Regulation of International Trade in Endangered Species of Flora: A Critical Appraisal. Dickinson Journal of International Law, volume 8/2, p. 203223.

Caro, T.M. (1994). Cheetahs of the Serengeti Plains. Chicago University Press, Chicago. 
Caro, T.M. and Laurenson, K. (1994). Ecological and genetic factors in conservation: a cautionary tale. Science, 263: 485-486.

CITES (1997). CITES Training Seminar South Africa: Participants' Manual. Geneva: CITES Secretariat.

CITES (1997). Press Kit: Tenth Conference of the Parties to CITES. Geneva: Secretariat of CITES

CITES (1997). Review of the Proposals Submitted by Botswana, Nambia and Zimbabwe to Transfer their National Populations of Loxodanta Africana from CITES Appendix I to Appendix II. Report of the CITES Panel of Experts on the African Elephant Geneva: CITES Secretariat.

CITES (1996). Proceedings of the Ninth Meeting of the Conference of the Parties. Geneva: Secretariat of CITES.

CITES (1996). Review of Significant Trade in Animal Species Included in CITES Appendix II: Detailed Reviews of 24 Species. Final Report to the CITES Animals Committee. TRAFFIC.

CITES (1994). Review of Alleged Infractions and Other Problems of Implementation of the Convention. Report of the Secretariat. CITES Doc. 9.22 .

Clark, C.W. (1976). Mathematical Bioeconomics: the optimal management of renewable resources. Wiley, New York.

Clutton-Brock, T.H. and Harvey, P.H. (1977). Primate ecology and social organisation. Journal of Zoology, 183:

Collar, N.J., Crosby, M.J. and Stattersfield, A.J. (1994). Birds to Watch 2: the World List of Threatened Birds. Birdlife International, Cambridge.

Contini, Paolo \& Sand, Peter H. (1972). Methods to Expedite Environment Protection: International Ecostandards. American Journal of International Law, volume 66/1, p. 37-59.

Craig, G.C., Gibson, D.St.C. and Hutton, J.M. (1992). A population model for the Nile crocodile and simulation of different harvesting strategies. In: The CITES Nile Crocodile Project (Ed. J.M. Hutton and I. Games), pp. 1-52. CITES Secretariat, Lausanne, Switzerland.

Crawford, Allan (1997). Making CITES Work: Examples of Effective Implementation and Enforcement. A Traffic Network Report. Cambridge: TRAFFIC. 
Cumming, D.H.M., du Toit, R.F. and Stuart, S.N. (1990). African Elephants and Rhinos: Status Survey and Conservation Action Plan. International Union for Conservation of Nature and Natural Resources, Gland, Switzerland.

Department of Wildlife. (1993). Policy for crocodile management and a management plan for the Nile crocodile in Tanzania. Department of Wildlife, Dar es Salaam.

Diamond, J. (1989). Overview of recent extinctions. In: Conservation for the Twenty-first Century (Ed. D. Western and M. Pearl), pp. 37-41. Oxford University Press, New York.

Dublin, H.T., Milliken, T. and Barnes, R.F.W. 1995. Four years after the CITES ban: illegal killing of elephants, ivory trade and stockpiles. Report to IUCN/SSC African Elephant Specialist Group.

Ehrlich, Paul R. \& Ehrlich, Anne H. (1981). Extinction: The Causes and Consequences of Disappearance of Species. New-York: Random House.

Eldridge, Kevin (1995). Whale for Sale? New Developments in the Convention on International Trade in Endangered Species of Wild Fauna and Flora. Georgia Journal of International and Comparative Law, volume 24/3 p. 549-565.

ERM (1996). Study on How to Improve the Effectiveness of the Convention on International Trade in Endangered Species of Wild Fauna and Flora. Geneva: CITES Secretariat.

Favre, David S. (1993). Debate Within the CITES Community: What Direction for the Future? Natural Resources Journal, volume 33/4, p. 875-918.

Fitzgerald, Sarah (1989). International Wildlife Trade: Whose Buisiness is It? Washington DC.: WWF-US. P. 333.

Flemming, Elizabeth H.(1994). The Implementation and Enforcement of CITES in the European Union. Brussels: TRAFFIC Europe.

Fletcher, Charles R. (1996). Greening World Trade: Reconciling GATT and Multilateral Environmental Agreements within the Existing World Trade Regime. Journal of Transnational Law and Policy, volume 5/2, p. 341-372.

Foose, T.J. and van Strien, N. (1997). Asian Rhinos: Status Survey and Conservation Action Plan. International Union for Conservation of Nature and Natural Resources, Gland and Cambridge.

French, Hilary F. (1992). After the Earth Summit: The Future of Environmental Governance. Washington: World watch Institute. World watch Paper No 107. 
Garrison, John L. (1994). The Convention on International Trade in Endangered Species (CITES) and the Debate over Sustainable Use. Pace Environmental Law Review. Volume 12/1.p. 301-329.

Groombridge, B. and Luxmoore, R.A. (1989). The Green Turtle and Hawksbill (Reptilia: Cheloniidae): world status, exploitation and trade. CITES Secretariat, Lausanne.

Grove, Noël (1981). Wild Cargo: The Business of Smuggling Animals. National Geographic Magazine, volume 159/3, pages 287-314.

Hagsater, E. and Dumont, V. (1997). Orchids: Status Survey and Conservation Action Plan. International Union for Conservation of Nature and Natural Resources, Gland and Cambridge.

Hanley (25 July 1983). Illegal Trade in Wildlife Thretens many Species. Hartford Courant.

Heppes, John B. \& McFadden, Eric J. (1987). The Convention on International Trade in Endangered Species of Wild Fauna and Flora: Improving the Prospects for Preserving our Biological Heritage. Boston University International Law Journal, volume 5/2, p. 229-245.

Hill, Kevin D. (1996). Zimbabwe's Wildlife Utilization Programs: Grassroots democracy or an extension of State Power? African Studies Review, volume 39/1, p. 103-122.

Hill, Kevin D. (1990). The Convention on International Trade in Endangered Species: Fifteen years later. Loyola of Los Angeles International and Comparative Law Journal, volume 13/ 2, p. 231278.

Hutton, J.M. and Games, I. (1992). The CITES Nile Crocodile Project. CITES Secretariat, Lausanne.

IATA- International Air Transport Association (1995). Live Animals Regulations. 22nd Edition. Montreal: IATA.

Inskipp, T. \& S. Wells. (1979). International Trade in Wildlife.

IUCN (1995). CITES' Ninth: Exploring New Waters. IUCN Bulletin, number 1/95.

IUCN. (1995). IUCN Red List Categories. International Union for Conservation of Nature and Natural Resources, Gland and Cambridge.

Jenkins, M. and Oldfield, S. (1992). Wild Plants in Trade. TRAFFIC International, Cambridge.

Johnson, K.A. (1989). Global CITES enforcement: any progress? TRAFFIC USA Newsletter, 9 (4): 9-11. 
Joseph, J., Evans, D. and Broad, S. (1986). International trade in Asian Boneytongues. TRAFFIC Bulletin, 7: 73-76.

Klemm, Cyrille de (1993). Guidelines for Legislation to Implement CITES. Cambridge: IUCN Publications Service.

Koford, C.B. (1957). The vicuna and the puna. Ecological Monographs, 27: 153-219.

Koford, C.B. (1976). Latin American Cats: economic values and future prospects. In: The World's Cats 3 (1): contributions to status, management and conservation (Ed. R.L. Eaton), pp. 79-88. Carnivore Research Institute, University of Washington, Seattle.

Leader-Williams, N. (1992). The World Trade in Rhino Horn: a review. TRAFFIC International, Cambridge.

Leader-Williams, N. and Albon, S.D. (1988). Allocation of resources for conservation. Nature, 336: 533-535.

Le Duc, Jean-Patrick (1996). Training: An Investment in the Future. CITES C\&M International Magazine. P.39-41.

Liwo, Karl J. (1990). The Continuing Significance of the Convention on International Trade in Endangered Species of Wild Fauna and Flora during the 1990's. Suffolk Transnational Law Journal, volume 25/1, p.122-152.

Luxmoore, R.A. (1990). Trade and captive breeding of Asian boneytongue in Indonesia. TRAFFIC Bulletin, 11:

Lyster, Simon (1985). International Wildlife Law: An Analysis on International Treaties Concerned with the Conservation of Wildlife. Cambridge: Grotius Publications. IUCN Environmental Policy and Law Paper No 22.

Mack, D. and R.A., M. (1984). The Primate Trade. World Wildlife Fund and TRAFFIC USA, Washington, DC.

Martin, E.B. (1983). Rhino Exploitation: the Trade in Rhino Products in India, Indonesia, Malaysia, Burma, Japan and South Korea. World Wildlife Fund, Hong Kong.

Martin, E.B. and Martin, C.B. (1982). Run Rhino Run. Chatto and Windus, London. 
Martin, E.B., Vigne, L. and Allan, C. (1997). On a Knife's Edge: the rhinoceros horn trade in Yemen. TRAFFIC International, Cambridge.

Martin, R.B. and de Meulenaer, T. (1988). Survey of the Status of the Leopard (Panthera pardus) in sub-Saharan Africa. CITES Secretariat, Lausanne.

Marshall, Nina T. \& Jenkins, Martin (1995). Hard Times for Hardwood: Indigenous Timber and the Timber in Kenya. Cambridge: TRAFFIC East/ Southern Africa.

Matsumura, S. and Milliken, T. (1994). The Japanese trade in boneytongue and CITES-listed fish. TRAFFIC Bulletin, 6: 42-50.

McCracken, C., Rose, D.A. and Johnson, K. (1995). Status, management and commercialization of the American Black Bear (Ursos americanus). TRAFFIC USA and World Widlife Fund, Washinton DC.

McNeely, Jeffrey A. (1990). What Value of Wildlife? IUCN Bulletin, Dec. 1990, at 4.

Messel, Harry and J. Perran Ross (1992). Crocodile Issues at CITES, 18 Species 60, June.

Milliken, T., Nowell, K. and Thomsen, J.B. (1993). The Decline of the Black Rhino in Zimbabwe: implications for future rhino conservation. TRAFFIC International, Cambridge.

Mills, J.A. (1993). Market under Cover: the rhinoceros horn trade in South Korea. TRAFFIC International, Cambridge.

Mills, J.A., Chan, S. and Ishihara, A. (1995). The Bear Facts: the East Asian market for bear gall bladder. TRAFFIC International, Cambridge.

Mills, J.A. and Jackson, P. (1994). Killed for a Cure: a review of the world-wide trade in tiger bones. TRAFFIC International, Cambridge.

Mills, J.A. and Servheen, C. (1991). The Asian Trade in Bears and Bear Parts. TRAFFIC USA and World Wildlife Fund, Washington DC.

Milner-Gulland, E.J. and Leader-Williams, N. (1992). A model of incentives for the illegal exploitation of black rhinos and elephants: poaching pays in Luangwa Valley, Zambia. Journal of Applied Ecology, 29: 388-401.

Mittermeier, R.A., Kinzey, W.G. and Mast, R.B. (1993). Neotropical primate conservation. In: Primates of the Americas: strategies for conservation and sustained use in biomedical research 
(Ed. P. Arambulo, F. Encarnacion, J. Estupinan, H. Samame, C.R. Watson and R.E. Weller), pp. 1128. Battelle Press, Columbus, Richland.

Morsbach, D. (1987). Cheetah in Namibia. Cat News, 6: 25-26.

Mulliken, T.A., Broad, S.R. and Thomsen, J.B. (1992). A global overview of the wild bird trade. In: Perceptions, Conservation and Management of Wild Birds in Trade (Ed. J.B. Thomsen, S.R. Edwards and T.A. Mulliken), pp. TRAFFIC International, Cambridge.

Mulliken, T.A. and Thomsen, J.B. (1995). International trade. In: The Large Macaws: their care, breeding and conservation (Ed. J. Abramson, B.L. Speer and J.B. Thomsen), pp. 484-495. Raintree Publications, Fort Bragg, California.

Myers, N. (1973). The spotted cats and the fur trade. In: The World's Cats 1 (Ed. R.L. Eaton), pp. 276-323. World Wildlife Safari, Winston, Oregon.

Myers, N. (1975). The cheetah Acinonyx jubatus in Africa. IUCN Monograph No. 4, Morges.

Myers, N. (1976). The leopard Panthera pardus in Africa. IUCN Monograph No. 5, Morges.

Myers, Norman (1979). The Sinking Ark: A New Look at the Problem of Disappearing Species. Oxford: Pergamon. P. 18-20.

Nash, Stephen (1994). Making CITES Work: A WWF Report. Goldaming :WWF UK.

Nowell, K., Chyi, W.W.L. and Pei, K.C.J. (1992). The horns of a Dilemma: the market for rhino horn in Taiwan. TRAFFIC International, Cambridge.

Nowell, K. and Jackson, P. (1996). Wild Cats: Status Survey and Conservation Action Plan. International Union for Conservation of Nature and Natural Resources, Gland and Cambridge.

OECD (1997). Joint Session of Trade and Environment Experts: Experience with the Use of Trade Measures in the Convention on International Trade in Endangered Species ( CITES ). Paris: OLIS.

Oldfield, S. (1987). The Western European Trade in Cacti and other Succulents. In: Conservation and Commerce of Cacti and other Succulents (Ed. D. Fuller and S. Fitzgerald), pp. 32-65. TRAFFIC USA and World Wildlife Fund, Washington DC.

Otte, K.C. and Hofmann, R.K. (1981). The debate about the vicuna population in Pampas Galeras Reserve. In: Problems in Management of Locally Abundant Wild Mammals (Ed. P.A. Jewell and S. Holt), pp. 259-289. Academic Press, New York. 
Patel, Shennie (1995). The Convention on International Trade in Endangered Species: Enforcement and the Last Unicorn. Houston Journal of International Law, volume 18/2, p. 157-213.

PAWM. (1996). The bird trade in Tanzania: problems and future outlook. In: The Live Bird Trade in Tanzania (Ed. N. Leader-Williams and R.K. Tibanyenda), pp. 68-81. International Union for Conservation of Nature and Natural Resources, Gland and Cambridge.

Rabinovich, J.E., Capurro, A.F. and Pessina, L.L. (1991). Vicuna use and the bioeconomics of an Andean peasant community in Catamarca, Argentina. In: Neotropical Wildlife Use and Conservation (Ed. J. Robinson and K.H. Redford), pp. 337-358. Chicago University Press, Chicago.

Redford, K.H. and Robinson, J.G. (1991). Subsistence and commercial uses of wildlife in Latin America. In: Neotropical Wildlife Use and Conservation (Ed. J.G. Robinson and K.H. Redford), pp. 6-23. Chicago University Press, Chicago.

Said, M.Y., Chunge, R.N., Craig, G.C., Thouless, C.R., Barnes, R.F.W. and Dublin, H.T. (1995). African Elephant Database 1995. International Union for Conservation of Nature and Natural Resources, Gland and Cambridge.

Schneebaum, D. (1982). The Enforcement of Customary Norms of Public International Laws. 8 Brook. Journal of International Law.

Schonfeld, Alan H. (1985). International Trade in Wildlife: How Effective is the Endangered Species Treaty? California Western International Law Review, volume 15/1, p. 111-128.

Singh, Neena, Sharma, Anju \& Dasgupta, Sumita (1997). In dubios battle: An Ecofascist's last stand at Harare. Down To Earth, volume 6/ 5, pages 36-40.

Sharma, Anju (1997). In Favour of a lesser good. Volume 6/4. Down to Earth from July 151997.

Swanson, Timothy (1997). Global Action for Biodiversity: An International Framework for Implementing the Convention on Biological Diversity. London: Earthscan Publications.

Swanson, Timothy (1996). An Impact Assessment of CITES: A Case Study. Cambridge: Mimeo.

Swanson, Timothy M. (1994). The International Regulation of Extinction . Basingstoke: Macmillan.

Swanson, Timothy M. (1992). The Evolving Trade Mechanisms in CITES. Review of European Community and International Environmental Law. Volume 1/1, p.57-60. 
Thomsen, J.B. and Brautigam, A. (1991). Sustainable use of neotropical parrots. In: Neotropical Wildlife Use and Conservation (Ed. J. Robinson and K.H. Redford), pp. 359-379. Chicago University Press, Chicago.

Thomsen and Bräutigam (1987). CITES in the European Economic Community: Who Benefits? (n.54).

Thorbjarnarson, J. (1992). Crocodiles: An Action Plan for their Conservation. International Union for Conservation of Nature and Natural Resources, Gland and Cambridge.

Topkov, Izgred (1995). Conservation of Wild Fauna and Flora: The New Rules of the Game. CITES C\&M International Magazine. Volume 2/3, p. 6-14.

Topkov, Izgrev (1994). Sustainable Use is the Key. CITES C\&M International Magazine. Volume 1/2. P. 14-17.

Torres, H. (1992). South American Camelids: an action plan for their conservation. International Union for Conservation of Nature and Natural Resources, Gland, Switzerland.

Trexler, M.C. (1990). The Convention on International Trade in Endangered Species of Wild Fauna and Flora: Political or Conservation Success? Ann Arbour (Michigan): Dissertation Information Service.

UNEP (1995). The Use of Trade Measures in Select Multilateral Environmental Agreements. Environment and Trade Number 10. Washington: CIEL.

United States General Accounting Office (1992). International Environment: International Agreements are not well Monitored. Washington : GAO. P. 23-28.

Upton, Andrew F. (1995). The Big Green Stick: Reducing International Environmental Degradation through U.S. Trade Sanctions. Boston College Environmental Affairs Law Review, Volume 22/3, p. 671-692.

Yamin, Farhana \& Gualdoni, Annabella L (1996). A Case Study of a Regional Approach to Compliance with CITES in Southern Africa. In: James Cameron, James Werksman \& Peter Roderick. Improving Compliance with International Environmental Law. London: Earthscan.

Welsh, Hubertus (1984). CITES: Trade in Appendix I Species. Environmental Policy and Law, volume 13 /3-4, p. 100-105. Holland: Elsevier Science Publishers B.V.

Wolfheim, G. (1983). Primates of the World. University of Washington Press, Seattle WA. 
Wolfrum, Rüdiger (1996). Enforcing Environmental Standards: Economic Mechanisms as Viable Means?. Heidelberg: Springer. P. 413-450.

Wijnstekers, Willem (1995). The Evolution of CITES: A Reference to the Convention on International Trade in Endangered Species of Wild Fauna and Flora. Geneva: CITES Secretariat.

Zimbabwe Wildlife (1997). Pressure Mounts against Zimbabwe as CITES Countdown Starts. Zimbabwe Wildlife from April-June 1997, p. 20. 


\section{ANNEX 1.}

\section{TABLE OF SIGNATORIES AND PARTIES}

The following table lists Parties by geographic region:

STATE

SIGNATURE

INSTRUMENT/

ENTRY INTO FORCE

DEPOSIT

Group I: SOUTH AMERICA

$\begin{array}{lccc}\text { Argentina } & 03.03 .1973 & \mathrm{R} / 08.01 .1981 & 08.04 .1981 \\ \text { Bolivia } & 23.12 .1974 & \mathrm{R} / 06.07 .1979 & 04.10 .1979 \\ \text { Brazil } & 03.03 .1973 & \mathrm{R} / 06.08 .1975 & 04.11 .1975 \\ \text { Chile } & 16.09 .1974 & \mathrm{R} / 14.02 .1975 & 01.07 .1975 \\ \text { Colombia } & 04.06 .1973 & \mathrm{R} / 31.08 .1981 & 29.11 .1981 \\ \text { Ecuador } & 12.12 .1974 & \mathrm{R} / 11.02 .1975 & 01.07 .1975 \\ \text { Paraguay } & 30.04 .1973 & \mathrm{R} / 15.11 .1976 & 13.02 .1977 \\ \text { Peru } & 30.12 .1974 & \mathrm{R} / 27.03 .1975 & 25.09 .1975 \\ \text { Uruguay } & 09.01 .1974 & \mathrm{R} / 02.04 .1975 & 01.07 .1975 \\ \text { Venezuela } & 03.03 .1973 & \mathrm{R} / 24.10 .1977 & 22.01 .1978 \\ \text { Surinam } & \mathrm{X} & \mathrm{A} / 17.11 .1980 & 15.02 .1981\end{array}$

Group II: CENTRAL AMERICA

$\begin{array}{llll}\text { Antigua y Barbuda } & \mathrm{X} & \mathrm{A} / 07.08 .1997 & 06.10 .1997 \\ \text { Bahamas } & \mathrm{X} & \mathrm{A} / 20.06 .1979 & 18.09 .1979\end{array}$




\begin{tabular}{lllll} 
Barbados & $\mathrm{X}$ & $\mathrm{A} / 09.12 .1992$ & 09.03 .1993 \\
Belize & $\mathrm{X}$ & $\mathrm{T} / 19.08 .1986$ & 21.09 .1981 \\
Costa Rica & 03.03.1973 & $\mathrm{R} / 30.06 .1975$ & 28.09 .1975 \\
Cuba & $\mathrm{X}$ & $\mathrm{A} / 20.04 .1990$ & 19.07 .1990 \\
Dominica & $\mathrm{X}$ & $\mathrm{A} / 04.08 .1995$ & 02.11 .1995 \\
Dominican Republic & $\mathrm{X}$ & $\mathrm{A} / 17.12 .1986$ & 17.03 .1987 \\
El Salvador & $\mathrm{X}$ & $\mathrm{A} / 30.04 .1987$ & 29.07 .1987 \\
Guatemala & $\mathrm{O} .03 .1973$ & $\mathrm{R} / 07.11 .1979$ & 05.02 .1980 \\
Guyana & $\mathrm{X}$ & \multicolumn{4}{c}{$\mathrm{A} / 25.05 .1977$} & 25.08 .1977 \\
Honduras & $\mathrm{X}$ & $\mathrm{A} / 15.03 .1985$ & 13.06 .1985 \\
Jamaica & $\mathrm{X}$ & $\mathrm{A} / 24.03 .1997$ & 22.06 .1997 \\
Mexico & $\mathrm{X}$ & & $\mathrm{A} / 02.07 .1991$ & 30.09 .1991 \\
Nicaragua & $\mathrm{X}$ & $\mathrm{A} / 06.08 .1977$ & 04.11 .1977 \\
Panama & 03.03.1973 & $\mathrm{R} / 17.08 .1978$ & 15.11 .1978 \\
St. Kitts \& Nevis & $\mathrm{X}$ & $\mathrm{A} / 14.02 .1994$ & 15.05 .1994 \\
St. Lucia & $\mathrm{X}$ & $\mathrm{A} / 15.12 .1982$ & 15.03 .1983 \\
St. Vincent & $\mathrm{X}$ & $\mathrm{A} / 30.11 .1988$ & 28.02 .1989 \\
Trinidad y Tobago & $\mathrm{X}$ & $\mathrm{A} / 19.01 .1984$ & 18.04 .1984
\end{tabular}

Group III: NORTH AMERICA

$\begin{array}{llll}\text { Canada } & 02.07 .1974 & \mathrm{R} / 10.04 .1975 & 09.07 .1975\end{array}$

United States $\quad$ 03.03.1973 $\quad \mathrm{R} / 14.01 .1974 \quad 01.07 .1975$

Group IV: AFRICA

$\begin{array}{llrl}\text { Algeria } & \mathrm{X} & \mathrm{A} / 23.11 .1983 & 21.02 .1984 \\ \text { Benin } & \mathrm{X} & \mathrm{A} / 28.02 .1984 & 28.05 .1984 \\ \text { Botswana } & \mathrm{X} & \mathrm{A} / 14.11 .1977 & 12.02 .1978 \\ \text { Burkina Faso } & \mathrm{X} & \mathrm{A} / 13.10 .1989 & 11.01 .1990 \\ \text { Burundi } & \mathrm{X} & \mathrm{A} / 08.08 .1988 & 06.11 .1988 \\ \text { Cameroon } & \mathrm{X} & \mathrm{A} / 05.06 .1981 & 03.09 .1981 \\ \text { Central African } & & & \\ \text { Republic } & \mathrm{X} & \mathrm{A} / 27.08 .1980 & 25.11 .1980 \\ \text { Chad } & \mathrm{X} & \mathrm{A} / 02.02 .1989 & 03.05 .1989 \\ \text { Côte d'Ivoire } & \mathrm{X} & \mathrm{A} / 21.11 .1984 & 19.02 .1995 \\ \text { Comoros } & \mathrm{X} & \mathrm{A} / 23.11 .1994 & 21.02 .1995 \\ \text { Congo } & \mathrm{X} & \mathrm{A} / 31.01 .1983 & 01.05 .1983 \\ \text { Djibouti } & \mathrm{X} & \mathrm{A} / 07.02 .1992 & 07.05 .1995 \\ \text { Egypt } & 07.06 .1974 & \mathrm{~A} / 04.01 .1978 & 04.04 .1978 \\ \text { Equatorial Guinea } & \mathrm{X} & \mathrm{A} / 10.03 .1992 & 08.06 .1992\end{array}$




\begin{tabular}{|c|c|c|}
\hline Ethiopia & $X$ & A/05.04.1989 04.07.1989 \\
\hline Eritrea & $\mathrm{X}$ & $\mathrm{A} / 24.10 .199422 .01 .1995$ \\
\hline Gabon & $X$ & $\mathrm{~A} / 13.02 .198914 .05 .1989$ \\
\hline Gambia & $X$ & $\mathrm{~A} / 26.08 .1977 \quad 24.11 .1977$ \\
\hline Ghana & 16.12.1974 & $\mathrm{R} / 14.11 .1975 \quad 12.02 .1976$ \\
\hline Guinea & $\mathrm{X}$ & $\mathrm{A} / 21.09 .1981 \quad 20.12 .1981$ \\
\hline Guinea-Bissau & $\mathrm{X}$ & A/16.05.1990 14.08.1990 \\
\hline Kenya & 30.04 .1973 & $\mathrm{R} / 13.12 .1978 \quad 13.03 .1979$ \\
\hline Lesotho & 17.07.1974 & $\begin{array}{ll}X & X\end{array}$ \\
\hline Liberia & $\mathrm{X}$ & $\mathrm{A} / 11.03 .1981 \quad 09.06 .1981$ \\
\hline Madagascar & 04.04 .1973 & $\mathrm{R} / 20.08 .1975 \quad 18.11 .1975$ \\
\hline Malawi & $\mathrm{A} / 0$ & 2.198206 .05 .1982 \\
\hline Morocco & 09.03 .1973 & $\mathrm{R} / 16.10 .1975 \quad 14.01 .1976$ \\
\hline Mozambique & $\mathrm{X}$ & $\mathrm{A} / 25.03 .1981 \quad 23.06 .1981$ \\
\hline Namibia & $X$ & $\mathrm{~A} / 18.12 .1990 \quad 18.03 .1991$ \\
\hline Niger & 05.03 .1973 & $\mathrm{R} / 08.09 .1975 \quad 07.12 .1975$ \\
\hline Nigeria & 11.02.1974 R/OS & $5.1974 \quad 01.07 .1975$ \\
\hline Rwanda & $\mathrm{X}$ & $\mathrm{A} / 20.10 .1980 \quad 18.01 .1981$ \\
\hline Senegal & $\mathrm{X}$ & A/05.08.1977 03.11.1977 \\
\hline Seychelles & $X$ & A/08.02.1977 09.0 \\
\hline Sierra Leone & $X$ & $\mathrm{~A} / 28.10 .1994 \quad 26.01 .1995$ \\
\hline Sudan & 27.04.1973 & $\mathrm{R} / 26.10 .1982 \quad 24.01 .1983$ \\
\hline Swaziland & $\mathrm{X}$ & $\mathrm{A} / 26.02 .1997 \quad 27.05 .1997$ \\
\hline Somalia & $\mathrm{X}$ & $\mathrm{A} / 02.12 .198502 .03 .1986$ \\
\hline South Africa & 03.03 .1973 & $\mathrm{R} / 15.07 .1975 \quad 13.1$ \\
\hline Togo & 07.03 .1973 & $\mathrm{R} / 23.10 .1978 \quad 21.01 .1979$ \\
\hline Tunisia & $21.03 .1973 \quad \mathrm{R} / 1 \mathrm{C}$ & $7.1974 \quad 01.07 .1975$ \\
\hline Uganda & $\mathrm{X}$ & $\mathrm{A} / 18.07 .1991 \quad 16.10 .1991$ \\
\hline \multicolumn{3}{|c|}{ United Republic } \\
\hline of Tanzania & 30.04 .1973 & $\mathrm{R} / 29.11 .1979 \quad 27.02 .1980$ \\
\hline Zaire & $\mathrm{X}$ & $\mathrm{A} / 20.07 .1976 \quad 18.10 .1976$ \\
\hline Zambia & $X$ & $1.1980 \quad 22.02 .1981$ \\
\hline Zimbabwe & $X$ & $\mathrm{~A} / 19.05 .1981 \quad 17.08 .1981$ \\
\hline
\end{tabular}

Group V: WESTERN EUROPE

$\begin{array}{llll}\text { Austria } & \mathrm{X} & \mathrm{A} / 27.01 .1982 & 27.04 .1982 \\ \text { Belgium } & 03.03 .1973 & \mathrm{R} / 03.10 .1983 & 01.01 .1984 \\ \text { Cyprus } & 03.03 .1973 & \mathrm{R} / 18.10 .1974 & 01.07 .1975 \\ \text { Denmark } & 03.03 .1973 & \mathrm{R} / 26.07 .1977 & 24.10 .1977 \\ \text { Finland } & \mathrm{X} & \mathrm{A} / 10.05 .1976 & 08.08 .1976\end{array}$




$\begin{array}{llcc}\text { France } & 03.03 .1973 & \mathrm{R} / 11.05 .1978 & 09.08 .1978 \\ \text { Germany } & 03.03 .1973 & \mathrm{R} / 22.03 .1976 & 20.06 .1976 \\ \text { Greece } & \mathrm{X} & \mathrm{A} / 08.10 .1992 & 06.01 .1993 \\ \text { Ireland } & 01.11 .1974 & \mathrm{X} & \mathrm{X} \\ \text { Italy } & 03.03 .1973 & \mathrm{R} / 02.10 .1979 & 31.12 .1979 \\ \text { Liechtenstein } & \mathrm{X} & \mathrm{A} / 30.11 .1979 & 28.02 .1980 \\ \text { Luxembourg } & 03.03 .1973 & \mathrm{R} / 13.12 .1983 & 12.03 .1984 \\ \text { Malta } & \mathrm{X} & \mathrm{A} / 17.04 .1989 & 16.07 .1989 \\ \text { Monaco } & \mathrm{X} & \mathrm{A} / 19.04 .1978 & 18.07 .1978 \\ \text { Netherlands } & 30.12 .1974 & \mathrm{R} / 09.04 .1984 & 18.07 .1984 \\ \text { Norway } & 23.12 .1974 & \mathrm{R} / 27.07 .1976 & 25.10 .1976 \\ \text { Portugal } & 06.12 .1974 & \mathrm{R} / 11.12 .1989 & 11.03 .1981 \\ \text { Spain } & \mathrm{X} & \mathrm{A} / 30.05 .1986 & 28.08 .1986 \\ \text { Sweden } & 03.04 .1973 & \mathrm{R} / 20.08 .1974 & 01.07 .1975 \\ \text { Switzerland } & 02.04 .1973 & \mathrm{R} / 09.07 .1974 & 01.07 .1975 \\ \text { United Kingdom } & 03.03 .1973 & \mathrm{R} / 02.08 .1976 & 31.10 .1976\end{array}$

Group VI: EASTERN EUROPE

\begin{tabular}{|c|c|c|}
\hline Belarus & \multicolumn{2}{|c|}{ A/10.08.1995 08.11.1995 } \\
\hline Bulgaria & $X$ & $\mathrm{~A} / 16.01 .1991 \quad 16.04 .1991$ \\
\hline Czech Republic & $\mathrm{X}$ & $\mathrm{T} / 14.04 .1993 \quad 01.01 .1993$ \\
\hline Estonia & & $\mathrm{A} / 22.07 .199220 .10 .1992$ \\
\hline Georgia & $X$ & $\mathrm{R} / 13.09 .1996 \quad 12.12 .1996$ \\
\hline Hungary & $X$ & $\mathrm{~A} / 29.05 .198527 .08 .1985$ \\
\hline Latvia & $\mathrm{X}$ & A/11.02.1997 12.05.1997 \\
\hline Poland & 08.10 .1973 & $\mathrm{R} / 12.12 .198912 .03 .1990$ \\
\hline Romania & $\mathrm{X}$ & A/18.08.1994 16.11.1994 \\
\hline Russian Federation & $X$ & $\mathrm{~T} / 13.01 .1992 \quad 13.04 .1992$ \\
\hline Slovakia & & $\mathrm{T} / 02.03 .1993 \quad 01.01 .1993$ \\
\hline Urbekistan & $X$ & $\mathrm{R} / 10.07 .1997 \quad 08.10 .1997$ \\
\hline
\end{tabular}

Group VII: FAR EAST

$\begin{array}{llll}\text { Afghanistan } & \mathrm{X} & \mathrm{A} / 30.10 .1985 & 28.01 .1986 \\ \text { Australia } & 21.09 .1973 & \mathrm{R} / 29.07 .1976 & 27.10 .1976 \\ \text { Bangladesh } & 07.08 .1973 & \mathrm{R} / 20.11 .1981 & 18.02 .1982 \\ \text { Brunei Darussalan } & \mathrm{X} & \mathrm{A} / 04.05 .1990 & 02.08 .1990 \\ \text { Cambodia } & 07.12 .1973 & \mathrm{R} / 04.07 .1997 & 02.10 .1997 \\ \text { China } & \mathrm{X} & \mathrm{A} / 08.01 .1981 & 08.04 .1981 \\ \text { Fiji } & \mathrm{X} & \mathrm{A} / 30.09 .1997 & 29.12 .1997\end{array}$




$\begin{array}{llll}\text { India } & 29.07 .1974 & \mathrm{R} / 20.07 .1976 & 18.10 .1976 \\ \text { Indonesia } & \mathrm{X} & \mathrm{A} / 28.12 .1978 & 28.03 .1979 \\ \text { Japan } & 30.04 .1973 & \mathrm{R} / 06.06 .1980 & 04.11 .1980 \\ \text { Malaysia } & \mathrm{X} & \mathrm{A} / 20.10 .1977 & 18.01 .1978 \\ \text { Mali } & \mathrm{X} & \mathrm{A} / 18.07 .1994 & 16.10 .1994 \\ \text { Mauritius } & 03.03 .1973 & \mathrm{R} / 28.04 .1975 & 27.07 .1975 \\ \text { Mongolia } & \mathrm{X} & \mathrm{A} / 05.01 .1996 & 04.04 .1996 \\ \text { Myanmar } & \mathrm{X} & \mathrm{A} / 13.06 .1997 & 11.09 .1997 \\ \text { Nepal } & \mathrm{X} & \mathrm{A} / 18.06 .1975 & 16.09 .1975 \\ \text { New Zealand } & \mathrm{X} & \mathrm{A} / 10.05 .1989 & 08.08 .1989 \\ \text { Pakistan } & \mathrm{X} & \mathrm{A} / 20.04 .1976 & 19.07 .1976 \\ \text { Papua New Guinea } & \mathrm{X} & \mathrm{A} / 12.12 .1975 & 11.03 .1976 \\ \text { Philippines } & 03.03 .1973 & \mathrm{R} / 18.08 .1981 & 16.11 .1981 \\ \text { Republic of Korea } & \mathrm{X} & \mathrm{A} / 09.07 .1993 & 07.10 .1993 \\ \text { Singapore } & \mathrm{X} & \mathrm{A} / 30.11 .1986 & 28.02 .1987 \\ \text { Sri Lanka } & \mathrm{X} & \mathrm{A} / 04.05 .1979 & 02.08 .1979 \\ \text { Taiwan } & 27.04 .1973 & \mathrm{X} & \mathrm{X} \\ \text { Thailand } & 03.03 .1973 & \mathrm{R} / 21.01 .1983 & 21.04 .1983 \\ \text { Vanuatu } & \mathrm{X} & \mathrm{A} / 17.07 .1989 & 15.10 .1989 \\ \text { Viet Nam } & \mathrm{X} & \mathrm{A} / 20.01 .1994 & 20.04 .1994\end{array}$

Group VIII: MIDDLE EAST

$\begin{array}{llrr}\text { Israel } & 05.03 .1973 & \mathrm{R} / 18.12 .1979 & 17.03 .1980 \\ \text { Iran } & 03.03 .1973 & \mathrm{R} / 03.08 .1976 & 01.11 .1976 \\ \text { Jordan } & \mathrm{X} & \mathrm{A} / 14.12 .1978 & 14.03 .1979 \\ \text { Kuwait } & 09.04 .1973 & \mathrm{X} & \mathrm{X} \\ \text { Saudi Arabia } & \mathrm{X} & \mathrm{A} / 12.03 .1996 & 10.06 .1996 \\ \text { Turkey } & \mathrm{X} & \mathrm{A} / 23.09 .1996 & 22.12 .1996 \\ \text { U.A.E. } & \mathrm{X} & \mathrm{A} / 21.11 .1974 & 01.07 .1975 \\ \text { Yemen } & \mathrm{X} & \mathrm{A} / 05.05 .1997 & 03.08 .1997\end{array}$

